THE EVOLUTION OF CRISIS AT CITY COLLEGE OF SAN FRANCISCO

\author{
A dissertation submitted to the faculty of \\ San Francisco State University \\ In partial fulfillment of \\ the requirements for \\ the Degree
}

Doctor of Education

In

Educational Leadership

\author{
by \\ Megan Diane Corry \\ San Francisco, California
}

August 2016 


\section{CERTIFICATION OF APPROVAL}

I certify that I have read The Evolution of Crisis at City College of San Francisco by Megan Diane Corry, and that in my opinion this work meets the criteria for approving a dissertation submitted in partial fulfillment of the requirements for the degree: Doctor of Education in Educational Leadership at San Francisco State University.

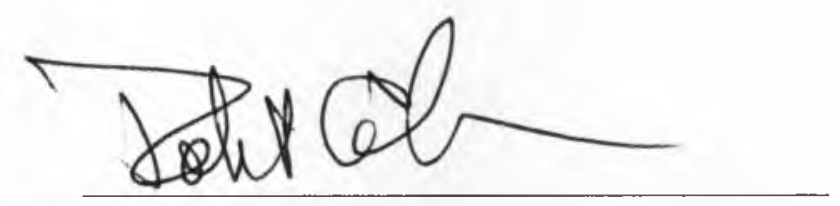

Robert Gabriner, Ed.D.

Professor of Education

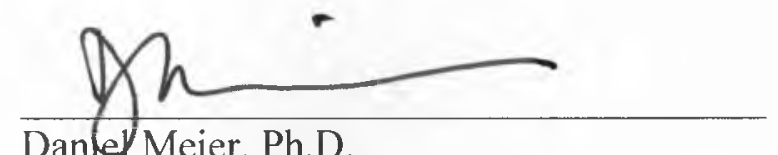

Danlel Meier, Ph.D.

Professor of Elementary Education

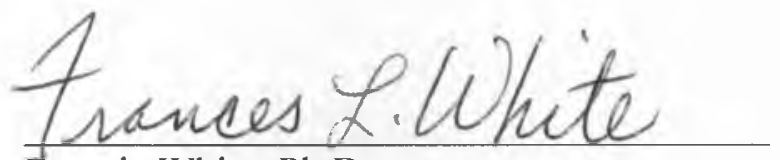
Francis White, Ph.D. Professor of Education 


\title{
THE EVOLUTION OF CRISIS AT CITY COLLEGE OF SAN FRANCISCO
}

\author{
Megan Corry \\ San Francisco, California \\ 2016
}

In July of 2013, the Accrediting Commission for Community and Junior Colleges (ACCJC) determined that the City College of San Francisco (CCSF) did not meet the eligibility criteria and standards for accreditation and announced that they would terminate accreditation within one year. Following this decision, it was revealed that there were early warning signs of impending financial insolvency and a history of noncompliance with regulatory standards. In the 1980's, the college experienced a similar crisis, after which it embarked on a major reorganization designed to integrate operations, improve communications, and ensure fiscal solvency. But decades later the college found itself in the same condition. Studies of community colleges in fiscal or accreditation crisis focus on leadership responses and recovery; however, few have closely examined the evolution of the crisis through a historical perspective. This qualitative study examined the factors that may have contributed to the development of an institutional blindspot that prevented CCSF leaders at all levels from recognizing and responding to the impending crisis. Through interviews and archival document review, this study found that college leaders consistently normalized deviations in financial operations and in decision-making processes on student learning outcomes. Three factors that contributed to normalization of deviance included an environment of competition for scarce resources stemming from shifts in state community college finance laws and increasing accountability standards, a culture of expectation to be "all things to all people", and a self-affirming ideology fed by a culture of "uniqueness", which isolated the institution and insulated its leaders from acting on the warning signs of impending crisis. Recommendations outline strategies for leaders to better recognize problems before they become major crises.

I certify that the Abstract is a correct representation of the content of this dissertation.

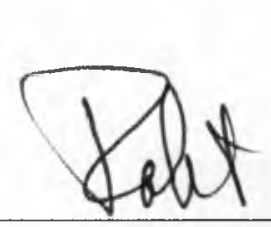

Chair, Dissertation Committee

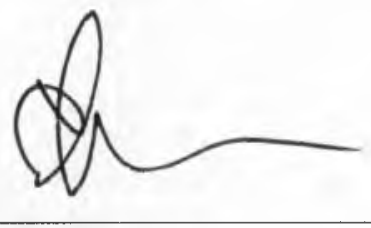

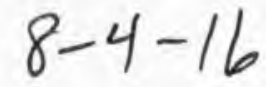

Date 


\section{ACKNOWLEDGEMENTS}

This research would not have been possible without the cooperation and candid communication of the interview participants, and the many faculty, administrators and support personnel who ushered me through the history of San Francisco's community college district. A special thanks to Christopher Kox and Julia Bergman for guiding me through the archives collection and for their dedication to maintaining this valuable treasure. I thank my dissertation committee for their patience with me through this process. Dr. Gabriner, thank you for your persistence and for having faith in my abilities. Finally, I extend a special note of gratitude to my family for their support and enthusiasm throughout this project. 


\section{TABLE OF CONTENTS}

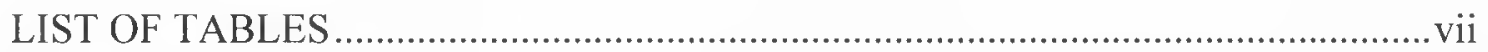

LIST OF FIGURES ….........................................................................................ii

LIST OF APPENDICES ................................................................................................

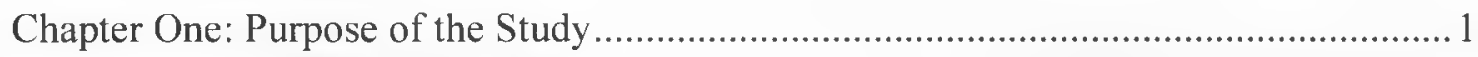

Introduction and Problem Statement ........................................................................ 1

Background of the crisis ...................................................................................

The importance of CCSF to the community ........................................................

A history of problems …………………………………….............................

Purpose of the study and research questions......................................................... 9

Conceptual Framework …………………………….......................................

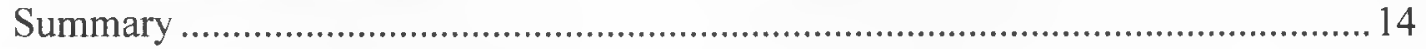

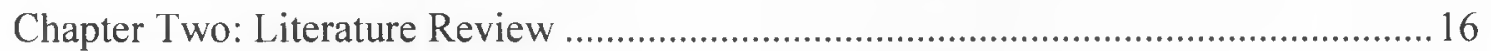

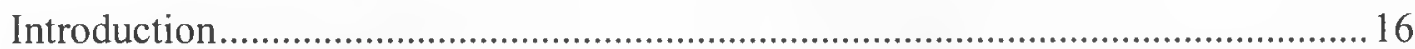

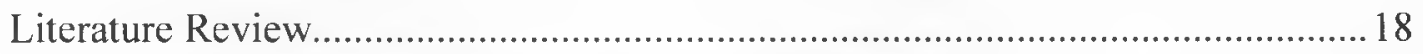

Crisis in higher education: the influence of culture ……………….................... 19

The cultural implications of multiple missions....................................................2

The role of leadership in the development of crisis..........................................26

Organizational mistake and normalization of deviance.......................................28

Summary and Implications ..................................................................................... 32

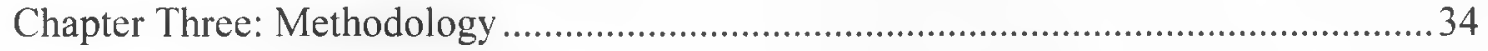

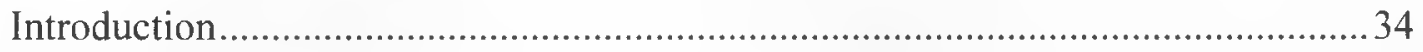

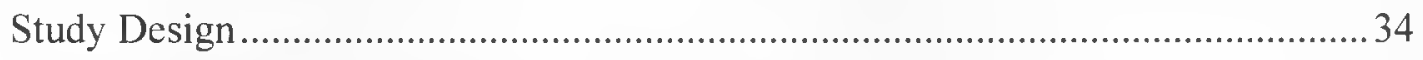

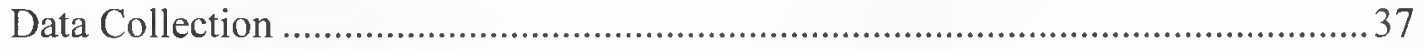

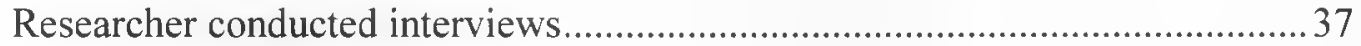

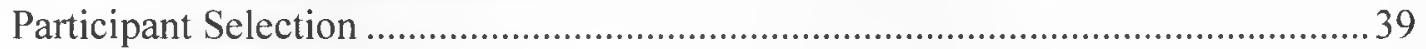

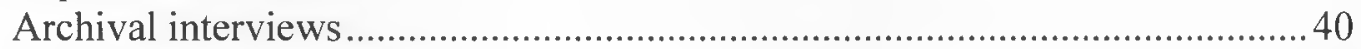

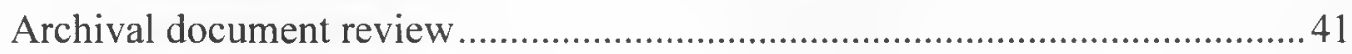

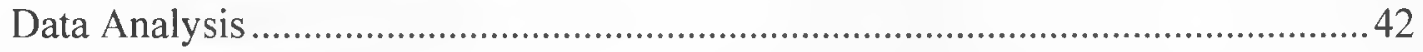

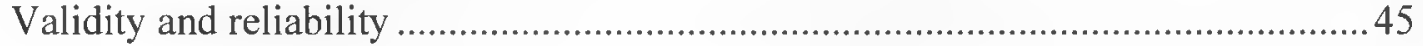

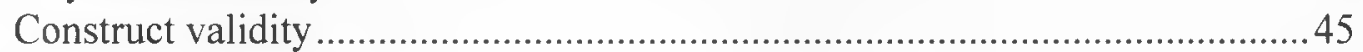

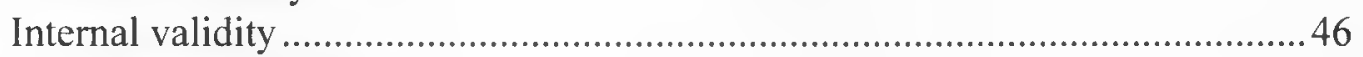

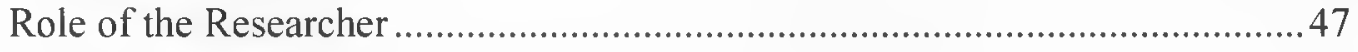

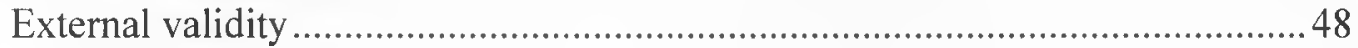




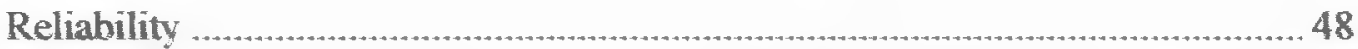

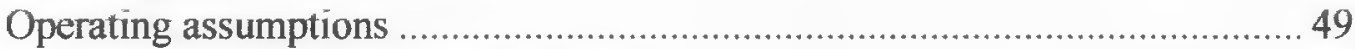

Ethics and Protection of Human Subjects .......................................................... 50

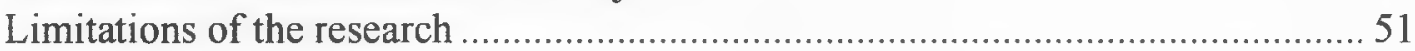

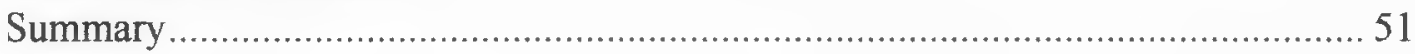

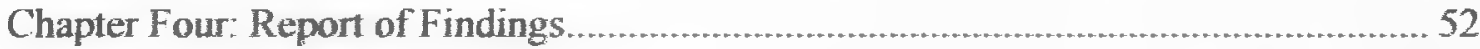

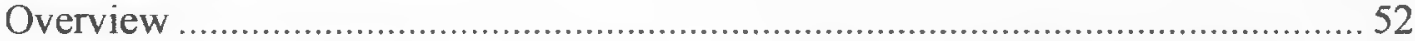

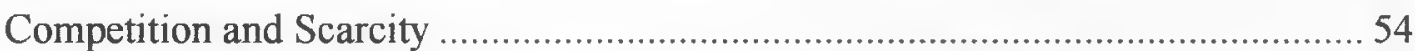

State reductions in funding for California community colleges .........................5 57

Collective bargaining and Proposition 13 at the SFCCD ....................................6 60

An era of accountability and unpredictable funding ……….......................

Student Learning Outcomes (SLO's) ............................................................. 76

Structural design of the SFCCD promotes internal competition........................ 78

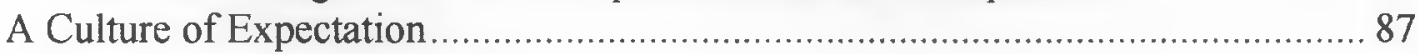

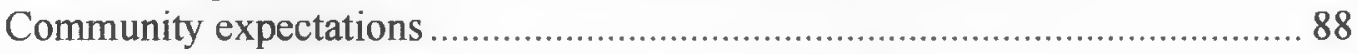

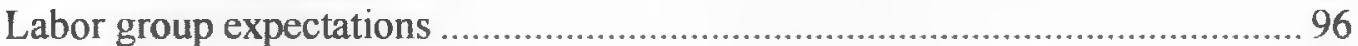

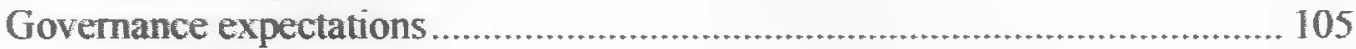

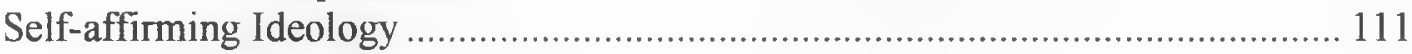

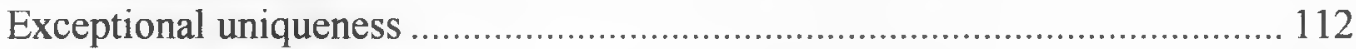

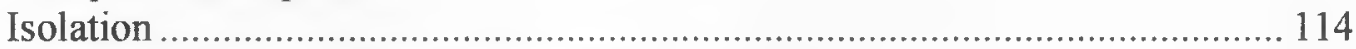

Acceptance of operational dysfunction …………………............................. 118

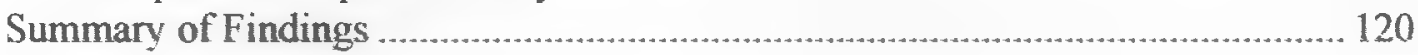

Chapter Five: Conclusions and Implications ..................................................... 121

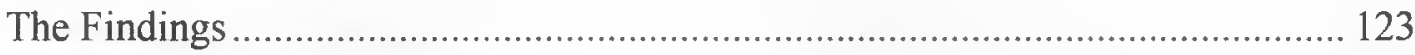

Normalization of deviance....................................................................... 123

Why problems persisted at CCSF .............................................................. 124

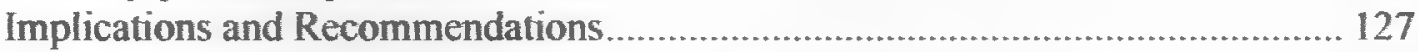

Recommendations for Institutional Leaders ................................................. 128

1. Recognize the causes and historical roots of the crisis......................... 128

2. Promote and practice evidence-based decision-making ...................... 130

3. Develop best practices ……………................................................... 130

Challenges Facing the San Francisco Community College District (SFCCD) ....... 131

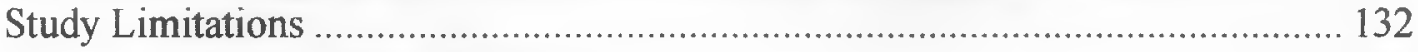

Recommendations for Further Study ............................................................ 132

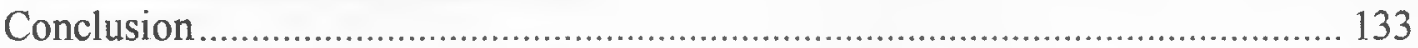

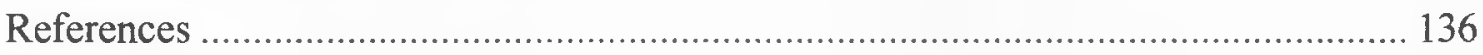

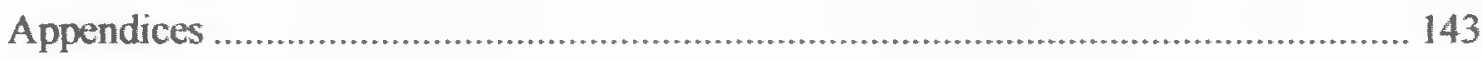




\section{LIST OF TABLES}

Table

Page

1. History of funding at California Community Colleges 1970-2012 _.......................56

2. Total number of employees at the SFCCD

75

3. History of student learning outcomes (SLO's) at the SFCCD

110 


\section{LIST OF FIGURES}

Figure

1. Relationship between accreditation and funding ............................................ 7

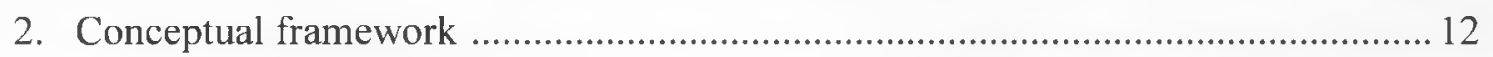

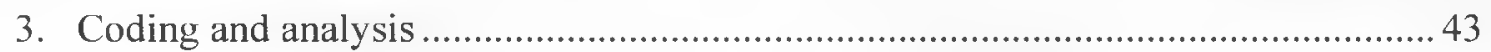

4. Unduplicated headcount at the SFCCD 1992-2012 ..........................................71

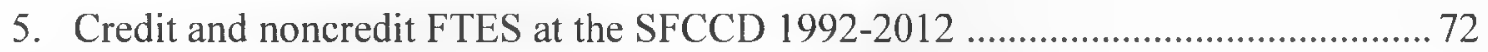

6. Credit sections (minus summer) at the SFCCD 1992-2012 ................................ 73

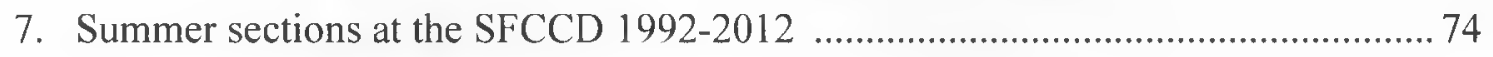

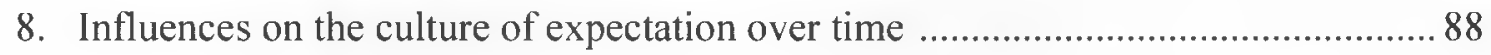




\section{LIST OF APPENDICES}

Appendix Page

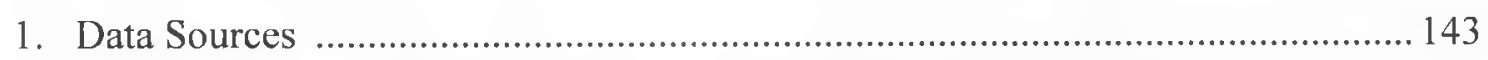

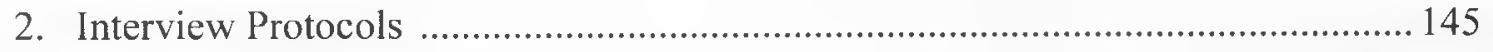

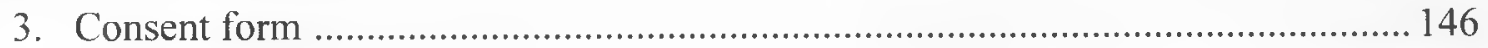


Chapter One: Purpose of the Study Introduction and Problem Statement

This research is the story of a community college in crisis. More importantly, it is a study that reveals the significance of history and the effects of political decisionmaking and organizational culture on the evolution of crisis at one of the largest community college districts in the country. Retracing time, history, and the trajectory of actions, the results show how leaders at this community college, despite repeated signs of impending crisis, were unable to turn things around in time and avoid catastrophe. Leaders at all levels: program coordinators, department chairs, labor leaders, faculty governance leaders, administrators and, most critically, chancellors and governing board members, collectively over decades normalized persistent problems and warning signs and this led to and resulted in a threat to institutional viability. Ultimately, this research underscores the critical importance of leadership responsibility to uphold the mission of this public institution, and promote equity and social empowerment for its diverse communities through high quality education.

\section{Background of the crisis}

City College of San Francisco (CCSF) has been a beacon in the community for over 75 years, providing entry-level college courses, degree and certificate programs, transfer opportunities to 4-year institutions, award winning career preparation programs, transitional studies, and adult education. In 2004, CCSF was recipient of the prestigious MetLife award and identified as among the top community colleges in the nation based 
on its broad spectrum of course offerings, cultural representation of the community, and $75 \%$ retention to second year (Kazis \& Newton, 2004). And despite fiscal and operational issues over many decades, CCSF has benefitted from the continuous support of the San Francisco residents (Bergman, Mathis \& White, 2010). Today, that same institution is at the most serious crisis point in their history: the fight for survival.

In July of 2012, the Accrediting Commission for Community and Junior Colleges (ACCJC) determined that City College of San Francisco (CCSF) was significantly out of compliance with eligibility criteria and standards for accreditation and issued the most serious sanction possible, "show cause", challenging the college to prove worthiness or lose accreditation. Among the fourteen major citations, eleven were issues that CCSF had failed to resolve from the 2006 accreditation visit; three of the recommendations went completely unaddressed despite recommendations made by the ACCJC in letters to CCSF in 2007, 2009 and 2010. Two overarching issues were a lack of integrated budgeting and planning to prioritize scarce resources and ensure financial stability, and the failure to institute the student learning outcomes (SLO) process to evaluate program and institutional effectiveness (ACCJC, 2012).

Accreditation standards evaluate fiscal decision-making practices of a college to ensure financial stability of the institution. Standards also examine outcomes and how an institution uses outcome data to ensure accountability to primary stakeholders: the students. These two elements (financial stability and SLO processes) are distinct but 
interrelated. An accredited college measures outcomes at all levels (course, program, administration, and institution) and then uses outcomes evidence to drive planning and budgeting in alignment with the institutional mission. In the years leading up to the 2012 sanction, CCSF did not use student outcomes to drive planning and budgeting, nor did it ensure that financial decisions were consistent with the institutional mission. Risky financial decisions were made without regard to the warnings from outside agencies, and without regard for evidence as to whether programs and services benefitted students. City College of San Francisco promotes an expansive mission of access, equity, and outreach to the local community, and a promise of higher education for all, but without the outcomes evidence, this message falls short.

But the message from the state chancellor's office was clear: "take focused and rapid action to address the challenges that are facing your district"' (October 2012, Governing Board meeting). One year later, despite a flurry of activity by CCSF aimed at corrective action, the accrediting commission determined that the college had not corrected the problems sufficiently enough to change the course of the sanction and terminated accreditation effective July 31, 2014. Overall, the ACCJC determined that CCSF "does not adhere to each of the Eligibility Requirements and Accreditation Standards and has failed to follow Commission directives to address the deficiencies noted by the 2006 evaluation team" (ACCJC, 2012). Adding to the commission's decision, new concerns outlined in a comprehensive report by the state's Fiscal Crisis 
and Management Assistance Team (FCMAT) indicated severe problems with fiscal administration, accountability, and viability that had persisted for decades at the district.

As of this writing, many actions are underway to keep the college open. The college made changes to leadership positions, overall administrative structure, participatory governance decision-making processes and financial planning and reporting. The American Federation of Teachers (AFT) and the California Federation of Teachers (CFT) filed lawsuits against the ACCJC to overturn the initial termination decision, stating that the ACCJC violated their own rules during the initial and subsequent site visit. In August of 2013, the San Francisco City Attorney filed legal challenges to keep the ACCJC from revoking accreditation. This action triggered a preliminary injunction in early 2014 to delay the revocation so that these complaints could be reviewed in a court of law. City College of San Francisco has not filed a lawsuit but rather focuses sustained efforts to address the issues outlined by the ACCJC in the hopes of another chance to meet the standards of accreditation. Most recently, the accrediting commission established a new "restoration status" so that a college under threat of losing accreditation might extend the timeline by an additional two years to allow time to meet the standards. The commission then granted this "restoration" status to CCSF. The next review of the college will take place in October 2016 with a final determination of accreditation status in January 2017. 
The importance of CCSF to the community

City College of San Francisco (CCSF) is an urban, public, community college that serves a population of approximately 85,000 students each year. CCSF offers more than 50 academic programs and over 100 occupational programs with a range of courses that lead to Associates degrees, certificates, or transfer to four-year universities. Over $75 \%$ of students are first generation college students. Representative of the city of San Francisco, the college serves an ethnically diverse student population. In 2010 , CCSF enrolled 26\% of the graduates from the San Francisco Unified School District (SFUSD) public high schools, making CCSF a primary access point of higher education for local high school graduates. Overall, the average age of students at CCSF is thirtythree, which highlights the vast range of course offerings for adult students who are either returning or attending college for the first time. Many of these adult students return for credit recovery and high school completion, preparatory classes for the GED, occupational training, educational enrichment, or short-term community service courses designed to provide training for local business, industry, and government agencies. Adult education coursework also includes a large number of noncredit courses that lead to English as a second language (ESL) certificates and pathways to citizenship. Unlike other California community colleges, approximately half of all students enrolled at CCSF are in noncredit coursework (CCCCO DataMart, 2013). In 2011-2012, of the 85,000 enrolled students, 37,000 enrolled in ESL classes, including credit and 
noncredit, academic, conversational, and vocational ESL courses offered at six of the campus centers (CCSF Foundation, 2013).

In 2012, CCSF operated a total of twelve campus centers and over 100 instructional sites, employing over 800 full time faculty and at least 1,000 part time faculty. In addition, in 2012 CCSF employed 42 administrators and 900 classified employees to operate one of the largest community college systems in the country. CCSF is pervasive in the San Francisco community, as evidenced by a 2009 poll of registered voters, which showed that one in every seven San Francisco residents either attended the college or hired a CCSF graduate (CCSF Foundation, 2013).

Since community college accreditation is linked to State allocations (Figure 1), the loss of ACCJC accreditation for CCSF would mean certain closure. If CCSF closed, this would shut the door to educational opportunity and occupational advancement to tens of thousands of people, in particular to those with the greatest need in the local area. Many of these working class, low income, and disabled students who don't have the means to travel to neighboring community college districts (assuming there would be space and course offerings) would be left without access to higher education. It doesn't make sense that CCSF and its dedicated leaders, faculty, and staff would allow this historical institution to get to the brink of closure. 


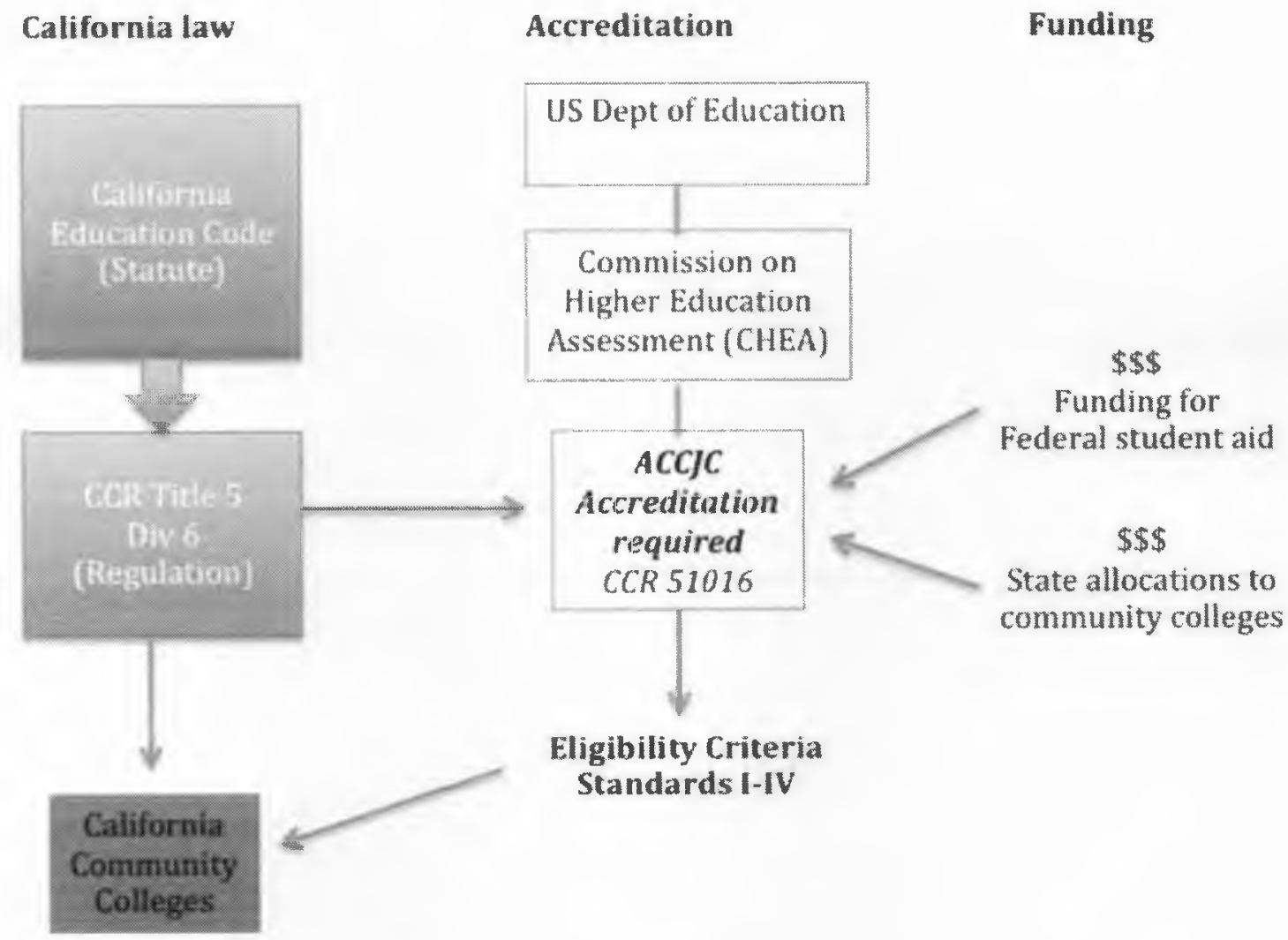

Figure 1: Relationship between accreditation and funding

\section{A history of problems}

CCSF has had a long history of financial problems. A 2012 report by the Fiscal Crisis and Management Assistance Team (FCMAT) and the ACCJC report earlier that same year described fiscal issues that stemmed from decades of poor decision-making and internal operational neglect. And as the July 2012 ACCJC report mentioned, the problems were not just financial. Like other community college in California, in 2002 CCSF was given 10 years to develop and implement the SLO process, and at the time of 
the March 2012 site visit, CCSF had hardly begun. Interim chancellor Pamela Fisher commented that CCSF "needs to fix other problems and even 100 million dollars doesn't make them go away" (July 2012, Governing Board meeting). The 2013 interim chancellor Thelma Scott-Skillman also noted that although "governance, administration and fiscal solvency matters" are the primary issues, "when you start peeling that back, its layered with a great deal of structural issues" that developed over a long period of time (February 2013, interview with The Guardsman). In its decision letter of July 2013, the accrediting commission noted,

Throughout CCSF's accreditation history, including one period of Warning and notably since 2006, the ACCJC has provided extensive professional advice and support to CCSF to help it come into full compliance with Standards. (2013, ACCJC letter p.1)

This "period of warning" to which the commission refers took place in 1988 and launched one of the major reorganizations of the institution in its history. This reorganization was implemented to solve problems that had plagued CCSF in the early years after the district's formation in the 1970's. And yet this crisis repeated nearly 25 years later, and it didn't happen suddenly. Just as it was in the 1980's, crisis developed over time after a period during which warning signs from both inside and outside of the institution should have alerted leaders to take action. So, why didn't leaders see it coming? 
Purpose of the study and research questions

This study explores the evolution of crisis at CCSF and identifies factors that could potentially explain why action wasn't taken to thwart disaster. The primary question that forms the foundation for this research is: Why did City College of San Francisco reach this stage of crisis that threatens its existence? More specifically, what factors may have contributed to the inability of leaders and decision makers at CCSF to see the magnitude of the crisis as it approached? These questions were addressed through a review of CCSF archival data, and interviews of selected leaders and decision-makers at the college, many of whom were a part of the formation of the San Francisco Community College District (SFCCD) in 1970, the major reorganization in the 1990 's, and remain employed at the institution to this day. The research used a qualitative historical case study design to examine the history of crisis at the institution, and to discover how key leaders at a range of levels understood and made meaning of their experiences in the years preceding the July 2012 "show cause" sanction.

\section{Conceptual Framework}

The conceptual framework for this research is based on organizational theory known as normalization of deviance, which has been used to explain why people within organizations fail to perceive the threat and degree of impending crisis.

Organizations are social systems that rely on human interaction and decision-making while operating within the context of events of the time and in various cultural 
environments. Most organizations, and certainly higher education institutions, are social systems. Historical context affects rule and decision-making and the interactions of various groups within an organization. The history of crisis at CCSF suggests a deeply embedded culture at all levels of the institution that not only resisted change, but also constructed barriers that prevented detection of oncoming crisis. This pattern has been studied in research on organizational misconduct, mishap and mistake, most notably in the study of major accidents such as the Challenger space shuttle disaster (Vaughan, 1997), and is suggestive of organizational behavior known as normalization of deviance. More recently, normalization of deviance has been applied to the development of crisis in the fields of management (Greve, Palmer, \& Posner, 2010), and healthcare (Banza, 2010).

According to Vaughan $(1997,2004)$, normalization of deviance is an evolutionary process whereby members of the organization redefine deviations as acceptable and normal, causing an incremental descent into poor judgment. Because the process typically involves repeated small mistakes without immediate consequences, the members are unaware of the magnitude of an oncoming crisis. When crisis strikes, those within the organization are initially shocked at the seemingly sudden onset; however, most are able to articulate in hindsight the trail of problems that led to the crisis. Because normalization of deviance takes place over time, early problem detection is difficult. 
Normalization of deviance results from the interplay of three conditions: an environment focused on production and efficiency under pressure of limited resources, a culture that accepts risk by redefining norms, and processes that obscure the seriousness of problems within an organization (Vaughn 1996, 2004). This research found that at CCSF, these same three conditions developed over time, including: 1 . Competition for scarce resources, 2. Culture of expectation and 3. Self-affirming ideology (Figure 2). Over the history of the SFCCD, the culture of expectation to provide "all things to all people" clashed with an ongoing competition for scarce resources between the college and the district centers, as an increasing focus on enrollment, regulatory standards, and operational efficiency pressured leaders to deviate from standards. Finally, a self-affirming ideology, a view of CCSF as unique among the state's community colleges, pervaded the institution, as over time leaders and decision makers became increasingly isolated and insulated from outside influences, preventing any warning signals from causing immediate and transformative action. To those within the college, particularly among faculty, the signals of potential problems were mixed or misinterpreted, thus perpetuating the acceptance of internal deviations as normal for this "unique" organization. 


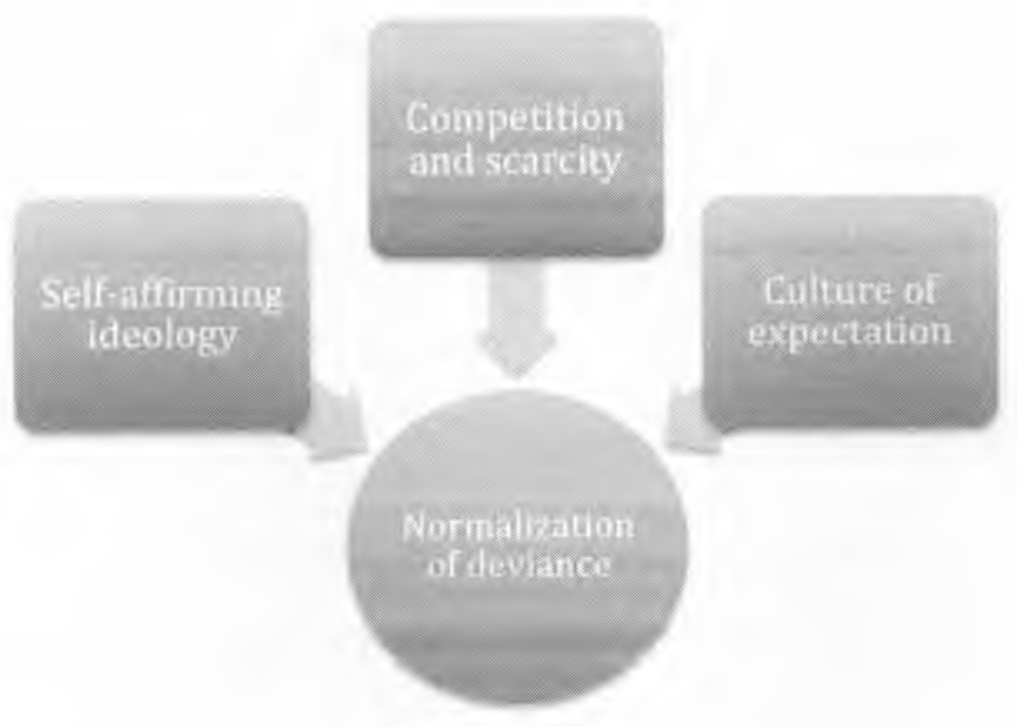

Figure 2. Conceptual Framework

This research examines decision-making over time on the two main issues at CCSF that were most prominently identified in the 2012 show cause report: budgeting priorities and student learning outcomes (SLO). These two issues were selected for several reasons. Budget priorities were highlighted in several reports as persistently problematic in the years leading up to the sanction. In particular, decision-making surrounding budgeting priorities at CCSF deviated from what was considered "best practice" in California Community Colleges to maintain institutional viability. The California Community College Chancellor's Office defines a financially healthy college district as one that maintains a minimum of a $5 \%$ reserve, balances the cost of personnel with those of facilities and technology so that personnel costs do not rise above approximately $85 \%$ of the total expenditures, uses enrollment management to determine 
target class sizes and avoid budget overruns, plans for and funds retiree health benefits, taking into account the rising cost of healthcare, and uses data and evidence to drive budget priorities. CCSF was found deficient in all of these areas.

The SLO issue was selected because it represented the larger problem at CCSF regarding the lack of evidence-based decision-making as cited in several accreditation reports. The SLO initiative grew out of the accountability movement of the 1990's when data from the higher education literature suggested that learning outcome measures could better represent the students' college experience and the quality of education (Astin, 1997; Kuh, Kinzie, Schuh, \& Whitt, 2010; Pascarella \& Terenzini, 2005). In 2002, California and regional accreditors revised and adopted new regulations and standards that gave colleges a decade to fully implement a process of outcomes assessment and integrated planning to ensure the quality of students' educational experiences. Full implementation of the SLO process represents the commitment of college leaders at all levels to providing high quality higher education through effective strategic planning and sound fiscal decision-making.

Leaders in a community college district include the elected board of trustees (governing board), which creates policy, passes board resolutions, and hires the chancellor who then implements these policies through the administration. The board has a fiscal responsibility to ensure institutional viability, and an obligation to ensure that the administrative and academic leaders provide an environment that supports 
teaching and learning. Faculty, personnel, and student input is sought through a system of participatory governance. The faculty leadership is essential for complete and effective SLO implementation by ensuring meaningful assessment of teaching and learning (Hutchings, 2010). At CCSF, deviations in decision-making on the budget priorities and SLO implementation took the institution to the brink of closure.

This research addressed the possible reasons why the deviations in decisionmaking on budget priorities and SLO's persisted at CCSF, and how the convergence of these two critical factors caused the crisis. Through evaluation of interview and archival data, this research examined factors associated with the incremental descent into crisis. Finally, this research explores potential alternative explanations for the accreditation crisis, proposes that normalization of deviance is a one possible explanation of organizational failure at CCSF, and emphasizes the importance of avoiding simpler explanations that invariably result in nonviable "solutions" to crisis.

\section{Summary}

This research is a case study of a community college with a historical perspective over the period of 1970-2012. Chapter 2 , the literature review, describes the conceptual framework and study design through an evaluation of the existing literature. Through qualitative historical case study design using thematic analysis of interview and archival data as described in Chapter 3, this research examines decision making surrounding budgeting priorities and student learning outcomes (SLOs) against the 
theory of normalization of deviance. The data in Chapter 4 are presented along the historical timeline and illustrate the elements of normalization of deviance at CCSF and the incremental descent into crisis. Finally, Chapter 5 presents the implications of this research in identifying factors associated with crisis development and normalization of deviance as a means of helping leaders become problem finders, instead of just problem solvers (Roberto, 2009). 


\section{Chapter Two: Literature Review}

Introduction

This research is a case study with a historical perspective of a large urban community college in a state of operational crisis. Crisis for the purpose of this research is focused on that which led to the breakdown of routine operations in a community college district. In this case study, the crisis is the impending loss of accreditation and the threat of closure. Research on crisis development in the broader organizational literature provided the theoretical underpinnings for this study. This project began as an exploratory case study and through initial data gathering, review of the existing literature and constant comparison methodology, I arrived at the framework and study design. At that point, the research became explanatory as it related to normalization of deviance theory.

Existing research on crisis at higher education institutions primarily focus on fiscal issues (Clark, 2012) and the success or failure of planned change initiatives (Locke \& Guglielmino, 2006; Willson, 2006). More recently, community college research has examined crisis associated with accreditation sanctions (Lattimore, D'Amico, \& Hancock, 2012; Patel, 2012). In these studies, particular emphasis is placed on the role of the college president and actions of key decision makers in determining the outcome of a crisis. Case study research on community colleges emphasizes the role of the college leaders in crisis development (Clark, 2012) or in its 
eventual resolution (Andersen, 2011; Brigham-Sprague, 2001) and the performance of the leader in the context of organizational cultures (Shaw \& London, 2001; Willson, 2006) and subcultures (Locke \& Guglielmino, 2006; Palter \& Gill, 2012). Several case studies contained similarities to the cited issues at the SFCCD in 2012, describing problems with governance (Brigham-Sprague, 2001; Lattimore, D'Amico, \& Hancock, 2012; Patel, 2012) and fiscal decision-making (Clark, 2012) at community colleges. Collectively, the body of research on crisis development in higher education emphasizes the role of the leader in identifying problems and managing solutions that are temporally related to a crisis; however, existing research does not examine cases when problems persist or reoccur despite several changes in institutional structure and leadership. At City College of San Francisco, crisis seems to have developed incrementally and aspects of the current crisis bear similarities to a crisis during an earlier period of the college's history. Overall, higher education literature lacks research that provides an in-depth, longitudinal examination of how such crisis develops in the first place and how problem patterns could persist over decades. For this I turned to other areas of the organizational literature.

Research on organizational behavior, such as in the technology and healthcare industry, reveals that even seemingly sudden crises actually show evidence of incremental development (Banja, 2010; Prielipp, Magro, Morell \& Brull, 2010; Vaughan, 1997, 2004). In the aftermath of a crisis, the tendency is to focus on 
individual decision makers and events temporally related to the crisis. But research demonstrates that rather than the result of a single individual committing an act of misconduct, often these crises develop from the tolerance and normalization of small "mistakes" or deviations from standards (Banja, 2010; Vaughan, 1997, 2005). This theory, known as normalization of deviance, provides an explanatory model for how an organization can develop a "blind spot" for impending crisis. The theory also considers the relevance of historical and political context, and organizational cultures, and their affects on leader decision-making over time. Vaughan $(1997 ; 2005)$ and Gummer (1998) have suggested that normalization of deviance could be applied to any large, complex organization, including educational institutions. Similarities in the early data analysis from my research and the existing literature on normalization of deviance drove the study design, methods, and analysis plan for this research.

\section{Literature Review}

This review is structured into three main sections. The first describes the literature on crisis in higher education institutions with a focus on the influence of institutional constituencies and organizational cultures. The second section examines case study research specifically on community colleges with an emphasis on the role of leadership and power dynamics among decision-makers in the development of operational or fiscal crisis. In the higher education literature there is a paucity of historical case study research on organizational behavior that leads to crisis within a 
community college, as seems to be the case with the CCSF. The third section fills this gap through a review of research from the organizational literature on problem persistence and negative patterns that incrementally lead to crisis, focusing on a specific theoretical construct known as normalization of deviance. This formed the conceptual framework and the foundation of my research.

Crisis in higher education: the influence of culture

Research on higher education institutions in operational or fiscal crisis tends to focus on institutional leaders and change initiatives that move an institution from crisis toward success. Higher education theorists focus on the leadership traits of the college president (Bush, 2011; Kotter, 1996; Kotter \& Cohen, 2002; Nevarez \& Wood, 2010), and ability to change institutional culture as a recipe for success of change initiatives (Kotter \& Cohen, 2002; Shein, 1992). Some emphasize ethical characteristics of the leader, such as transparency, humility, and trustworthiness (Bethel, 2009; Nevarez \& Wood, 2010), while others stress action qualities such as flexibility, creativity, and the ability to reframe (Bolman \& Deal, 1997), and adapt to a complex and dynamically changing environment (Kotter, 1996). Most researchers recognize that leaders must confront issues of conflict within the context of organizational culture(s) of an institution, particularly when enacting change (Berquist, 1992; Berquist \& Pawlak, 2008; Tierney, 2008). 
Cameron and Quinn (2006) conclude that most change initiatives fail because the change agent(s) neglect to consider the cultures within an organization, resulting in strong resistance to change and paralysis in decision-making. This principle has been demonstrated in several studies of failed change initiatives in higher education (Anderson, 2011; Willson, 2006). Successful change initiatives reflected an "alignment" of cultures with planning strategies (Kezar \& Eckel, 2002; Tierney, 2008; Willson, 2006), participatory processes (Locke \& Guglielmino, 2006), and a "culture of evidence" that permeates the institution (Lattimore, D'Amico, \& Hancock, 2012). These studies attempt to "unpack" the elements temporally related to a crisis by examining the relationship between the planning process, leadership styles, and/or organization cultures and subcultures that affect decision-making.

Smart, Kuh, and Tierney (1997) examined the roles of institutional cultures and planning approaches on organizational effectiveness at thirty public 2-year colleges, developing a causal model between response to external variables, and institutional cultures (Cameron \& Quinn, 2006), on decision-making approaches that fulfill the educational mission. As confirmed by Kezar and Eckel (2002) and Willson (2006), the research underscored the influence of culture on organizational planning and transformational change. Alignment of change strategies with institutional cultures proved successful even when considering the negative influences of declining resources and financial scarcity (Kezar \& Eckel, 2002; Smart, Kuh, \& Tierney, 1997). In contrast, 
unresolved issues in organizational culture impeded agreement in the planning process and thwarted change, even when the stakes were high (Willson, 2006).

Willson (2006) examined a failed Academic Affairs Master Plan (AAMP) initiative at Cal Poly Pomona by analyzing the factors that paralyzed the planning process. The college began the process in preparation for a site visit by the Western Association of Schools and Colleges (WASC), the regional accrediting commission for four-year higher education institutions in California. But after months of workshops and meetings, the college was unable to complete the plan, even with regional accreditation at stake. Using the framework of matching organizational culture (Quinn, 1988) with planning types (Alexander, 2000), the qualitative research study examined the factors temporally related to the crisis. Willson (2006) found that each constituent group had its own nested culture (also called a "subculture" in other studies) within the overall shared culture at the college and that each had expectations of the planning process that differed from the others. This mismatch between culture and planning approaches may have accounted for the tensions that called for the planning process to "hurry up and slow down at the same time" (Willson, 2006, p. 8). Faculty wanted more trust building among the administrators. Administrators saw this as a stall tactic, siloism, and status quo protection by the faculty. Trustees called for a business like approach to planning, focused on efficiency and productivity, while the chancellor sought to innovate and focus on research at the institution (Willson, 2006). Most groups were unclear on the 
purpose of the initiative and some believed it to be a purely political process. Common vision and appreciation of subculture may have made the difference as shown in the following studies of successful initiatives at community colleges.

Locke and Guglielmino (2006) investigated a successful initiative at a community college, and the various subculture groups that experience, interpret, and influence the planned change process. Using an exploratory qualitative approach, this study applied Kotter's eight-stage leadership model (Kotter, 1996) to identify individual group perceptions about change, and Schein's three-tiered model of organizational culture (Schein, 1998) to define the levels at which these subcultural differences were most evident. As expected, the subcultural groups were distinguished by job type (administrator, faculty, classified staff) and seniority (junior versus senior faculty), and each group had distinctly different values and assumptions. Administrators viewed the change process from a global community perspective; the senior faculty from an analytical, intellectual perspective that was focused on academic freedom and student achievement; the junior faculty from an innovative, creative and change-oriented perspective, and the support staff from a "student first", grassroots empowerment perspective (Locke \& Guglielmino, 2006). But all groups shared a vision toward success of the initiative, and a value system centered on continuous improvement and open communication, which Locke and Guglielmino (2006) attribute to the overall success of the initiative. 
Lattimore, D'Amico, and Hancock (2012) examined three successful community colleges and their strategic response to increasing accountability demands by state agencies and regional accreditors. Their qualitative multisite comparative case study analyzed leadership and planning approaches through an accountability framework (Burke, 2005). Integrating five themes that defined implications for practice, the authors noted that the plan can meet the needs of various stakeholders if the stakeholders are involved in both planning and implementation, within a studentcentered culture that values data-driven continuous improvement, and integrates accountability principles into the planning strategies.

But what does it mean to "consider the cultures" (Cameron and Quinn, 2006; Quinn, 2011), and "meet the needs of stakeholders" (Lattimore, D'Amico, \& Hancock, 2012) for the leader of a large, historic, multicenter community college with an expansive mission and extensive participatory governance system like CCSF? Certainly not all constituent groups will be on board with change initiatives even under ideal planning conditions. Complicating this, community colleges by definition contain a wide variety of subcultures, stemming from "multiple missions" (transfer, career and technical education, noncredit adult education, etc.), which are often at odds with one another and their relationship to the overall institutional mission. 
The cultural implications of multiple missions

An organization with multiple missions brings the potential benefit of being able to meet a broader range of expectations and demands of the community (Pratt \& Foreman, 2000). However, resistance to multiple missions in community colleges is often reflected by the tensions between credit versus noncredit missions (Palter-Gill, 2012), and vocation versus academic missions (Bailey \& Averianova, 1998; Bailey \& Morest, 2006; Desai, 2012; Shaw \& London, 2001;). Tensions rise during times of fiscal constraint as divisions compete for financial resources and student enrollments (Bailey \& Morest, 2006; Palter-Gill, 2012). Pratt and Foreman (2000) found that these "multiple organizational identities" could result in conflicting demands of powerful internal groups ("internal elites") and multiple external constituencies (regulatory agencies, community groups). Leaders can manage this identity conflict by adjusting the plurality (number of groups), and/or synergy (relationships between groups). One of these methods is integration of the identities, which reduces plurality and increases synergy (Pratt \& Foreman, 2000). This was the concept behind the integration of credit and noncredit divisions at the San Francisco Community College District (SFCCD) in 1990. But as Pratt and Foreman (2000) caution, true integration can be thwarted in a large organization, especially if the organization continues to grow in size and complexity. Specialized departments can develop their own identity and become more aligned with the goals and objectives of their own unit more so than the organization as 
a whole (Pratt \& Foreman, 2000). Although organizations can thrive with highly functioning specialized units, this has the potential to create "structural secrecy", a condition where fragmentation and segmentation of information conceals problems in an organization (Vaughan, 1996, 2004).

Overall, these studies suggest that despite great risk or consequences, individual constituent groups will protect their own interests or "identities" in the planning process. It also demonstrates that even when colleges used a transparent, participatory planning process, constituent groups may prioritize their own needs over the institutional goals (Willson, 2006). An organization can survive and function with highly differentiated specialized units; however a change in the external environment that favors alignment and standardization (ex. accreditation), can result in decisionmaking paralysis (Anderson, 2011; Pratt \& Foreman, 2000), particularly if the synergy between departments or units is low. Individual groups may resist efforts at institutional alignment since they see their own unit as highly functioning, creating an unwillingness to change (Anderson, 2011). Fragmentation of the institution could also lead to layers of decision-making processes, creating an inability to change (Anderson, 2011).

Power dynamics between and among constituency groups may also play a role in the inability to make institutional change (Pratt \& Foreman, 2000). Brigham-Sprague (2001) found that crisis was a catalyst for rearranging power relationships among decision-makers in a community college, suggesting that power dynamics played a role 
in the development of crisis in the first place. Patel (2012) discovered the importance of the college executive leader as the "chauffeur" of effective governance practices at community colleges under accreditation review, confirming the concept that the leader must "reframe" (Bolman \& Deal, 1997) to effect lasting cultural and behavioral change (Berquist, 1992; Berquist \& Pawlak, 2008; Tierney, 2008). Therefore, the literature suggests that the leader is the crux of change that is focused on changing power dynamics among decision-makers to support the overarching goal (i.e. positive student outcomes). But if a single leader is so important in institutional reform, then why did CCSF repeat the pattern of the 1988 accreditation crisis in 2012 despite having several changes in leadership between those years? To address this question, I turned to the literature that examines the role of community college leadership in the development and evolution of crisis over time.

The role of leadership in the development of crisis

In a case study of a governance and leadership crisis at a single community college, Brigham-Sprague (2001) sought to better understand the meaning and significance of the crisis from a historical perspective and to identify the effects of the crisis on the leadership approach used to "right" the college. The urban community college studied was engulfed in a crisis of "major proportions" with forced resignations of board members, firing of the $\mathrm{CEO}$, threats to withhold state funding plus a probationary accreditation status by the regional accreditors. The research examined a 
thirty-year period of the college history providing a "rich description of culture, change, and community college leadership" (p. 21) during a period of crisis and change. One of the major findings illustrated the importance of power dynamics in the relationships between leaders in the creation of crisis. Major factors that Brigham-Sprague (2001) attributed to the development of the crisis involved the "breakdown in roles and perceptions of how the college should be run" (p. 69), as described in the tensions between faculty and CEO, the "personal agendas" of inexperienced board members, and the back channel lobbying of board votes by internal constituency groups.

Clark (2012) studied leader responses to fiscal crisis in three California community colleges and showed that leaders were less likely to make major or lasting changes and more likely to make temporary fixes with the hope that the fiscal climate would improve. Leaders noted that they were "unable to make substantial changes" within the "new normal" of a fiscally scarce environment. Also, there was an optimism that the community college system would survive the crisis that Clark likened to the optimism of the builders of the Titanic. This "optimism may blind them from the perilous storms that threaten the existence of their institutions and that of the traditional community college mission" (p. 8).

Clark's qualitative study of four California community colleges examined what the leaders (who she refers to as the captains of the ship) were doing to make change in light of the fiscal crisis. Leaders had a tendency to fall back on what was done in the 
past, "looking for short-term fixes such as implementing hiring freezes, initiating furloughs, reducing course offerings, and eliminating travel and supply budgets....in the hopes that the financial situation will eventually improve" (p. 161).

Mileti and Gailus (2005) noted that when leaders encounter a situation that is unprecedented, they rely on past experience. When that past experience involves a crisis brought about by outside forces, and the result was eventual recovery, then leaders adopt a "batten down the hatches and weather the storm" approach, as Clark (2012) noted. This behavior has been described in other areas of the organizational literature, particularly in business (Roberto, 2009), aerospace technology (Predmore, 2006; Vaughan, 1997), and healthcare (Banja, 2010; Prielipp, Magro, Morell, \& Brull, 2010).

\section{Organizational mistake and normalization of deviance}

On close examination of seeming sudden and catastrophic crises, researchers noted long periods of incubation during which repeated warning signs should have signaled impending disaster. Complicating matters, this incremental pattern is often only noted after it's too late and only in hindsight, following a catastrophic event, such as Vaughan (1997) first described after examining the historical events at NASA leading up to the destruction of the space shuttle Challenger.

The Presidential Commission that investigated the Challenger incident concluded that managerial wrongdoing resulted in the fatal decision to launch; however Vaughan challenged that conclusion by reconstructing the history of decision-making 
and considering the context of the political climate, and organizational cultures within which those decisions were made. The commission found that managers ignored the rules; Vaughan found that managers followed the rules but that these rules had changed and been "normalized" to ones that increasingly accepted risk.

Research on organizational behavior outside of higher education institutions has shown that organizations can over time accept practices that violate a previously accepted cultural norm or behavior (Vaughan, 1997), through a process known as "normalization of deviance". First coined in the sociological study of NASA following the Challenger disaster, this theory was later studied in organizations that engage in high-risk activities such as anesthesia and surgery (Prielipp, Magro, Morell, \& Brull, 2010) or aerospace technology (Vaughan, 1997); however, Vaughn (2005) and others (Gummer, 1998), suggest that this organizational behavior is applicable to all social organizations. Although seemingly sudden occurrences, these organizational mistakes have a long incubation period, as Vaughn (2005) notes: "Incrementalism, commitment, feedback, cultural persistence and structural secrecy seem to have created an organizational blind spot that allowed actors to see their actions as acceptable and conforming, perpetuating a collective incremental descent into poor judgment" (p. 54). Vaughan described the elements that contributed to the normalization of deviance: an environment of competition for dwindling resources, a culture that 
increasingly accepts risk, and organizational structures and processes that conceal warning signs of impending crisis.

In early era of spaceflight, NASA was supported by a funding stream that would later become massively reduced. By the time the Shuttle program was under development, long before the first launch, NASA had transitioned to an organization that was focused on doing more for less. In fact, the Shuttle design was accomplished on the concept of efficiency, and funding that shifted from government funds to an increasing emphasis on privately funded payloads. Political and organizational leaders also set goals without the resources available to achieve them by declaring that NASA would launch 25 shuttles each year and thereby pay for itself through privately funded payloads on each launch. NASA also became a larger, more complex organization of subcontractors for many of the high-risk systems such as the solid rocket boosters, which became the focus of investigation after the Shuttle disaster. Vaughan (1997) concluded that these changes to NASA created an environment of competition for dwindling resources, and placed pressure on managers to increasingly accept risk. In addition, Vaughan (1997) described the development of a "workgroup culture" within the SRB unit that over time redefined risk, allowing safety issues to go unresolved despite warning signs that the system was failing. Vaughan found that there were no rule violations but rather a redefining of risk and acceptance of deviations from normal that resulted in the fatal decision to launch the Challenger shuttle. Normalization of 
deviance takes into account the history of an organization, its development over time, the cultures within it, and how workgroups function and communicate within the organization.

Banja (2010) found in healthcare systems that the "recipe for disaster" is that mistakes or deviations "go unattended, unappreciated, or unresolved for an extended period of time" (p. 1). Even egregious violations of safety standards could persist for years, despite their importance. From an organizational perspective this "decouples" organizational intentions from outcomes. Decoupling in organizational theory is the creation and persistence of gaps between formal policies and actual practices (Meyer \& Rowan, 1977). When those policies are designed for the protection of patients (healthcare) or students (education), then this decoupling separates the institutional goals from the intended outcome. This jeopardizes the purpose and threatens the existence of the institution.

Decision-makers do not intend this to happen. In fact, Banja (2010) found that one of the reasons healthcare workers deviated from policy is because they believe it was in the best interest of the patient, even for policies designed with the purpose of protecting the patient. This "organizational mistake" differs from organizational misconduct in that it does not involve corrupt practices and deviant behavior with malicious intent (Vaughan, 1997). Kahn (2012) notes “dysfunctional behaviors are maintained because they serve certain functions for those performing those behaviors" 
(p. 225). Banja (2010) found that reasons given for deviations from standards in healthcare included: 1) Rules are stupid or inefficient; 2) knowledge is imperfect; 3) disrupts work practice; 4) acting on behalf of patient; 5) rules don't apply/trust me; 6) fear of speaking up; 7) leaders dilute findings on system problems.

At CCSF, problems cited in 2012 ACCJC and FCMAT reports were shown to be problems in the 1970's and 80 's, despite major structural reorganization in the 1990's and six chancellors between 1977 and 2012; therefore, it is not likely that the crisis can simply be attributed to a mismatch between leadership types and institutional culture, nor to a misalignment of planning process with internal subcultures. Higher education research is lacking on the issue of persistent or recurrent problems in community colleges. At CCSF the problems of the 1988 accreditation repeated in 2012. Informed by general organizational literature this research uses normalization of deviance theory to examine why CCSF leaders were unable to thwart institutional crisis that threatens its existence.

\section{Summary and Implications}

In higher education crisis literature, there is a tendency to focus on the leader and the actions taken to mitigate a crisis; but sometimes a problem persists and/or recurs despite changes in leadership. Existing research also focuses on events temporally related to the development of a crisis instead of taking a longitudinal view, which 
incorporates factors such as external environment during which critical decisions were made, and persistence of organizational cultures that may affect leader decision-making. Without incorporating the historical relevance of critical decisions, and closely examining why the crisis pattern persists or reoccurs, a college leader may enact only short-term solutions, such as changing leaders or restructuring the organizational chart (Clark, 2012).

Understanding early warning signs and the historical significance of repeated or continuous problems can have important implications for organizations in avoiding crisis and may be useful for leaders at higher education institutions. Informed by the literature on organizational crisis combined with the higher education literature on the influence of leaders, decision-makers and cultures, this research recreates historical developments from the formation of the San Francisco Community College District (SFCCD) in 1970 leading up to the July 2012 "show cause" sanction. Two major areas cited in the 2012 report: lack of integration of budgeting and planning to maintain financial solvency and the failure to use student learning outcomes (SLO's) to evaluate institutional effectiveness, will be placed on the historical timeline recreated through archival and interview data and examined for factors associated with normalization of deviance. The methods used to further organize and analyze the data, build the theoretical constructs and formulate theory are described in the next section. 


\section{Chapter Three: Methodology}

Introduction

This research is a case study of a single community college over a period of several decades with the purpose of reconstructing key events and decisions made within the context of the external environment and internal cultures. Decision-making by leaders and governance structures was examined in two areas, each related to major recommendations by the accrediting commission: prioritizing financial resources and the use of student learning outcomes to determine institutional effectiveness. This qualitative research study addresses the primary research question: Why did City College of San Francisco reach a stage of crisis that threatens its existence? What began originally as an exploration into the historical significance of the current crisis, after constant comparison to the literature and emerging thematic elements from the data, became an explanatory study of normalization of deviance at CCSF. The use of this theory strengthened the research design (Yin, 2014) by providing a structural organization, and focused the analytical process to address the broad research question.

\section{Study Design}

This research is a historical case study of a single community college and uses an explanatory analytical framework (Yin, 2014). Although Yin (2014) describes a case study and a history as two distinct methods, this research is a blend of both. For example, both case study and history examine how and why research questions and 
neither requires control over behavioral events, but a case study tends to focus on contemporary events by using direct observation, interview, documents, and artifacts (Yin, 2014). Historical research emphasizes the availability of documents and artifacts, and uses interviews to confirm, corroborate, and/or refute the historical documents. Since this study asserts that certain historical events and trends played a significant role in the contemporary state of the college, it blended both historical and case study methods. Data sources included researcher-conducted interviews of 20 college leaders, observations of videotaped board meetings, and review of archival records. Appendix 1 lists data sources used in this study. The Rosenburg library archives collection at City College of San Francisco has a rich collection of artifacts, records, documents, media, reports, and photographs dating back to the 1930's. These archives also included audiotaped interviews of over 30 college leaders (administrators, faculty and support staff) conducted during the period of 2006-2008. These archival interviews were collected and stored in the CCSF archives for the purpose of documenting CCSF history through employee experiences at the college. I selected 12 of these archived interviews for use in this case study. The interviews were selected on the basis of relevance to the data collected from researcher-conducted interviews and document analysis.

One challenge of historical qualitative research is recognizing the criticality of events and decisions made years ago that may be associated with the current crisis. The research can become bogged down in massive volumes of data that may or may not 
have relevance to the current crisis at CCSF. Another pitfall of using a historical structure to data collection is a tendency to focus on events in the past and not give sufficient attention to more recent events (Yin, 2012). I dealt with this by working backwards, starting from the crisis and using the 2012 ACCJC accreditation report and the 2012 FCMAT report to focus the research on two cited deficiencies: fiscal operations and use of student learning outcomes. I also watched and took notes on approximately 80 hours of videotaped board meetings to learn the stakeholder groups, individual leaders, their priorities, and processes through which decisions are made. Videotapes are public and accessible online for the period of 2010-2013. These videotapes proved valuable to observe verbal and non-verbal communications among the various individuals and constituent groups. Board meetings are the venue for public airing of major issues and voting on critical decisions that affect the college operations. These videotapes served as an artifact to provide both current context and in some cases, review of CCSF history. Several board members and constituent leaders have decades of history at the college, and occasionally refer to certain aspects of the history that drew my attention to the documentary record in the archives.

In this way, the videotapes and the interviews intersect with the documentary record in the archives located at the CCSF Library. The archival record helped me develop a basic timeline and develop interview questions and a list of potential 
interviewees, and the interviewees also pointed me in a particular direction on my archival research.

\section{Data Collection}

Researcher conducted interviews

Researcher conducted interviews were semi-structured and focused on CCSF leaders with key decision-making roles between the time period of 1970-2012. Leaders included former chancellors/presidents, administrators (vice chancellors and deans), and faculty leaders who participated as either department chair or on a shared governance committee or both. I collected data from three types of interview: formal, informal and targeted. I describe an interview as formal when I selected the participant based on their tenure and role in decision-making, and used my interview protocol (Appendix 2), and process (audiotaped, transcribed). Informal interviews I characterize as conversations during personal meetings that I scheduled with senior faculty members in my office or at the library for the purpose of verifying events. I took written notes during these interactions. Targeted interviews were designed to help me understand jargon and procedures, and focused largely on the budget and fiscal processes over the last 30 years at CCSF. I interviewed two key people, one formally and the other informally, about the budget.

Data were collected, organized and analyzed from a total of 20 researcherconducted interviews: 13 formal, five informal, and two targeted interviews. The 13 
formal interviews included two former chancellors, six administrators, and five faculty leaders. Two of the administrators had also served as faculty at CCSF before becoming administrators. These 13 interviews were conducted individually at a site chosen by the participant, and audiotaped with the signed consent of the participant (Appendix 3). Total interview time for the 13 interviews was 30 hours. I listened to the audiotape at least once prior to transcribing each interview. Each interview was transcribed verbatim and the transcription and audiotape stored in locked files for later analysis. Informal interviews were conducted with five individuals: two administrators and three faculty members. Field notes of these informal interviews and one targeted interview were included in coding and analysis.

The sequence of formal interviews was important since I was learning about the district with each interview and visit to the archives. After conducting the initial five interviews, and constructing the historical timeline, I decided to delay the chancellor interviews until the end of all other interviews, so that I had a clear picture of the key events that occurred during each chancellor's tenure before each of these interviews took place. This allowed me to adjust the interview protocol to each chancellor and insert follow up questions on topics relevant to the chancellor's tenure at City College of San Francisco. 


\section{Participant Selection}

Participants in the researcher-conducted interviews were selected on the basis of functional decision-making role, longevity of employment, and willingness to participate. In addition, participants were purposefully selected to represent both genders and diversity of ethnicities, position levels, and academic disciplines.

Additional participants were included using snowball sampling based on recommendations of participants or upon review of archival data that suggests the participant may add to the data already collected. There were no exclusion criteria. Three potential participants were contacted by email and/or telephone, but did not respond to the inquiry. One participant acknowledged the invitation but declined to participate.

The interviews were semi-structured (Seidman, 2006), using an interview protocol (Appendix 2) as a template and building on preliminary data obtained from an initial document review of the CCSF archives on decisions related to fiscal matters and student learning outcomes between the time period of 1970-2012. The constant comparison of archival data to emerging interview data generated more specific interview questions.

Participants were contacted by phone or initially by email to explain the purpose of the research, and assess interest. At the time of initial meeting, I explained the purpose of the research, the risks and benefits, and provide the participant with the 
informed consent document (Appendix 3). Participants were given the option to end participation at any time during the interview. Permission to audiotape and use direct quotes were also included in the informed consent document as well as the options to not be audiotaped and/or to remain anonymous if the participant so chose.

Archival interviews

During the data collection process, I discovered at least 30 audiotaped interviews stored in the Rosenburg Library archives collection. These audiotaped interviews were conducted during the years 2006-2008 for the purpose of preserving and celebrating the rich history at City College of San Francisco, and included faculty, administrators, support staff (classified), and chancellors. Each interview was approximately 1-2 hours in length and was semi-structured, focusing on each participant's personal story at City College of San Francisco and the most memorable experiences with students. From these interviews, I selected 12 for use in my research. These particular interviews were selected because the interviewees included those who have history of participation in decision-making and/or leadership structures within the institution during the time period of study (1970-2012). These interviews included 3 former chancellors, 2 former presidents, 2 trustees, 2 administrators, 2 faculty leaders, and 1 classified staff leader. Two of the former chancellors and one administrator were also participants in the researcher-conducted interview. 
Archival document review

The initial archival document review focused on accreditation reports including institutional self-studies, site visit team reports, letters and written communications between CCSF and the ACCJC, as well as the 2012 FCMAT reports. As I developed the timeline and conducted subsequent interviews, the document review expanded to include reports from key points in the college's history, governing board meeting minutes, transcriptions and videotapes, academic senate meeting minutes, and department chairperson council (DCC) meeting minutes. The campus newsletter, City Currents, publishes the chancellor's address to the college on faculty flex days twice each year at the start of the semester. "People files" that are stored in the CCSF archives and contain various artifacts related to key people in the institution,

Archival document review included all accreditation self studies, decision letters, response reports, and supporting documentation related to accreditation between 1988 and 2012. Other documents included academic senate meeting minutes, department chairpersons council (DCC) meeting minutes, governing board documents, audio and video files of governing board meetings, campus newsletters (City Currents) that publish the chancellor's address twice per year, and other documents such as memos, letters, and articles identified during the data collection process as relevant to the direction of the research. In addition, data from field notes of personal observations were included during the data collection period (Emerson, Fretz, \& Shaw, 1995). 


\section{Data Analysis}

Data collection, coding and analysis took place concurrently, beginning with the initial formal interviews and review of key documents in the archives. Figure 3 is a visual representation of the coding and analysis techniques. First cycle coding of interviews and key documents used event codes (Auerbach \& Silverstein, 2003) and reconstructed the historical timeline of the college from the development of the district in 1970 through the "show cause" sanction in 2012. On the timeline I placed critical events, names of CCSF leaders, and relevant legislation as they were mentioned during interviews and confirmed in archival documents. Event coding gave structure and organization to the historical data and added context of both internal and external forces that may have shaped the college operations and leader decision-making over time. 
Figure 3: Coding and analysis

Data Analysis

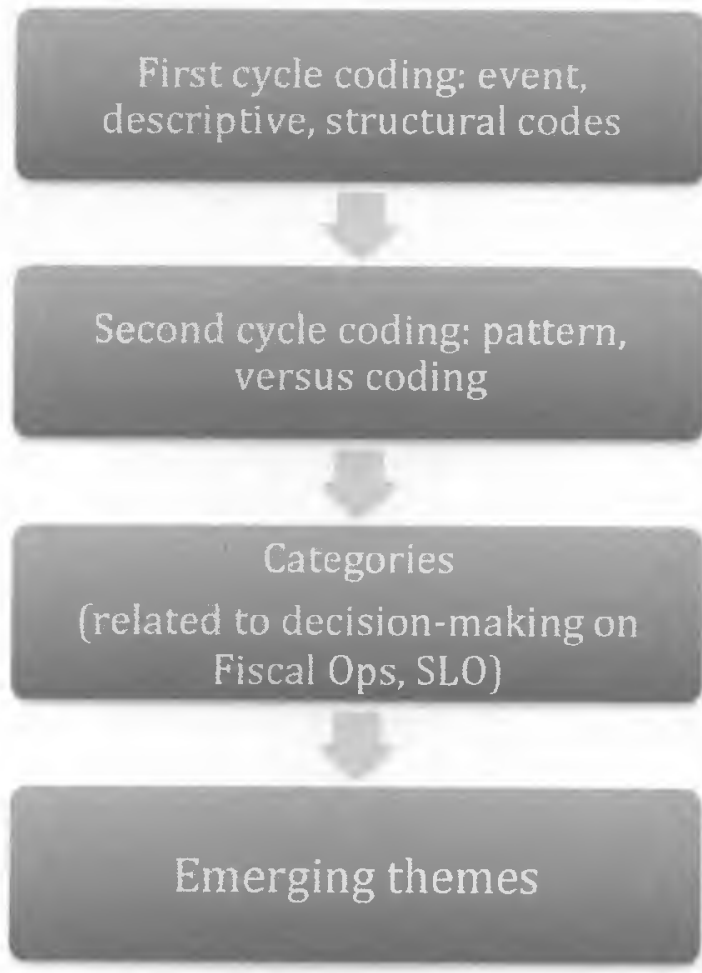

\section{Theoretical Framework}

RQ: Why did City College reach a stage of crisis that threatens its existence?

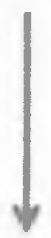

What factors may have contributed to the inability of leaders and decision-makers at CCSF to see the magnitude of the crisis as it approached?

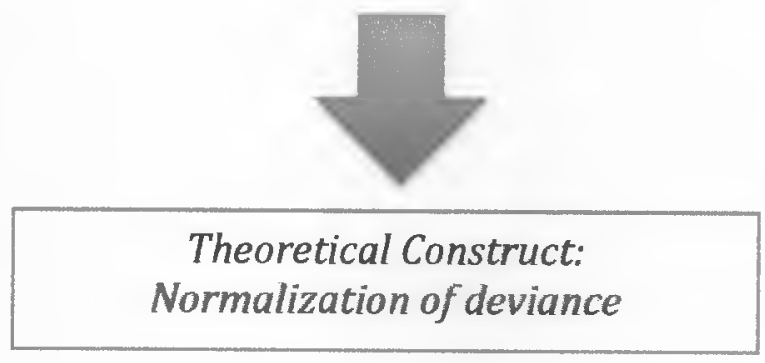

One of the challenges of the initial exploratory research was identifying which events would be considered critical to the college and relevant to this research. An event or decision was considered critical or relevant if it was mentioned during at least two 
formal interviews and could be confirmed in the archives and verified by an informal participant; triangulating to improve integrity of the data. To my surprise, most of the participants had rich knowledge of the key events in the formation of the district, its reorganization in the early 1990's and of general operational challenges within the San Francisco Community College District. Certain events that I expected to be mentioned by two or more key participants were referenced in every interview.

Interview data from transcribed formal interviews of the 20 participants were coded first through a combination of descriptive coding, event coding, and structural coding (Saldana, 2013), using the protocol questions as a guide to organize the codes. Second and third cycles used pattern coding to further group the codes into categories as they related to decision-making over time related to fiscal operations and the student learning outcomes process. One subtype of pattern coding included versus coding (Saldana, 2013), which are codes that describe dichotomies such as "credit versus noncredit". This code type helped to visualize the tensions within various groups at CCSF. Patterns and categories became the basis for the emerging themes that were then compared to the theory of normalization of deviance to form the theoretical construct and explanatory model for the current crisis.

First, second and third cycle coding were completed by hand as was pattern matching and category formation. The software program NVivo was used to recode the formal interview transcripts a second time, independent of the references to archival 
data. This was done to closer examine the themes within the category of organizational culture, and to glean notable quotes (i.e. invivo codes) from the data as they related to the emerging theoretical construct.

\section{Validity and reliability}

Well-constructed research links the study design, the data to be collected, and the analysis plan, directly back to the research question. Four elements were considered when designing the protocol to ensure the quality of this research: construct validity, internal validity, external validity, and reliability.

\section{Construct validity}

Construct validity is ability of the study design to address the research question, and is a particular challenge in qualitative research, which tends to take an exploratory rather than hypothesis-driven approach. The primary way I addressed construct validity was to begin the study with an exploratory approach, but then transition to an explanatory design as the emerging themes converged with the existing literature on organizational crisis. I began by first reviewing documents and videos most closely related to the fiscal and accreditation crisis, such as board meetings, accreditation documents, and budget reports. I also interviewed the first three participants and returned to the archival data to explore and discover the circumstances and meaning around key events in the history of the college. Informal interviews proved valuable at this early stage to confirm and validate the data. Only after the initial interviews, 
archival document reviews, and a return to the existing literature, did the research become less exploratory and more explanatory.

Another way I addressed construct validity was to select two main areas of focus in which to evaluate decision-making: fiscal operations and the student learning outcomes process. These two areas relate to the research on crisis at CCSF since they are repeatedly mentioned in reports and interviews as areas of struggle for the college. Also the use of multiple sources of evidence enhanced validity; sources such as interviews from past and present (before and after the crisis), and a variety of documents from the archives that included both official documents such as meeting minutes, reports and memos, and unofficial documents such as newspaper articles and campus newsletters. Finally, construct validity was addressed by establishing a clear chain of evidence through a chronological reconstruction of the history of critical events and decisions and by having a key informant review and confirm the data. Internal validity

Internal validity considers whether the data, participants, and selected documents from the archives are an accurate measure of the critical events, decisions, and conditions relevant to the research question. Internal validity became a concern in this study once I settled on an explanatory approach, which draws causal inference between the findings and the crisis at City College of San Francisco. Internal validity was addressed during data collection by including archival interviews from pre-crisis 
years, which were available in the CCSF archives. During data analysis internal validity was addressed by investigating rival explanations for the crisis at CCSF. Both construct validity and internal validity were addressed through triangulation of the data from researcher-conducted interviews, archival interviews, and historical documents with constant comparison to the literature. Triangulation converges the data from different sources to verify consistency in the finding. Also, at every step during the research process, I had to check my own biases and consider any filters that I could unwittingly introduce that may threaten internal validity and influence the outcome of the research. Role of the Researcher

I consider myself an "insider-outsider" in this research. I am full time faculty with over thirteen years of employment at CCSF and the program coordinator of the paramedic program, an 18-month credit vocational training program. This situates me as an "insider" with knowledge of the institutional structures and processes and familiar with many of the people in various leadership roles for over a decade. Also, I completed the CCSF EMT program in 1985, and am a native San Franciscan from a working class background with many family and friends who completed programs at CCSF. This places me in the position of having a personal bias from the perspective of successful student.

I consider myself an "outsider" in my role as a researcher and through my doctoral training as a researcher, which requires I maintain an objective distance. 
Despite this training, I sometimes experienced tension between researcher-observer and teacher-participant. I rectified this tension by returning to the timeline, constantly comparing data from various sources to existing literature, checking and rechecking my sources, and enlisting the advice of a few close colleagues on the logic of my analysis.

In 2013, after completing my data collection but during the writing of this work, I became a site visitor for the Committee on Accreditation of Educational Programs for the EMS Professions (CoAEMSP), a group that advises the larger Commission on Accreditation of Allied Health Education Programs (CAAHEP) on the programmatic accreditation of paramedic programs. This introduces a perception of bias in favor of accreditation.

\section{External validity}

External validity addresses the ability to generalize the results of the research to other community colleges or higher education institutions in crisis. Since this study involves a single community college, generalizability is limited; however, the use of theory during data analysis allowed analytical generalization not only to higher education institutions, but to other large organizations as well.

\section{Reliability}

Reliability measures the repeatability of the research results if another researcher conducted the same study using the same research protocol. Would other researchers come to the same conclusions as I did using the same tools and information? To 
increase reliability in this study, I attempted to create a clear chain of evidence that takes the observer from the research question through the initial events temporally related to the crisis, then through the history of decision-making at CCSF, and back to the present. I also had key advisors review the data, and the logic of my analysis during data collection and analysis.

\section{Operating assumptions}

Some operating assumptions as I collect, organize, and analyze data include: 1 . The current crisis, although seemingly sudden, most likely had a long incubation period filled with early warning signs that were missed, misinterpreted, or ignored, 2. I assume "goodness" in all members of the institution; therefore my purpose is one of exploration and explanation, not indictment of any one group or individual as to the possible reasons CCSF reached near closure. Outside forces such as statewide reductions in higher education funding, increasing pressure from the Department of Education on accrediting commissions to increase accountability of member institutions, privatization of public education and expansion of the for profit student loan market, and changing state statutes and regulations that affect community college operations will each be considered only as they are mentioned in the historical archival data. I recognize that the interviewees will be unable to remove themselves from their views on the significance of these outside forces when attempting to reconstruct historical events of the 1980 's and 90 's. 


\section{Ethics and Protection of Human Subjects}

The major ethical consideration in this study is the confidentiality of interviewees. Appendix 1 outlines a proposed interview protocol and Appendix 2 includes the standard consent form that will be used to obtain informed consent of all interviewees. Each interviewee was initially given a choice to be identified by name or opt to remain anonymous in the research process, documentation, and final written product. Despite this process, there remains a chance that an individual may be identifiable since the college is named and interviewees are faculty, administrators or past Chancellors known to others within the institution. In two cases, the participants wished to remain anonymous; therefore, to maintain the individual's confidentiality, the signed consent forms were stored in a locked cabinet. In addition, direct quotes from the interviewees were reviewed and confirmed for accuracy before used in the final publication. Overall, every attempt was made to keep the identities of participants anonymous. Since the focus of this research is on the overall organizational behavior, the conclusion is that no single individual leader or faction of leaders is the source of institutional crisis. This research asserts that City College of San Francisco developed an "institutional blindspot" to the severity of an oncoming crisis and attempts to explain how it may have occurred over time, escaping detection and preventing prompt action by the various levels of leadership. 


\section{Limitations of the research}

Since this research is a historical exploration of people and events at a single community college, the greatest limitation will be its ability to generalize the results to other institutions. The results may be able to inform future leaders at CCSF and contribute methodological knowledge to study the evolution of crisis in higher education. More importantly, I hope the research can provide some insight on how leaders can recognize problems before they lead to crisis.

\section{Summary}

Studying organizational crisis after the fact is challenging. Interview participants rely on hindsight observations and recall of their feelings and actions about certain precrisis events. Building a chain of evidence required the use of pre-crisis interviews and documents from the library archives. Through historical case study design, this study examines contributing factors to crisis development at City College of San Francisco related to decision making on fiscal operations and student learning outcomes. Thematic analysis was then conducted using analytical generalization against the theory of normalization of deviance to present the elements that may have contributed to the development of an "institutional blindspot" and prevented prompt action to avert crisis. 


\section{Chapter Four: Report of Findings \\ Overview}

City College of San Francisco, one of the largest community college districts in the country, is in a fight for its survival. After a comprehensive review of the college and its centers, the Accrediting Commission for Community and Junior Colleges (ACCJC) determined in June 2012 that the college was significantly out of compliance with the eligibility requirements and standards for accreditation and issued a "show cause" sanction, giving the college one year to meet these requirements or lose accreditation. One year later the commission issued the ruling to terminate CCSF's accreditation as of July 2013, which would have cut off state funding and closed the institution. Although the accrediting commission recently issued a 2-year extension through a newly established "restoration status", the fight for survival is far from over. Many of the problems facing CCSF had their roots decades into the past, raising the question as to why nothing was done to right the path of the institution that in hindsight seemed headed directly toward crisis.

The purpose of this study was to examine the historical evolution of the crisis at CCSF for factors that may have led to the development of an "institutional blindspot" to impending threat of closure. In the aftermath of crisis, there is a tendency to focus blame on individuals; however organizational characteristics such as economic resources, decision-making structures, politics, and organizational culture, all affect 
decision making and place pressure on individuals to deviate from accepted norms in order to meet organizational goals (Vaughan, 1996; 2005). Such deviations may persist in organizations despite the existence of standards designed to prevent them, most likely because incrementalism (Vaughan, 1996) makes problems difficult to see before crisis can be averted. Banja (2010) noted that major accidents typically involve multiple people committing and/or tolerating seemingly small mistakes or deviations that breach safety nets, resulting in serious harm. Educational systems may be vulnerable to this organizational pattern as well as they are forced into an environment of competition for scarce resources and increasing pressure to meet regulatory standards. Ashforth and Anand (2003) found that normalization occurs when deviations from acceptable practices are rationalized by key groups within the organization and then institutionalized as these groups socialize newly hired individuals. This suggests that both environment and organizational culture play key roles in the normalization of deviance in an organization, as noted by Vaughan $(1997,2005)$ and others (Banja, 2010).

This qualitative study used interview and archival document review to examine the historical evolution of the crisis at CCSF starting with the formation of the district in 1970 and ending with the 2012 "show cause" sanction. The evidence suggests that CCSF consistently normalized deviations in decision making on fiscal matters and student outcomes processes and that these deviations persisted due to three factors: an 
environment of competition and scarcity, a culture of expectation to be "all things to all people" both within and outside of the institution, and a self-affirming ideology that allowed leaders at all levels to rationalize CCSF uniqueness as exempt from regulation.

Findings are presented in this chapter in three main sections. The first section presents evidence of an environment of competition for scarce resources at CCSF in the face of state reductions in funding for community colleges, growing accountability standards from the state and regional accreditors, and a structural organization of the district that promoted competition between constituency groups. The second section describes a culture of expectation; over time college leaders experienced fiscal and political pressure to meet expectations of various constituency groups as the college increased in size, scope, and complexity. The third section describes a self-affirming ideology at CCSF; a belief that CCSF is so unique that rules became irrelevant. The chapter concludes with a summary of these findings and how these elements collectively resulted in the normalization of deviance in fiscal and outcomes decisionmaking and ultimately in the current crisis at CCSF.

\section{Competition and Scarcity}

Research shows that leaders and decision makers are more likely to take risks, violate rules, or deviate from acceptable practices when the organizational environment is under the pressure of competition for diminishing resources (Vaughan, 2005). This competition may take place between organizations that compete for the same source of 
funding (i.e. community college districts within the same state) and within the organization between various constituency groups (i.e. departments, programs, and constituency groups within a single community college district). Analysis of factors at City College of San Francisco that contributed to an environment of competition for scarce resources revealed three main themes: state reductions in funding for community colleges, growing accountability standards from the state and regional accreditors, and a structural organization of the district that promoted competition between constituency groups. 
Table 1: History of California Community College Funding 1970-2012

\begin{tabular}{|c|c|}
\hline Year & State of California Community College Policy changes \\
\hline $1970-1977$ & $\begin{array}{l}\text { Funding of community colleges based on basic state aid and ADA; } \\
\text { Collective bargaining begins in } 1977\end{array}$ \\
\hline 1978 & $\begin{array}{l}\text { Proposition } 13 \text { passes limiting local property tax and marking the } \\
\text { transition from local to state funded public education }\end{array}$ \\
\hline $1980-1984$ & $\begin{array}{l}\text { Each district assigned an ADA growth cap; noncredit ADA is funded at } \\
50 \% \text { of full credit rate }\end{array}$ \\
\hline 1984-1988 & $\begin{array}{l}\text { Student fees imposed for the first time at } \$ 5 \text { per unit or } \$ 50 / \text { semester } \\
\text { for } 6 \text { or more units }\end{array}$ \\
\hline $1988-1989$ & $\begin{array}{l}\text { AB1725: Establishes program based funding and } 75: 25 \text { ratio of FT to } \\
\text { PT faculty teaching credit courses; Proposition 98: establishes } \\
\text { minimum funding for K-12 and Community colleges }\end{array}$ \\
\hline $1990-1993$ & $\begin{array}{l}\text { Program based funding implemented; Enrollment fees increase in } \\
1991 \text { ( } \$ 6 / \text { unit), } 1993 \text { ( } \$ 10 / \text { unit); Shortfall of } \$ 79.3 \text { million; Prop } 98 \\
\text { funds to community colleges reduced }\end{array}$ \\
\hline 1994-1996 & $\begin{array}{l}\text { Enrollment fees increase to } \$ 13 / \text { unit; Property tax shortfalls at state } \\
\text { continue and cause fiscal problems at districts around the state }\end{array}$ \\
\hline 1997-1999 & $\begin{array}{l}\text { Growth funds approved for districts that grew; Partnership for } \\
\text { Excellence funding begins }\end{array}$ \\
\hline $2000-2001$ & $\begin{array}{l}\text { Proposition } 39 \text { passes, allowing community college districts to pass } \\
\text { bond measures with } 55 \% \text { majority vote; Growth funds, increased } \\
\text { Partnership for Excellence funding and a drop in fees to } \$ 11 / \text { unit }\end{array}$ \\
\hline $2001-2002$ & $\begin{array}{l}\$ 4 \text { billion revenue shortfall causes base funding reductions to } \\
\text { community college programs }\end{array}$ \\
\hline $2002-2003$ & Community College budget increased by $\$ 72$ million \\
\hline $2003-2004$ & $\begin{array}{l}\text { Community College funding reduced by } \$ 86.8 \text { million } \\
\text { Enrollment fees increase from } \$ 11 \text { to } \$ 18 / \text { unit }\end{array}$ \\
\hline $2005-2006$ & $\begin{array}{l}\text { No equalization funding; cuts made to Prop } 98 \text { money for community } \\
\text { colleges; Statewide workgroup meets to develop new finance model }\end{array}$ \\
\hline $2006-2007$ & $\begin{array}{l}\text { Enrollment fees decrease from } \$ 26 \text { to } \$ 20 / \text { unit } \\
\text { SB 361: new funding greatly benefits CCSF. }\end{array}$ \\
\hline $2007-2008$ & $\begin{array}{l}\text { Basic Skills funding provided plus other one-time initiatives. The } \\
\text { community college system faces } \$ 74 \text { million property tax shortfall. }\end{array}$ \\
\hline $2008-2009$ & $\begin{array}{l}\$ 14 \text { billion in cuts proposed in State budget. State defers } \$ 340 \text { million } \\
\text { in apportionment to } 2009-2010 \text {. }\end{array}$ \\
\hline $2009-2010$ & $\begin{array}{l}\text { Student fees increase to } \$ 26 / \text { unit. } \$ 703 \text { million in cash deferrals. } \\
\text { Estimated statewide } 3.4 \% \text { workload reduction from cuts to classes. }\end{array}$ \\
\hline $2010-2011$ & $\begin{array}{l}\text { State budget signed } 100 \text { days past deadline. Funding for five } \\
\text { mandated categorical programs suspended. }\end{array}$ \\
\hline $2011-2012$ & $\begin{array}{l}\text { Student fees increase to } \$ 36 / \text { unit; } \$ 400 \text { million cut to state } \\
\text { apportionments. Midyear trigger cuts; additional cuts in February } \\
2012 \text { ("February surprise") totaling } \$ 179 \text { million in cuts. }\end{array}$ \\
\hline $2012-2013$ & Prop 30 Tax initiative passes; $\$ 50$ million in restoration funds. \\
\hline
\end{tabular}


State reductions in funding for California community colleges

Decision-making by college leaders on budget matters takes place within the context of external fiscal regulation. Table 1 outlines historical events in state level funding of community colleges in California during the period of 1970-2012. At the start of this timeline, the San Francisco Unified School District (SFUSD) consisted of the K-12 system, adult education programs, and the community college. But this would change after an amendment to the California State Education Code in 1967 established the State Board of Governors to oversee a statewide community college system.

To meet the mandate of the state legislation, in 1969 the San Francisco Board of Education and the San Francisco Board of Supervisors established the San Francisco Junior College District, later designated by the Governor in 1970 as the San Francisco Community College District (SFCCD). The new city ordinance ordered the separation of the SFCCD from SFUSD, established boundaries of the district and entered into public record the use of the CCSF site for the newly formed SFCCD. Unlike most districts in California, the SFCCD retained the noncredit adult education courses and programs.

The first local governing board membership was established by City Charter, holding the first meeting on August 8, 1972. The first policy manual of the Board of Governors for the SFCCD in 1972 defined the sole purpose of the board policies as "to facilitate instruction" as "determined in accordance with the educational needs of the 
community" and is "limited only by the extent of local resources" (1972, SFCCD). The board policy manual structured the SFCCD into three divisions: the District Office Division, the College Division and the Adult-Occupational Division (1972, SFCCD policy 2.02). Often referred to as the "Centers Division", the Adult-Occupational Division ran noncredit programs and courses at the various adult education centers and sites throughout the city. Each center had its own site director and a single president collectively administered the centers. Credit courses and programs were located at the Ingleside district CCSF campus and were administered by a college president. A single chancellor/superintendent presided over the entire district (SFCCD Governing Board Policy Manual, 1972).

The period of 1970-1977 was a time of great expansion for the fledgling district. Then Chancellor Louis Batmale was charged with "trying to put the district together" and noted that,

We had a great surplus at the time. One of the advantages of unified coming in to the community college at that time in 1970 was fiscal ... so we were getting a lot more money from the state so we built a big surplus. (2006 interview transcript).

Using this surplus for expansion, the SFCCD acquired two new centers: one at the San Francisco International Airport and the other in the heart of downtown San Francisco. 
At the time of the SFCCD formation, the state apportionment for community college districts was derived primarily from enrollment or "ADA" (average daily attendance), and districts could receive additional revenue through local property taxes. By the mid-1970's the state began to limit allocations for each district. The 1974 guarantee of full funding for ADA growth was limited to a five percent cap in 1975 (Murphy, 2004). Districts with greater than five percent growth were forced to seek additional revenues from local taxes or to reduce expenditures.

At the SFCCD, Batmale had assembled a financial team, which he coined as "guardians of the district resources":

It's good to have people like that who can say no to the faculty because otherwise you erode your resources. It was important to protect those because the outcome of integrating the two (Adult education and CCSF) had important implications for the funding of the district... You need somebody in your organization who can say no...can confront people and say it's against the rules, you can't do that. (Batmale, 2006)

But in the late 1970 's, two initiatives would impact state funding for California community colleges and the fiscal environment at the SFCCD. The first was the Rodda Act (SB 160), which took effect in 1976 and marked the onset of collective bargaining for public school teachers in California. The second was the passage of Proposition 13 in 1978, which shifted the control of public education funding from local governments 
to the state. Over the next three decades the trend of increasing expenditures on compensation and benefits for employees ran counter to the trend of unpredictable revenues resulting from the steady decline in state support for community colleges. Collective bargaining and Proposition 13 at the SFCCD

At the SFCCD, the American Federation of Teachers (AFT) 2121 won the representation rights for the faculty in 1978. At the same time, a supervisory unit known as the Department Chairpersons Council (DCC) negotiated as a separate and distinct bargaining unit at the college. At CCSF, Department Chairs are faculty with release time and administrative authority over of the each of the 56 departments. The DCC is independent of the Academic Senate and shared governance system and the DCC bargaining unit is independent of the AFT. Classified personnel at CCSF belong to the ranks of Civil Service; therefore, labor negotiations take place between the classified union (now SEIU 1021) and the City and County of San Francisco. This structural organization of having a distinct DCC bargaining unit and Classified Civil Service personnel is unique to CCSF as compared to other California community colleges. Archival documents and participant interviews revealed an overall trend that rising labor costs strained the college resources, particularly in times of fiscal uncertainty, as noted by the administrator of financial operations:

The trump card always on the horizon that's never spoken of is labor negotiations - it's "we're planning this, we're planning that" - boom, the 
money is all gone - "okay, we'll think about that for next year". (INT 3, line 504-506, 2013)

Over a five-year period between 1982 and 1987, salaries and fringe benefits increased by over $15 \%$ for certificated and classified employees. By 1988 , the percentage of the district's budget dedicated to personnel was $89 \%$. The district attributed this increase to having "no control over classified salaries, which are set by the City" (SFCCD Institutional Self Study, 1988, p. 215) and to "higher incremental salaries for faculty and administration" (p. 219). Negotiated increases in salaries and benefits occurred during the period of "expansive growth" of the district and hiring of faculty, administrators, and support personnel. This number would grow to $92 \%$ by 1993 and remain in the $90-92 \%$ range through 2012 (CCSF, 1988; KH, 1993; INT 3, 2012). The cost of facilities and emerging technologies would compete with the rising cost of personnel and, despite concessions taken in times of fiscal crisis, this competition for resources would last for more than two decades.

Fiscal uncertainty for California community colleges began with the passage of Proposition 13 in 1978, which established limits on new property taxes and shifted the primary source of funding for community colleges from local sources to a centralized state allocation system based largely on sales and income taxes. Local government was also limited by a two-thirds majority vote to levy new taxes for their local school districts. Packaged as anti-tax and anti-spending legislation, Proposition 13 and the 
1979 "Gann initiative" were designed to reign in expanding public programs, which included the state's public education system. California community colleges are particularly vulnerable to fluctuations in state revenues since, unlike other higher education institutions in the public sector, they have no significant source for external funding. The SFCCD, however, has consistently received the votes needed by the local San Francisco voters for additional taxes and bond monies to expand sites and services since the founding of the San Francisco Junior College in 1935. Although this unprecedented public support aided the college in difficult times, like other community colleges in the State, the largest single source of funding came from state revenue.

The timing of the two initiatives, collective bargaining and then Proposition 13, was an important factor in the development of financial issues at the SFCCD. As one former chancellor noted,

Collective bargaining was passed by the legislature before Proposition 13. At that time they (state legislators) assumed that the governing boards of each district had the power to levy tax and determine how much it was after negotiating with the unions and so forth. Now it just turned things totally upside down. You negotiated, but there was no power to determine what they should do and couldn't do. (Archival INT $14,2006)$ 
Without the ability to directly control revenue, governing boards were faced with the need to reduce expenditures at a time of increasing demand to fund personnel, classes, and programs. This represented a shift in practice for the district:

Since the passage of Proposition 13 on June 6, 1978 the budgeting process starts on the revenue side of the budget. A calculation of the estimated revenues is made and then we proceed to fit the expenditure budget into a finite revenue budget. (1988-89 budget report to the governing board on August 22, 1989)

But as Table 1 shows, the ability to estimate revenue from the state became increasingly difficult since community college revenue became prone to fluctuations in the state economy. Community college enrollment typically swells during economic downturns as unemployed workers return to education for additional job training or a change in career (Moltz, 2008); however, under the new model of funding, the community college would be underfunded by the state during the time of greatest need for resources.

As the first chancellor/superintendent of the SFCCD, Louis Batmale spent seven years expanding access to the diverse communities of San Francisco; but anticipating these shifting tides in community college funding, he decided to retire in 1977:

I had a different vision of how this was going to develop. Proposition 13 and collective bargaining were not my style. I didn't want to get 
confrontational with faculty. These were my friends. It was a good time for me to retire. (Batmale, 2006 interview).

Despite the fallout from Proposition 13 and dependence on state block grants that in 1979 created a "terrible year for funding the district" (Hsu, 2006), throughout the 1980's the SFCCD was able to build and maintain a surplus at the closeout of the budget each year. Several interview participants attributed this to the conservative methods of the financial team, specifically the Chief Financial Officer (CFO), who one administrator referred to as "smart and conservative, with foxy pockets of money". Several faculty and administrator participants also noted that the early financial managers concealed the fund balance, with one administrator noting that, The union always accused him (CFO) of hiding money... but we always managed to come out at the end of the year with surplus. And the reason later it was explained why we had surpluses was that (he) would always fully fund each position. Even if the position was vacant. He always fully funded every position and therefore, you wouldn't see in the budget. (INT 1 lines 196-207, 2013)

Participants also credited then chancellor Herb Sussman, for his ability to control spending despite the demands from the various college constituency groups and from members of the governing board. A native of New York and the first "outsider" chancellor at the SFCCD, Sussman took over at this critical juncture in the district in 
1977. After spending the previous five years as President of the New York City College of Technology (NYCCT), Sussman was experienced with budgeting at community colleges during a national recession, having reduced personnel and programming in the face of an $8 \%$ budget deficit at NYCCT (CUNY Heritage \& History, 2014). Although accounting tactics and conservative leadership preserved SFCCD funding through the early 1980 's, the attempted cutbacks to the budget did not bode well with many of the faculty and union leaders. The AFT president at the time declared, "Sussman was hired because he was a strong man who was going to stand up to the union" (Archival INT $15,2006)$

Throughout the early 1980's, the state implemented growth caps for both credit and noncredit ADA. In 1982, growth in noncredit ADA was funded at 50\% of the credit rate and in the following year a major reduction was implemented in "recreational and avocational" programs (CDE, 2005). In 1985, the state imposed student fees for the first time in all community colleges. Revenue from those fees were treated like local property tax and used to equalize the amount for each district in the state general apportionment (CCCCO, 2014).

Interview participants recall this as a time of crisis at the SFCCD with "a lot of uncertainties" when "we didn't know how to plan". One former trustee noted, "The budget became particularly bad in the late 80 's when the state went into recession" (Archival INT 17, 2006). Frustration was apparent in a memo from a trustee who 
presented at a board meeting in January 1988, "the less money, the fewer programs; the fewer programs, the fewer students; the fewer students, the less ADA; the less ADA, the less money, etc." Competition for scarce resources between personnel and operational costs became apparent in 1988-89 in transcripts and documents from governing board meetings:

In a state and district of limited resources, funding for projects must be based on priorities...personnel costs take up to $86 \%$ of its total budget...there is very little room for taking care of facilities needs. (Chancellor Hsu, March 1988)

The time has come to look hard at our institution. Where are we heading? What is our future? We are trying to maintain a facility with insufficient support. Growth in our student body and faculty must be paralleled by adequate support staff, office space, supplies, equipment, and contingency funds for maintenance...we have patched here and there, using a band aid approach, in order to keep the facilities functions. This approach is no longer a viable solution. (memo from College President Willis Kirk to the governing board, August 1989) 
The budget provides for no increased amount in instructional hours...yet we need to start as many classes as we have a demand for or we will not meet the needs of our population. (memo from Centers President Rena Bancroft to the governing board, August 1989)

At the same time, state community college leaders met to address the fallout from Proposition 13, and revisit the 1960 Master Plan, which defined the role of community colleges in public higher education. The outcome of these meetings would lead to AB 1725 and launch an era of accountability in the midst of unpredictable revenue for California community colleges. Increasing accountability on top of reductions in state funding together contributed to an environment of competition for scarce resources at the SFCCD as described in the next section.

An era of accountability and unpredictable funding

The 1960 California Master Plan for Higher Education solidified the open access mission of the community colleges when it defined a coherent three-tiered system of public higher education in the state. The plan limited admissions at the University of California (UC) and California State Universities (CSU) and designated the California Community College system as the college system for all people in the community. As former State community college chancellor Jack Scott noted, "we simply accept the top 100\% who graduate from high school" (2010 meeting of the 
Commonwealth Club). The curtailing of budgets, classes, and programs at community colleges in the years after Proposition 13 conflicted with this open access mission. Community colleges were originally designed to be responsive to the local communities. The passage of Proposition 13 transferred control from local districts to the state. AB 1725, which was signed by the governor in 1988 was intended to update the mission of community colleges, establish a system of funding and accountability, and return control of the districts to the local communities through an inclusive system of governance and finance (CCC, 1989).

Although the majority of interview participants referred to $A B 1725$ as the "shared governance bill", the provisions of this bill were comprehensive and created sweeping reform to community colleges. The main provisions of $\mathrm{AB} 1725$ included: 1) a clarification of the community college mission as a transfer institution that also offers remedial courses and vocational training programs; 2) goals on faculty hiring; 3) recommendations on a system of governance based upon collegiality between administrators and faculty; and, 4) "program based funding" formulas for determining state apportionment. The rollout of these changes would also include a comprehensive accountability model designed to measure the institutional effectiveness of each college. Financial and educational indicators of effectiveness aligned with the accreditation standards and included indicators of student access, success, and satisfaction, plus 
faculty diversity, professional development and overall fiscal condition of the college (CCC, 1990).

The funding model that came from AB 1725 and AB 3049, "program based funding", removed the use of ADA and replaced it with workload measures based on full time equivalent students (FTES), student headcount, and other measures that would determine local district operational costs and revenue through a state-determined formula. The administrator of financial operations at SFCCD described the new climate as "FTES driven" in order "to determine your allocation for student services"(INT 3, line $34-39,2013$ ). The FTES per FTEF (full time equivalent faculty) became a measure of a college's productivity since FTES is the largest source of revenue and FTEF the largest expenditure. The SFCCD struggled with productivity by continuing to run low enrolled classes in the late 1990's and 2000's despite the potential for long-term effects on the budget (FCMAT, 2012; governing board meeting, March, 2011). The next section on organizational culture will examine why this practice may have continued at the district despite the potential negative consequences.

The advent of program based funding and the accountability model that began with AB 1725 would also force the SFCCD to prove its effectiveness through evidence aligned with the standards of accreditation. Anticipating the changes after the adoption of $\mathrm{AB} 1725$, the $1988 \mathrm{ACCJC}$ site visit team report contained several warnings to San Francisco Community College (SFCC) to "increase the college's efficiency" and 
"implement the program review process", which "plays a role in future directions of instructional programs and provides data for planning appropriate utilization of personnel, facilities, and resources for the overall benefit of the community served" (ACCJC, 1988).

The SFCCD struggled to match revenue with expenditures and implement a budget based on prioritizing scarce resources. In the early 1990's it was placed on the state watch list twice by the State Chancellor's office (ACCJC, 1994; FCMAT 2012). Between 1989-1993 a "pattern of deficit spending developed, reflecting the growing structural imbalance between revenues and expenditures" (KH, 1993, p. 4). The spending pattern was described as a "drawdown of hidden surpluses" to fund mostly long term and fixed costs associated with personnel, which by 1993 constituted over $90 \%$ of the overall budget. An operational report described this spending pattern as "the core of the current crisis" in 1993. By 1997, this crisis was averted through wage freezes and limitations on hiring, plus an improvement in the state's economy. Unfortunately this spending pattern and subsequent financial crisis would return a decade later despite a warning in the 2000 ACCJC report that "in light of past difficulties, due diligence must be exercised".

In general, the period between 1994-2003 marked a period of economic stability and growth in the State and during that time the college enrollment grew as did the course and program offerings. Between 1994 and 2008, student headcount in credit 
courses rose from 36,000 to 51,000 and in noncredit courses from 38,000 to 48,000 (Figure 4). During that same time period, credit FTES rose from 17,000 to 31,000 and noncredit FTES remained stable at approximately 12,000 (Figure 5). Credit course sections also showed steady growth overall (Figures 6 and 7) with steep reductions in 2009 with the advent of the housing and fiscal crisis in California.

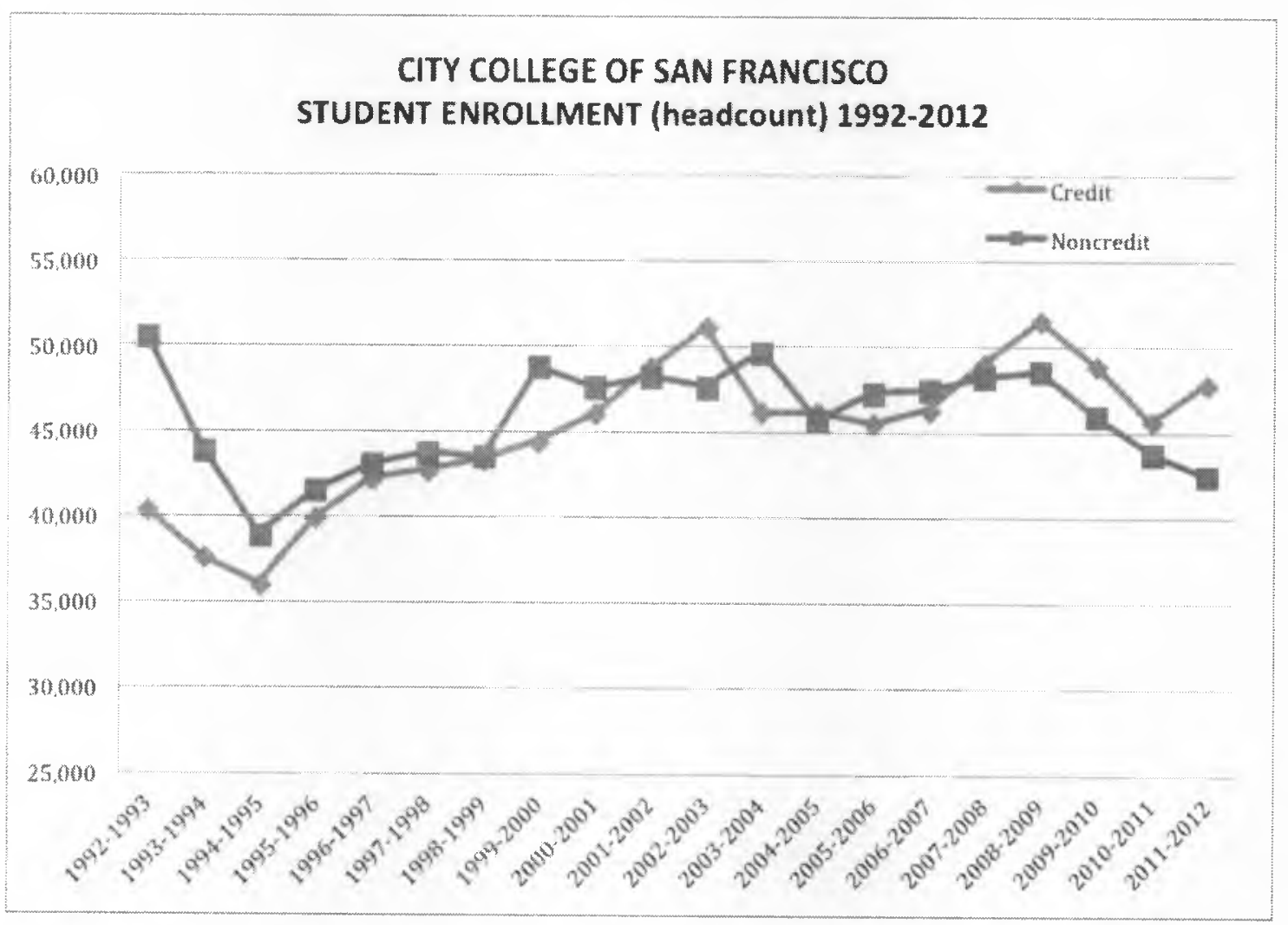

Figure 4: Unduplicated headcount at the SFCCD 1992-2012 


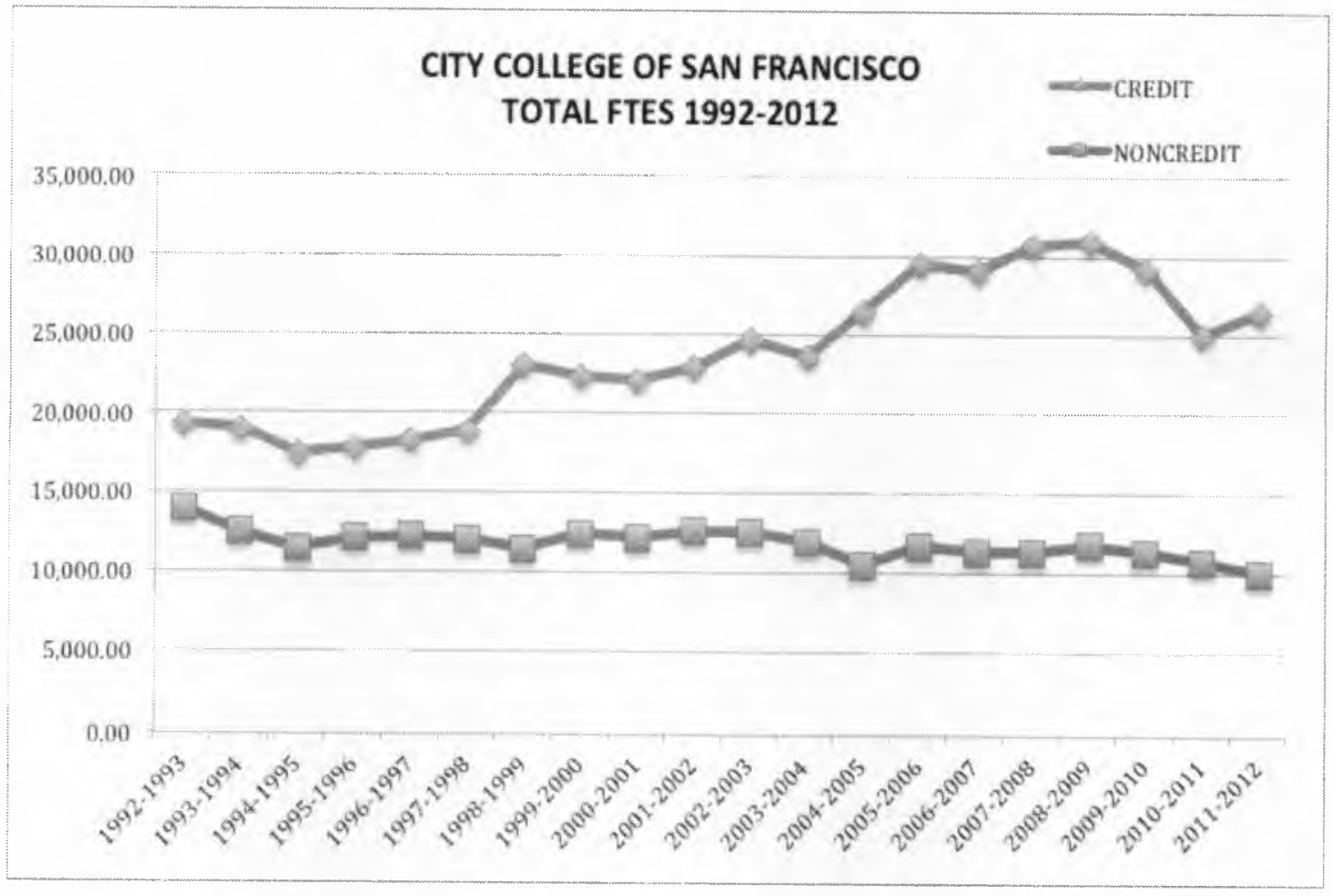

Figure 5: Credit and Noncredit FTES at the SFCCD 1992-2012 


\section{City College of San Francisco \\ Credit sections 1992-2014}

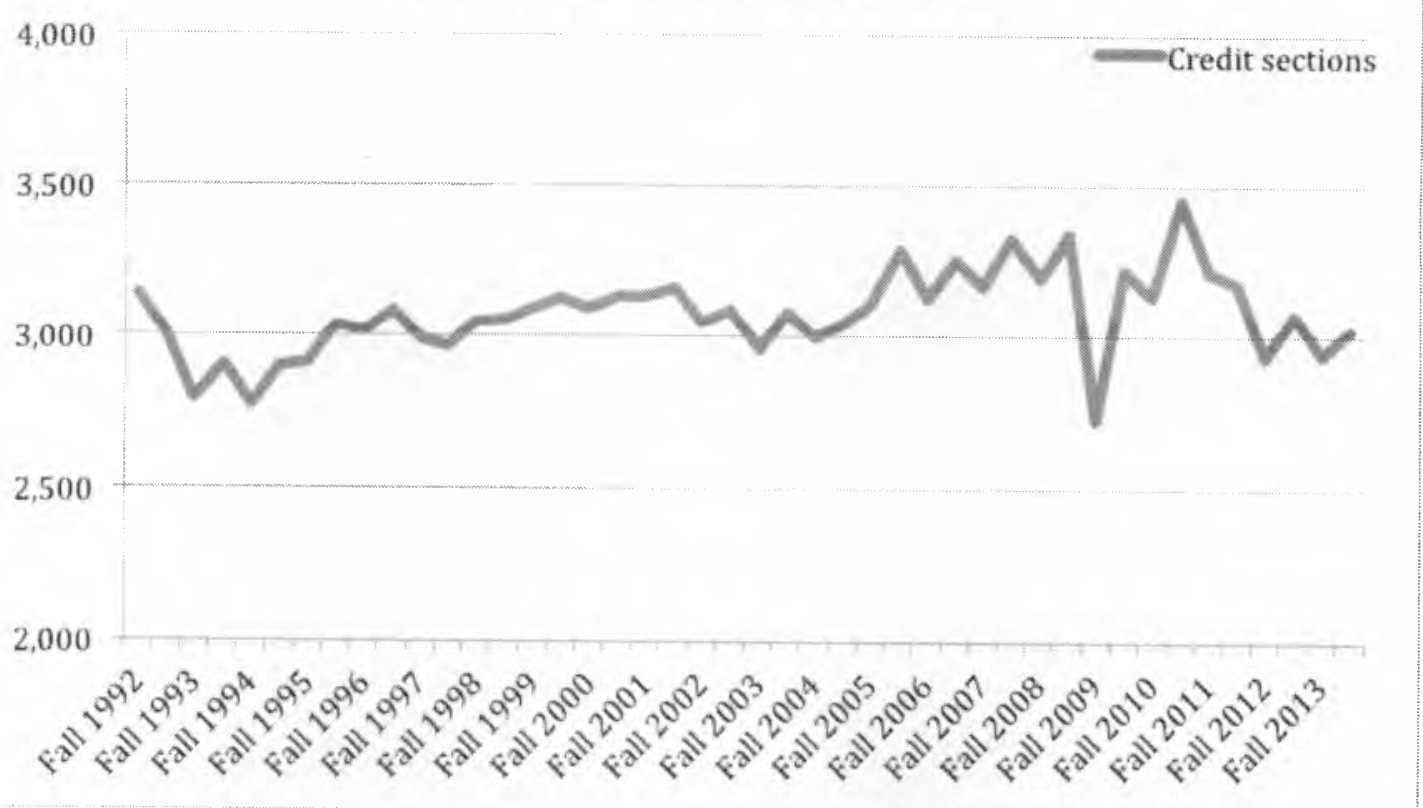

Figure 6: Credit Sections (minus summer) at the SFCCD 1992-2014 


\section{City College of San Francisco Summer Credit Sections 1992-2014}

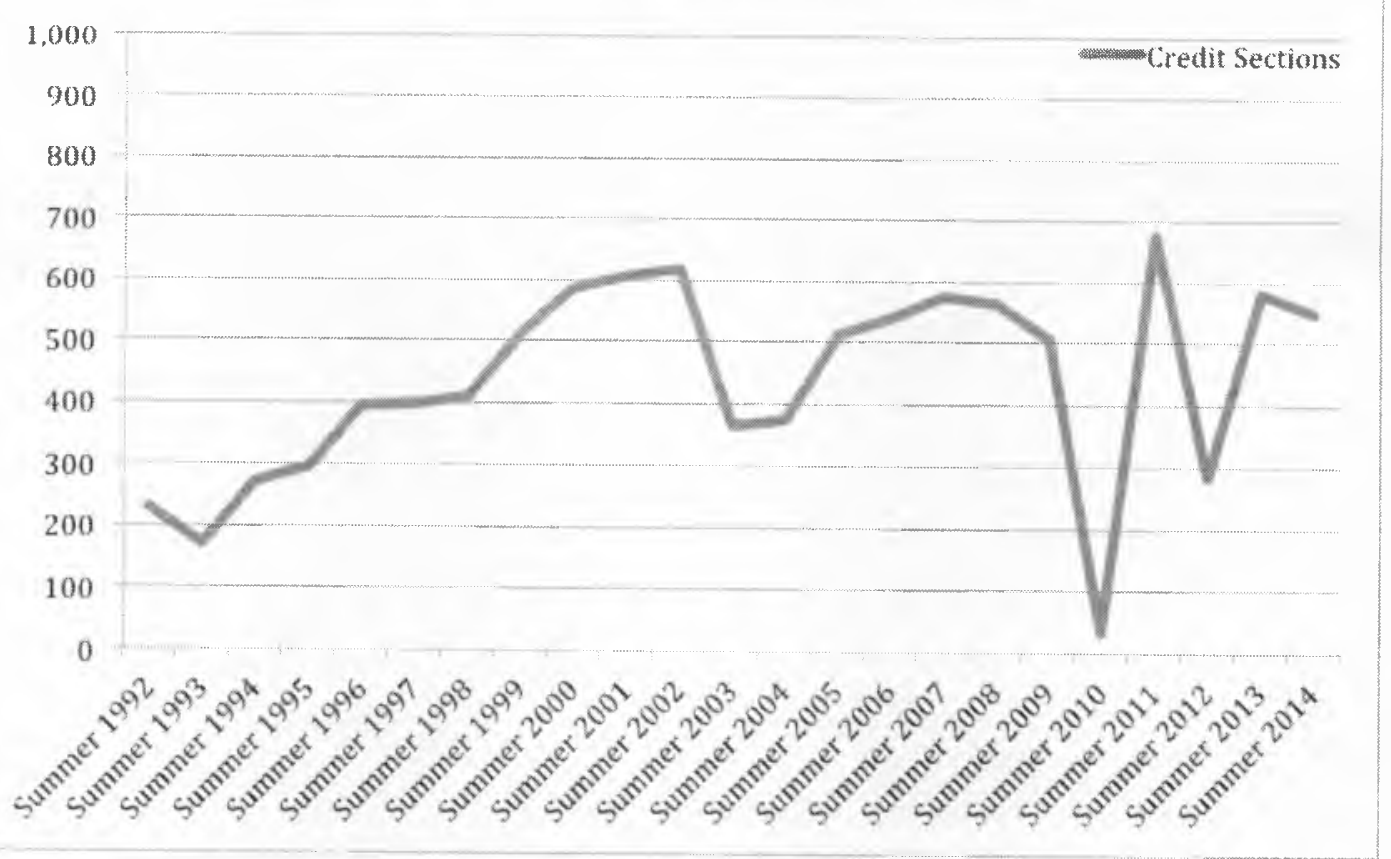

Figure 7: Summer credit Sections at the SFCCD 1992-2014

The number of total employees (faculty, administrators and classified personnel) also grew by nearly 500 individual hires, mostly in the categories of part time faculty and classified personnel (Table 2). It appeared that as the State fiscal condition and the funding for community colleges improved, the SFCCD grew along with it but committed much of these resources to long-term liabilities associated with wage and step increases, retirement benefits, and expansion of courses without the guaranteed 
revenue to support them in the long term. As one long time finance administrator remarked,

This is a place, with a few exceptions, that has always been hard to balance because the needs are so high. Everyone needs more, all the time, and the unions always need more for their members. And even when revenue is growing, it always looks like this - oh, revenue is up, oh, the requests are up like this. (INT 3, line 510-512, 2013)

Table 2: Total number of employees at the SFCCD

\begin{tabular}{|c|c|c|c|c|c|}
\hline Year & Administration & FT faculty & PT faculty & Classified & TOTAL \\
\hline 1993 & 39 & 736 & 901 & 779 & 2455 \\
\hline 1994 & 38 & 736 & 931 & 738 & 2443 \\
\hline 1995 & 42 & 720 & 970 & 838 & 2570 \\
\hline 1996 & 37 & 725 & 965 & 835 & 2562 \\
\hline 1997 & 37 & 721 & 872 & 771 & 2401 \\
\hline 1998 & 39 & 716 & 1013 & 884 & 2652 \\
\hline 2000 & 42 & 742 & 1169 & 917 & 2870 \\
\hline 2001 & 43 & 748 & 1184 & 941 & 2916 \\
\hline 2002 & 45 & 754 & 1230 & 943 & 2972 \\
\hline 2003 & 40 & 699 & 1034 & 860 & 2633 \\
\hline 2004 & 44 & 714 & 1183 & 884 & 2825 \\
\hline 2005 & 51 & 728 & 1224 & 878 & 2881 \\
\hline 2006 & 52 & 723 & 1208 & 865 & 2848 \\
\hline 2007 & 54 & 741 & 1184 & 883 & 2862 \\
\hline 2008 & 52 & 764 & 1188 & 893 & 2897 \\
\hline 2009 & 52 & 757 & 1092 & 880 & 2781 \\
\hline 2010 & 43 & 793 & 1030 & 831 & 2697 \\
\hline 2011 & 40 & 810 & 1004 & 813 & 2667 \\
\hline 2012 & 42 & 754 & 895 & 766 & 2457 \\
\hline
\end{tabular}

Sources: CCSF Self Study, 2000 and 2006; CCCCO, 2000-2014 
This allowed for very little flexibility during times of State revenue reductions. The $1993 \mathrm{KH}$ report referred to an "absence of sound expenditure controls" as the district made budget decisions "without adequate information about the impact on class schedules" that "guaranteed budget over-runs", and "reductions to district reserves and year end balance" ( $p$ III-18). And although the district reported that in 1998 it negotiated union contracts that "tied future wage and benefit increases to increases in general revenues" (CCSF response to ACCJC, 2000), other factors related to the organizational culture created barriers to implementation of such policies.

By the time the early 2000's arrived, the SFCCD already showed the strain under the California Community College funding model and increasing regulatory pressure to demonstrate productivity. The district also had developed a pattern of committing existing and new revenue to long term fixed costs of personnel (existing and retired) despite an unpredictable State funding source. At the same time regulatory pressure increased across the nation as the accountability movement had evolved into the student learning outcomes (SLO's) movement, an initiative designed to enhance student learning and link outcome evidence to budgetary decisions.

Student Learning Outcomes (SLO's)

Although regional accreditation had been in place since the 1960's and statewide program review since the 1980's, the environment in the 1990's following the adoption of $\mathrm{AB} 1725$ and subsequent revisions of the ACCJC standards for 
accreditation in 2002 marked a shift from the emphasis on institutional viability to an emphasis on institutional accountability. On a national level, a 2006 Spelling Commission study concluded that colleges were not forthcoming with what their graduates were learning and with whether or not these institutions reflected on the value of their own teaching and learning. This launched a series of efforts such as the voluntary system of accountability (VSA) and the university and college accountability network (U-CAN), which allowed colleges to enter their outcomes data into a publicly available database. At the same time, regional accreditors moved from encouraging to requiring SLO's and since 2000, there has been an associated increase in the number and variety of assessment tools and organizations associated with assessment. The Commission on Higher Education Assessment (CHEA), which oversees the regional accrediting agencies, also published its statement of guiding principles to promote and foster assessment.

In 2002, ACCJC standards of accreditation were revised from the ten major standards to four and the shift in focus from college processes that maintain viability of the institution to an emphasis on accountability to students as measured through student learning outcomes (SLO's). In the western region, the ACCJC initiated a directive that gave community colleges 10 years to fully implement a quality improvement process based on student learning outcomes at the course, program, and institutional levels. One participant (faculty/administrator) recalled, 
In 2002, the accreditation commission said to all of the community colleges, "we're gonna give you 10 years to get up to speed on student learning outcomes." And the west coast was 10 years behind - the east coast had been doing student learning outcomes already. (INT 2, line $171-175,2013)$

All California community colleges experienced fiscal and regulatory pressure over these four decades between 1970-2012. In that way, the SFCCD crisis cannot be solely attributed to the drastic reductions in state support or the increase in regulations placed on colleges during this period. But the state fiscal and regulatory environment throughout the history of the district remains an important and relevant backdrop to the current state of crisis at CCSF. It provides historical context in which leaders made key decisions that may have contributed to the current crisis. A final factor in the theme of competition and scarcity was prominent in the archival and interview data: SFCCD structural design that promotes internal competition.

Structural design of the SFCCD promotes internal competition

Before 1970, the K-12, adult education noncredit programs, and the City College of San Francisco credit programs were together under the San Francisco Unified School District (SFUSD). In 1970, the SFCCD was "created apart from the unified school district" and a newly elected governing board took office in 1972 (CCSF, 1988). As stated previously, the district was divided into three divisions. The City 
College of San Francisco was responsible for credit courses and programs in what became known as the "Credit Division", and was located on one main college campus. The "Adult/Occupational Division" was responsible for all noncredit courses, which were located in centers and sites throughout the city. A third division, the District Business Office (DBO) was described as a "service organization to both divisions, primarily in business operations and personnel"(CCSF, 1988).

In 1974, after discussion with the accrediting commission for community colleges, the San Francisco Board of Supervisors adopted a resolution that recognized the SFCCD as the "umbrella" organization with two operating components: City College of San Francisco and the San Francisco Community College Centers. Since the ACCJC accredits colleges (not districts), then for the purpose of accreditation, this multi-division college was known as the San Francisco Community College (SFCC). The other options would have been to keep the adult education division within the SFUSD or to create a multiple college district consisting of two colleges, each with its own accreditation. The city chose to create the SFCCD as a single college district.

Although the three divisions were officially part of a unified SFCCD, in reality they operated independently of one another. Each of the two educational divisions had a president (Centers President and College President) and a single Chancellor administered the district, as directed by an elected Board of Trustees. Centers directors and assistant directors ran each of the centers of the adult division, whereas vice 
presidents and deans ran the college division. Interview participants who worked at the district at the time of its formation recalled the separation between the credit and noncredit divisions.

It was like "okay, you do your thing, we do our thing" and the two divisions never really talked to each other, trusted each other. (INT 1, lines 58-59)

You had a non-credit division and you had a credit division. And noncredit teachers were hired differently, and you had a non-credit ESL and you had credit ESL. I mean so it was kind of . . . it was separate. (INT 10 , lines 1209-1211)

I remember the high school faculty reps were kept very separate from the college reps. And they were viewed...made to view as each other's enemy...that there's the haves and the have nots. (INT 11, lines 100103)

By structuring the district into distinct credit and noncredit divisions, with separate administrative structures and hiring practices, and each with their own mission and purpose, each division became isolated despite being a part of the single SFCCD. The separate missions became a source of tension for district, particularly as the San 
Francisco community was changing and the demand for a wide variety of programs increased.

The original design that went into the establishment of this district is that it was a college at City College at Phelan and the community centers throughout the city through the noncredit programs. One of the tensions at that time was the demand by the communities for community service for noncredit...job training, English training... and the original academic purpose of City College. And so the tension was palpable. (Archival INT $14,2006)$

State reductions in funding after Proposition 13 clashed with the increasing demand for classes in the community, increasing demand from labor as a result of collective bargaining, and a "55-35-10" allocation model adopted by the district in the mid-1980's that distributed $55 \%$ of revenue to the college, $35 \%$ to the centers, and $10 \%$ to the DBO. The result was a contentious accreditation process in 1988 when the SFCCD submitted its self study report and the Academic Senate of the college division submitted a separate report refuting the official SFCC report on four of the ten accreditation standards. Competition for scarce resources is pervasive in this document. The separate report called for the chancellor to "cease making productivity - the high enrollment of students in classes - his 'battle cry' with regard to the College Division" (p. 8-4) and to 
make the "ADA-generating divisions" (College and Centers Divisions) the funding priority over the "Central Office Division":

This circumstance has caused the City College Division and the

Community Centers Division to fight among themselves for the funds that they desperately need to perform their essential educational service functions. (p. 8-3)

The report also repeatedly referred to a lack of transparency and "faculty voice" in the college processes, particularly in the area of budget planning and prioritizing. At the same time, AB 1725 state regulatory changes called for a collegial system of planning and budgeting between faculty and administrators. The 1988 ACCJC report suggested that SFCC undergo organizational change to address the institutional divisiveness and to meet changing statutory language in the wake of $\mathrm{AB} 1725$ :

The current administrative organizational structure may be inappropriate to meet the needs of the changing San Francisco population and emerging state mandated Education Code changes such as the areas dealing with credit and noncredit programs, state approvals, matriculation and articulation processes... will require careful coordination and knowledgeable leadership. Recommend comprehensive review by the board. (ACCJC, 1988) 
As a result, in 1989, the local governing board hired the Strategic Planning Associates (SPA), and launched a six-month organizational review. Their final report would launch a major reorganization of the district. Nine of the thirteen interview participants were faculty $(n=6)$ or administrators $(n=3)$ at the time of the reorganization. Participants recalled this as a time of major change in the district structure and processes.

And I was with the department when we were separate, and really had nothing to do with each other - you'd never meet, you'd never do anything together... and I don't think one side trusted the other much, and you wouldn't interact at all. And then in the early-'90s, then we were told that we were gonna merge and we did. And you know, when we came together, things went very well - I don't wanna say they were perfect, but they went really well (INT 5, line 380-387)

I think what the merger did was force the two divisions to talk to each other, to get to know each other and to appreciate each other. I think the college side always kind of looked down on the non-credit and it forced us to change a lot of the programs from non-credit to credit. It just kind of forced us to look at everything in a different way. (INT 1, line 121126) 
The principal recommendation from the Strategic Planning Associates' January 1990 report, The Challenge of Change in the SFCCD, was to adopt an "integrated systems model", restructuring the college from discrete separate units into one single institution, but maintain the multiple satellite campuses, each with a full range of course offerings and student services. The institutional restructuring, led by Chancellor Evan Dobelle, reduced the number of administrators, integrated the credit and noncredit sites, decentralized administrative functions, gave more responsibilities to the department chairs and deans, and created a participatory system of governance. The purpose was to promote and foster an integrated college environment and end the divisive battle over resources between the two teaching divisions. This remained the basic structure at CCSF until a new administrative structure was implemented in 2013.

But in 2012 both the ACCJC and FCMAT described this organizational model as the potential barrier to fiscal solvency. The FCMAT report noted that under the current "organizational and cultural model there is no responsibility or accountability because it is often unclear how or by whom decisions have been made" and that this has resulted in "operational dysfunction" which, in turn, contributed to the fiscal deficiencies (FCMAT, 2012). The ACCJC report noted that the "decision making process creates undue barriers to the implementation of institutional decisions, plan and initiatives" (ACCJC, 2012). 
A comparison of the language used in the SPA and KH reports from the early 1990's mirrors that used by the ACCJC and FCMAT two decades later. Chancellor Dobelle in his inaugural speech in 1990 outlined the major problems at the college including "committee addiction, memoranda fixation, and agenda paralysis", a centers division that was "treated as outside the family of City College", excessive use of "release time", and "appropriated money and no one has gotten around to spending it". He described a college that was "paralyzed by a system of arbitrarily assigned resources and non-existent accountability". In the years that followed this speech, the college underwent major changes to merge the divisions, develop fiscal accountability, and improve communications.

So, why did the structural changes of this "Integrated Systems Plan" implemented in 1990 not resolve the problems? The $1993 \mathrm{KH}$ report cited an "absence of sound expenditure controls" as a "long standing deficiency" in which "budget decisions are made without adequate information"(p. III-18), and that "deficit spending has depleted the reserves" (p. III-21). The 1994 ACCJC accreditation report recommended that "there is a need to monitor closely the college's fiscal operations and decisions", specifically citing "decisions on salaries that could impact substantially the college's financial well-being". This report also cited the need to resolve the "centralization and decentralization of educational programs, faculty and student services", and to make evaluation of student outcomes "a priority of the college and its 
operating units". These are the same issues that were again raised in reports from 2000 , 2006 , and finally in the "show cause" report of 2012.

Evidence from the archives and interviews suggest that the undercurrent of competition for scarce resources (college versus centers; credit versus noncredit) still exists. In fact, on the subject of the 1990 "integration", several participants noted, "we merged, but we didn't really merge", "some of that elitism still exists today", and "credit is seen as better...credit is college." Even SPA noted in their follow up report to the Board of Trustees on November 28, 1990, that the reorganization was well underway but the integration was lacking a full commitment calling it "insufficiently credible". The initial SPA report listed as one of the challenges facing the district, to "create and sustain an organizational culture and a sound set of decision-making procedures" and "organizational structures which facilitate leadership responsibility for the District" toward a common sense of purpose.

This first section has described the first of three factors that contribute to normalization of deviance: an environment of competition for scarce resources. The three themes described included reductions in state funding, increasing accountability, and a structure that promoted competition. The next two sections examine the evidence around organizational cultures, and suggest that a "culture of expectation" and a "selfaffirming ideology" persisted in the district and contributed to the development of the current crisis. 


\section{A Culture of Expectation}

One of the triggers of normalization of deviance is a gap between the organizational goals and the available means to achieve them (Greve, Palmer \& Pozner, 2010; Vaughan, 2005). Institutional leaders set these organizational goals, with influence from constituency groups and external regulators. Evidence from interviews and archival documents revealed that over time at the SFCCD, pressures to "be all things to all people" may have influenced a succession of leaders to set goals without the legitimate means to achieve them. A culture of expectation developed from the leadership response to meet the demands of the community (through the district governing board), labor groups, and governance committees as the district transitioned from the "three-division" model founded in 1970 to the "integrated system" model adopted in 1990 . The community expected the district to maintain the various campus centers, and expand classes, programs, and services to meet the needs of a diverse student population. Labor leaders expected the district to match employee compensation (salary and benefits) to living conditions in the expensive San Francisco Bay Area. Governance committees expected input into decisions affecting the college, citing the participatory governance regulations set forth by AB1725. Figure 8 is a representation of this historical timeline and illustrates a cumulative effect of growing expectation from various constituent groups over time. 


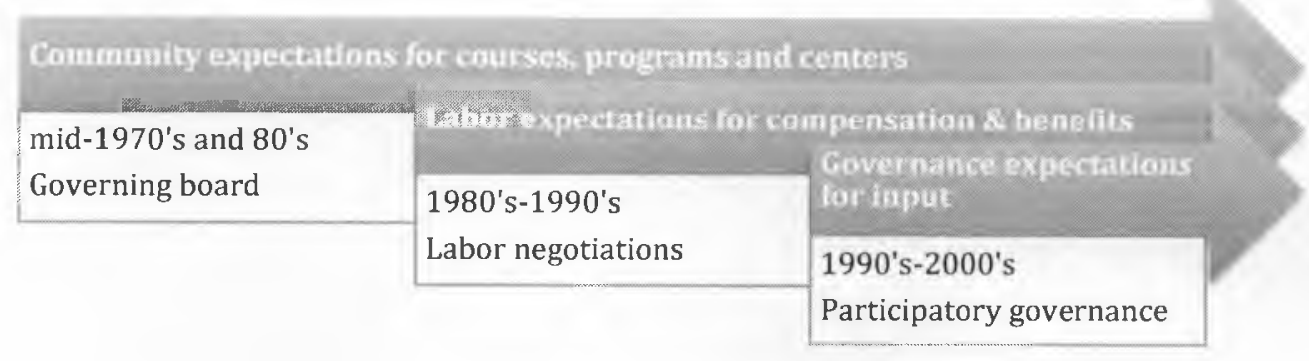

Figure 8: Influences on the culture of expectation over time

This section will describe the evolution of the culture of expectation through an examination of decision making and power relationships between the chancellor, governing board, and faculty leaders (governance and labor) over the period of 19702012 using evidence from coding of interviews and archival documents. The results in this section are presented in three sections: Community expectations, labor expectations, and governance expectations. Within each section, results are presented chronologically, examining the leadership response to constituency pressures and the power dynamics that played out between the governing board, chancellor, and other faculty/classified personnel leaders.

\section{Community expectations}

Evidence from interviews and archives showed the persistent theme of "San Francisco politics," particularly in reference to decision making by the CCSF governing 
board. This locally elected governing board establishes the institutional mission and priorities and, pursuant to the original Board Policy Manual and the California state chancellor's office, must be "responsive to the local community" (CCCCO, 1970; 2015). Participants associate some board members with political aspirations to run for the San Francisco Board of Supervisors, and see this as a major factor influencing the power relationships between chancellor, board, and other college leaders (governance and labor).

Since the mid-1970's, the governing board pressured college leaders to expand access and increase the number of classes offered within the various neighborhood communities through the Centers Division. While the purpose of the College division was to provide credit courses toward Associate degrees and opportunity to transfer to a four-year university, the Centers division provided outreach to the local communities, noncredit course work, pathways to credit course work and occupational training. The governing board hires and rehires or fires the chancellor, creating a critical power dynamic, a subject that was raised by every interview participant. All participants associated times of challenge in the district with strained relationships between the chancellor, the local governing board, and faculty leaders.

The governing board of 1972 was elected at large to represent the interests of the local community and as one former chancellor noted, the local community of San Francisco was under a dynamic transition at the time: 
Going back to the Immigration Act of 1965, the influx of new immigrants changed the social fabric of San Francisco; and thereby, given the nature of the community college, changed the demands on the community college... at the end of the 70's you have the removal of the authority of tax of the local governing board, the demands and the rising awareness of the new power in terms of the voting booth of these different groups in San Francisco. That's when you saw the change in the make up of the community... Because at the same time the various ethnic communities and the gay community started to realize that they had political power. (Chancellor Hsu, 2006 interview)

By the late 1970 's, the SFCCD governing board reflected this changing demography of neighborhood communities in San Francisco. Participants recalled that the board was unlike any other among the state's community college districts. One administrator described the make up of the board as "unique" among the state college districts: You had ...Amos Brown, African American community... Riordan for the Irish Catholics, Burton for the Burtons, then you had Wolfred for the gay community, Wong, Asian, and Ayala for Latino...so there you go! (INT 9, lines 250-255)

Trustee Wolfred attributed his election to the board in 1980 as a "part of the Harvey Milk machine" in reference to the rise of gay activism in San Francisco following the 
murder of supervisor Harvey Milk. "The gay community wanted to get someone elected to office and I had a doctorate and was interested in education". Trustee Wolfred was elected as "part of a coalition with Asian Americans, the Chinese-American Democratic Club, who wanted to get Asians elected" who then "created an alliance with the African American and Latino communities through Amos Brown and Chuck Ayala" (Wolfred, 2007 interview). One administrator participant recalled "people in Chinatown, mostly immigrants from Hong Kong, wanted their own campus" and in the late 1970's "went before the board of trustees" to obtain various sites throughout the Chinatown district. The governing board responded to community expectations by supporting additional sites and programs throughout the city.

By the early 1980's the centers division expanded access to meet the expectation for classes in neighborhood communities throughout the city. A faculty member who was promoted to administrator described this targeted expansion:

I was a site supervisor and I was basically told to grow the (Castro Valencia) campus. And this was in the " 80 s, so it was marketed as a "gay campus". . . but we didn't have a lot of gay classes at the time, we had two, but we offered those, and we marketed to the LGBT community. And we built that campus. (INT 2, lines 2-5)

Interview participants highlighted the power relationships between board and chancellor as a major influence on leader decision-making to meet expectations of the 
community for more programs and services at the various college centers. The first board-selected chancellor was Herb Sussman (1977-1982), often referred to as an "outsider from New York" by interview participants. Several faculty participants also referred to Sussman as a "union buster" who "came from a junior college model", perceiving his tenure as a threat to the expansive mission of the district.

The 1981 governing board meeting minutes indicated the board's continual support of growth as evidenced by the approval of two million dollars to fund the building of new centers. Although the board selected Sussman to lead the college at a time of financial uncertainty, they also expected him to "grow the college". A few participants recall that this board was seen as "supporting the interest of the centers". By the end of 1981, "Sussman had fallen out of favor with the majority of the board because he was perceived as not responsive enough to the diverse San Francisco communities" (Trustee Wolfred, 2006 interview). A 4-to-3 vote of the board decided against renewing Sussman's contract, sending a message that the board and community wanted a chancellor who would respond to their expectation to expand course offerings in the community centers.

The next chancellor Hilary Hsu (1982-1990) was selected from inside of the SFCCD but was considered an "outsider" by many college faculty since he came from the centers division. Hsu's "politics were in line" with the "activist board" who favored increasing resources into the neighborhood programs. "It was a new day for us after 
Sussman"(Trustee Wolfred, 2007 interview). In 1977 and 1982 ACCJC recommended that the college curtail community services program development partly since it duplicated similar activities in the community provided by other agencies. The district refused: "Even if it were correct to not 'duplicate', the fact remains that City College can make a vital contribution to the cultural life of San Francisco" (SFCCD Institutional Self Study, 1988, p. 23).

The 1988 accreditation report placed the district on "warning", citing under Standard IX (Governance/Administration) that there was a "preoccupation with narrow constituency interests among some board members" warning the college administration to "not allow vested interest on the part of a few to influence decision-making". The district leadership through the chancellor and governing board, by supporting ongoing expansion and increases in course and program offerings into the community through the district centers had created a culture of expectation for their presence. This is evidenced by the political controversy around cancelling classes, closing a center or ending a program.

The 1993 governing board president recalled a critical meeting at which the board was voting on a resolution that would support a policy to eliminate low enrolled classes. Prior to the meeting, he had "studiously lined up the votes" in favor of the policy, but then one trustee "changed her vote" and it was defeated 4-to-3. The president cited "pressures from constituencies", as the reason the resolution was 
defeated (archival interview, 2007). During the mid-1990's the college renewed it's resolve as a multi-center college, as evidenced in the October 1996 midterm report to the accrediting agency: "The Board is committed to having a presence in representative areas of the City and has demonstrated this by recently renewing rental/lease contracts and resolving to commit resources to upgrade and modernize all campuses" (p. 4).

Several times in the district's history, board members or chancellors proposed closing one of the district centers, citing low enrollment or duplication of services at a nearby center, but "when they talk about closing a center people rise up, because you create a culture of expectation for it (the center)" (INT 8). Following the accreditation sanction of 2012, the district did succeed in closing the Castro-Valencia center, citing nearby centers (Mission and Civic Center) to cover this region of the city. One participant explained that the district was able to close it only because of the crisis and the center "didn't have a constituency to rise up" since the demographics of the neighborhood had changed over time (INT 8). Two other participants cited the end of the watch repair program as an example of resistance to program closures.

I saw on the enrollment that there was the same people (in the program) over and over again. It was like a club! It was at the Mission campus and enrollment wasn't very good. The teacher died so I said this is the perfect time to end it. You wouldn't believe the people that went to board meetings to complain about ending that program! It wasn't just one board 
meeting, but several board meetings. Eventually we ended the program.

(INT 1, lines 300-304)

The controversy around the centers plays out throughout the history of the SFCCD, mostly through the governing board. Participants were unclear and inconsistent in their responses about the roles of the centers. Some believed they were outreach to the community and a pathway to credit coursework: "They're there because English is the gatekeeper to the next advancement or integration into our society" (INT 9). Others believed the centers are mostly political: "You don't have the campuses there because of the demand. You have the campuses there because of the politics and the history" (INT 8). This tension of "college versus centers" remains a common theme to this day. One finance administrator summed it up with this statement: "You can have a political decision, we're gonna keep them all open, we don't care, we just worry about whether the district's budget is balanced overall. And that really has been the prevailing view here for a long time" (INT 3, line 366-368).

The culture of expectation for expansive programs and courses in the community centers began in the 1970 's and continues to the present day. Throughout the district's history, attempts to prune programs or close a center have been met with strong resistance and political outcry at governing board meetings. In general, a succession of chancellors responded by meeting the expectations of the community and continuing to run a district with expansive course offerings at a variety of centers 
throughout the city. Often these decisions were made without the evidence of benefit to the community and only in response to political controversy. The next section describes the rising expectations of labor groups for increasing compensation and benefits to the district employees.

Labor group expectations

As stated previously, 1976 marked the onset of collective bargaining for public school teachers in California. During the 1980's the SFCCD negotiated labor contracts with the American Federation of Teachers (AFT), the Department Chairperson's Council (DCC), and the classified union. In 1985, the governing board passed a resolution to recognize collective bargaining for the classified personnel and in 1986 followed up with a resolution to recognize the classified bargaining unit as represented by SEIU 790. Statutory language in the Education Code 88137 establishes that classified personnel at the SFCCD operate under the civil service of the City and County of San Francisco. During the accreditation crisis of 1988, the chancellor cited "lack of control" over classified salary and benefits due to the relationship with the city, and "salaries for full-time faculty and administration that are considered low in relation to the high cost of living in the Bay Area and in comparison with other college districts" (SFCCD Institutional self study, 1988, p. 3). After the 1988 crisis, the governing board adopted a resolution to launch a major reorganization of the district and address these and other long-standing concerns. 
The major reorganization to merge the three divisions (College, Centers, and District Business Office) was left to Chancellor Evan Dobelle (1990-1995). Dobelle had a background in politics, having served as mayor of Pittsfield, Massachusetts, and Chief of Protocol for the Carter Administration prior to his college presidency. In general, Chancellor Dobelle was aligned with the governing board and faculty during the initial stage of the integration as the process moved through a collaborative Reorganization Implementation Steering Committee (RISC). Relationships between existing administrators and Dobelle, however, were strained. On May 8, 1991, the governing board adopted a new administrative structure, which would reduce the number of administrators by $36 \%$ (from 71 to 46 ). Within months, he fired administrators, and hired 71 new faculty members.

By 1992, the district had already implemented certain changes in the reorganization that would commit long term resources, such as the hiring and reclassification of faculty positions as the centers joined the college. Even with the reduction of administrators, the district still maintained a structural deficit largely due to the commitment of resources to salaries and benefits (KH, 1993). The outgoing CFO commented in his retirement speech, "We are spending more than our incoming revenues. It appears to me that the Board has yielded their control and management to the Chancellor." 
Dobelle was hired to implement "bold initiatives" that the district agreed would be required to solve the problems that plagued them since the late 1970 's. The governing board needed to support these "difficult decisions" and make the reorganization work in a climate of uncertain resources. They hired the KH consulting group to conduct a two-phase "strategic cost management study" that began in November 1992. The 1993 final KH report warned: "surpluses and the limited reserves ...was largely consumed by the funding of the remainder of the current year's operation." The report cites "relatively fixed costs" of salaries as the "core of the current crisis" (p. III-7). Chancellor Dobelle proposed a schedule reduction of classified staff from a year round schedule to a semester schedule, causing a rift between the chancellor and the classified union. Contract negotiations with the classified staff were drawn out and by end of Dobelle's tenure the classified union was on the verge of a strike.

By the time Chancellor Del Anderson (1995-1998) arrived, the college was still responding to the fallout from the merger. Anderson was a "traditional chancellor" who to some "quieted the storm" following the integration of the centers and college. One former administrator characterized her as "fair-minded", who "kept the place going" and "calmed the waters" after the reorganization. Other participants considered her a "short timer" who "didn't change much at the college", but then also noted that they "really couldn't take any more big changes" at that time. To those who participated in 
external activities, she was a "statewide leader" who recognized the issues facing community colleges in California. But inside the district, the climate was plagued by faculty distrust and a classified workforce that was still reeling from a drastic reduction to their schedule.

Early in her tenure, Anderson became mired in contract negotiations with the AFT, DCC, and later the classified personnel union. In 1996, the AFT and DCC were able to close with a contract that allowed additional release time for some Department chairs and an $8 \%$ increase in faculty salaries. But her tenure was also marked by a student take over of her office, and a classified contract negotiation that carried on for 14 months up until the time of her departure as chancellor in 1998. In 1996, her controversial 9.5 percent pay raise approved by the governing board played out in the newspaper just prior to negotiations with the classified union and did not sit well with the faculty who picketed a board meeting. One administrator commented that, "City College was just too political for her." Anderson retired in August 1998.

Participants all agreed that Chancellor Philip Day, Jr. (1998-2008) was "energetic", "visionary", and a "force of will guy" who "did his homework" prior to taking the helm at the district. Originally from Massachusetts, he came to the college after serving as college president for Daytona Beach Community College in Florida, and had leadership experience at two other community colleges before that. He came at a difficult time for the district with the classified union poised to strike, and faculty 
morale at an all time low. Anonymous newsletters circulated around the college, which were critical of the college administration and contained harshly personal attacks directed at particular administrators. "It was horrendous and Day took it on like in a 5-6 page letter to the college community and that was the end of it" (INT 9).

When he came there was a real sort of infighting and a bad environment here at City. There were anonymous newsletters circulating and he just immediately stopped all that stuff. He identified the players and he talked to them. He said 'look this is not okay and we are not gonna do this' (INT 7, line 118-122).

But some at the college worried about Day being from a "right to work" state (Florida) and coming into the labor-oriented state of California. In his first two weeks at the college he met with the head of the classified union and ended the strike by negotiating wage increases and equity adjustments. He also restored the yearlong calendar that had been reduced under Chancellor Dobelle. Soon after, he set up a college council consisting of representatives from administration, faculty and classified personnel. He held "listening sessions" around the various centers in the community to seek input on the state of the college.

Chancellor Day was also known for his statewide leadership on the 1999 passage of AB420, which provided pay equity and job security for part-time faculty at community colleges. At the SFCCD, part-time faculty would also receive health 
benefits if the workload equaled $50 \%$ of the full-time workload. To pay for this and other rising costs, he focused on new sources of state revenue through noncredit equalization funding with SB361, and through the Basic Skills Initiative. These initiatives had specific spending limitations but the focus of the chancellor was to bring in revenue to fund the "cost to continue" status quo operations. As the college grew in size, programs, courses, and personnel, the culture of expectation that all of these things would be preserved grew alongside it. Even with the cost of facilities and technology, the percentage of the budget spent on personnel remained $90-92 \%$. So when the state didn't follow through with fully funding these initiatives, the district had little flexibility.

When the district faced financial shortfalls in 2002-2003, Day was able to negotiate hiring freezes for classified personnel and administrators, and forego wage increases for six months across the board. At his January 2003 college address, he warned that the college was "on dangerously thin ice" and proposed a series of one-time solutions such as postponing sabbaticals, not replacing retiring faculty (attrition), reducing summer offerings, consultant costs, extra pay, uncollectible fees, and tapping into the dwindling reserve, which already sat below the $5 \%$ state minimum. Day was able to "protect the college family", noting that other systems, including the San Francisco City government and school system "are talking about massive layoffs and furloughs. We are not". 
This worst-case scenario would mean reduction and/or elimination of programs, personnel, and perhaps even campuses. City College as we know it would be radically restructured and downsized. We do not expect the worst-case, so we are not - I repeat not - proposing it, discussing it, or paying attention to it. (Day, 2003) But many participants felt that "he gave away too much" as a "quid pro quo" to meet the goals he set for the institution and the expectations of the labor unions. Among interview participants, one of the most controversial actions by Day was his proposal for a reduced work week (RWW) for classified personnel as a trade off for wage increases. In this proposal, classified personnel would work a 37.5 hour week instead of 40 hours, but make the same salary. He estimated that this "equated to a $4 \%$ raise because you won't lose any money but it give you $4 \%$ for doing less." Day defended this action through his experience at another college and through a vote of confidence in his workers:

From my viewpoint, and just studying the working habits of my employees, the fact of the matter is...you have about anywhere from 90$95 \%$ of your workforce who don't pay a damn bit of attention to punching in a clock, and they're gonna be there when you need them... So you're gonna see negligible impact on this stuff from a productivity and an efficiency standpoint. (Day, 2013 interview) 
But all participants, including Day himself, recognized the unintended consequences that came with the implementation of RWW. Participants noted that it "wreaked havoc on a departmental level", and "put an unreasonable burden on people accounting for it". More importantly, as one participant noted, it created a culture of expectation that "if you're classified, you think that you work 37.5 hours and get paid for 40", so that it's "hard to get rid of it".

By 2006, his college wide messages were colored with warnings about fiscal instability due to rising healthcare costs and retiree benefits (i.e. other post employee benefits, or OPEB). Up to this point, the board and chancellor were generally in balance and board resolutions passed with majority votes; however, in 2006 the balance shifted with the new board. Participants who worked at the district during this time noted this shift in balance: "for many years he had 6-1 or 5-2 (votes), but when he started getting 4-3, it started getting a little more dicey". The new board "began to pick away at finances, mostly through bond funds". And Day maintained an optimistic stance even though his message to the college included a caution that "nearly a third of the new funding is one-time only, and we do need to use $\$ 2$ million to replenish the reserves...I do not see this as a reduction process, but rather as a reallocation process. We do not have to live on fewer resources".

Following Day's departure in 2007, Chancellor Don Griffin (2008-April 2012) was a natural next choice to take the lead at the SFCCD. He served at the college as 
faculty since 1969 , and then after 27 years of teaching, promoted to Department Chair, then Dean, and then Vice Chancellor of both Student Services and Academic Affairs under Chancellor Day. When it came to responding to the expectations of the labor unions, he also maintained a philosophy of keeping the "City College family together." When the state proposed cuts and deferred $\$ 340$ million in apportionments during his first year as chancellor, he continued the resolve to maintain a "no layoff policy for all employees at CCSF". Cost savings were realized through a series of one-time solutions, such as cuts to consultants, removal of travel for administrators, and cancellation of summer courses. New revenue was sought through initiatives like the Bridge to Success grant, career ladders, and local partnerships. And throughout the years 2008-2010, his message to the college was optimistic, acknowledging the "serious fiscal situation", but "I am positive and confident that we have survived through our crises because of our collective philosophy that students come first...cuts and employee givebacks are no solution to the crisis...we will find other ways".

The SFCCD and a succession of chancellors since the latter 1970's and the onset of collective bargaining, has responded to the expectation of labor unions by committing long term resources to benefit its employees in an effort to "keep the City College family together". This resulted in a continuation of the over $90 \%$ of the budget dedicated to personnel that was criticized in ACCJC reports throughout the history of the district and the two FCMAT reports in 2012 and 2013. Chancellors focused on new 
revenue sources to pay for rising costs of personnel and one-time measures to survive immediate crisis. As the district survived, this perpetuated the culture of expectation for compensation and benefits to current and retired employees of the district.

The final element in the culture of expectation was a rising expectation of faculty input in the governance process, which stemmed from state legislation following the passage of $\mathrm{AB} 1725$ in 1988 . This expectation and the leadership response would be instrumental in the failure of the district to meet the goals on the student learning outcomes (SLO) processes.

\section{Governance expectations}

Faculty power has been a common theme at the SFCCD as far back as its formation in the 1970 's. References in the archives to the district as a "faculty led" institution were noted in the years leading up to the 1988 accreditation crisis. A dissenting governing board member aligned with a group of faculty leaders and denounced the chancellor and governing board policies in public at board meetings and in the local newspaper. This eventually played out in the 1988 ACCJC accreditation site visit and in a separate self-study report presented by the Academic Senate Executive Council (ASEC) to the accreditation visiting team. In this report, the ASEC refuted the district's "comprehensive report" in four of the ten standards of accreditation and called on the chancellor and administration for transparent communications on the budget and collegial negotiations with the faculty on matters affecting hiring, buildings and 
maintenance, and allocation of resources. Looking back on this time in the district's history, one trustee described the accreditation visit and divisiveness between administration, board, and faculty as a "low point" that "threatened the viability of the institution."

Faculty expectation for input and authority over "academic and professional matters" affecting the college was already present prior to the district's implementation of $\mathrm{AB} 1725$ in the 1990's. But these legislative changes formalized faculty input into a participatory governance structure. And like many other colleges, the district struggled to define which matters were "academic," despite regulatory language that lists "ten plus one" areas on which the Academic Senate should be consulted. AB 1725 opened the door for shared governance, but revisions of CCR Title 5 section 53200-53204 strengthened the authority of the academic senate with the local governing board. Several participants recalled that when participatory governance came to the district, that it was taken "to the extreme." One participant recalled that "it was the mantra of the senate to the board, 'this did not get shared governance review so you can't vote on it"' (INT 6). And faculty governance groups often bypassed Deans to directly address the chancellor or board members. The $1993 \mathrm{KH}$ report noted:

SFCCD initiated a shared governance structure which limited many administrators to roles of facilitators and not managers, leaving an administration in which many managers have less authority than is 
required by their responsibilities. At the same time others have less responsibility than is appropriate for their rank (p. I-5).

This same theme emerged in the 2012 FCMAT and ACCJC reports: "Past decisions have reduced the management team to spectators rather than organizational leaders" (FCMAT, 2012). "There exists a veil of distrust among the governance groups that manifests itself as an indirect resistance to board and administrative decision-making authority" (ACCJC, 2012). The response in 1990 and again in 2013 to the criticism about the district's participatory governance system was to reduce the number of committees and restructure the responsibilities of the governance committees, providing workshops and training for all levels of management (governing board, administrators, and governance committee members). In 1988, there were 55 standing governance committees, subcommittees, and task force groups. Following the 1990 reorganization, the number of committees was reduced in half. But over two decades and particularly in the 2000 's, this committee structure would once again swell to subcommittees, task force groups, and a committee on committees which would select the members of each of the committees. The justification for this expansion was to improve faculty voice and input on college matters and this led to an ongoing expectation of committee and faculty input on all college matters through this complex committee structure.

In addition, the college had developed a distinct faculty leadership within the Academic Senate Executive Council (ASEC) and the Department Chairpersons' 
Council (DCC). For several years, officers of the ASEC were also leaders in the DCC, but as mentioned earlier, the DCC is a distinct bargaining unit independent of the AFT, and the ASEC. The DCC structure provides a distinct advantage as the middle level leaders who have knowledge of programs and their specific resource needs. The DCC contract defines the Department Chair as a faculty member with supervisory responsibility over the Department and the first administrative line of authority for faculty members. But participants agreed that the contract sometimes blurred the lines of authority between the Department Chairs and the Deans. This became evident in the archival documents and interviews on the issue of SLO's.

As early as 2001 , the college became aware of the changing accreditation standards related to SLO's, as Chancellor Day's speech in August 2001 would attest: "new criteria have been adopted by WASC, which places extraordinary emphasis on effective and measurable student outcomes". During this speech he called for "developing a culture of continuous assessment". He reemphasized this point in his 2003 speech that focused on the two main issues confronting the college at the time: financial shortfalls and "three words - student learning outcomes". Administrators assigned to lead the effort on SLO's presented training materials to various participatory governance groups and to the DCC.

Despite speeches, memos, and workshops, over the period of 2002-2012, the full implementation of the required SLO process remained incomplete at the time of the 
ACCJC site visit in March 2012. The SLO process is designed to be a quality improvement feedback loop, where an institution establishes learning outcomes at the course, program, and institution wide level and then uses these outcome measurements to drive change. At the SFCCD, the process never scaled to an institution-wide level and never moved through governance beyond ad hoc committees and task force meetings. Although the 2006 ACCJC report recognized that the college identified it as a "major goal of the institution", the "student learning outcomes do not appear to be clearly presented as a significant goal within the program review process" and that "the college ensure that student learning outcomes are fully institutionalized as a core element of college operations" (ACCJC, 2006). Table 3 shows the timeline of events at SFCCD related to the SLO process.

On his departure from the college, Chancellor Day's final address pointed to the need to address the student learning outcome (SLO) initiative, which "remains the most prominent recommendation of our regional accreditation agency. The issue of SLO's is not going to go away and the college needs to address this issue in a substantial way prior to the next round of re-accreditation". But interview participants recalled that the system of governance and the DCC were allowed to stall the process and those administrators who led the SLO process were not supported in their efforts. Without a top down approach, the culture of expectation from governance groups for faculty input 
delayed the SLO implementation. By 2009, one year into Chancellor Griffin's tenure, the state fiscal crisis peaked and financial issues were prioritized over the SLO process.

Table 3: History of SLO activities at the SFCCD

\begin{tabular}{|c|c|c|}
\hline Year & SLO Activity & Evidence \\
\hline 2001 & $\begin{array}{l}\text { Chancellor Day announces new WASC criteria } \\
\text { adopted includes "extraordinary emphasis" on } \\
\text { measurable outcomes }\end{array}$ & Flex day address \\
\hline 2003 & $\begin{array}{l}\text { Chancellor Day reviews SLO process in his January } \\
\text { Flex day address; announces SLO workshops at } \\
\text { August Flex day address; releases college wide } \\
\text { memo on SLO process }\end{array}$ & $\begin{array}{l}\text { Flex day address January } \\
\text { 2003; August 2003; } \\
\text { Memo to college February } \\
2003\end{array}$ \\
\hline $\begin{array}{l}2003- \\
2004 \\
\end{array}$ & $\begin{array}{l}\text { Deans and VC's undergo training on SLO's and } \\
\text { provide training to Department Chairs }\end{array}$ & $\begin{array}{l}\text { Copy of presentation with } \\
\text { notes }\end{array}$ \\
\hline 2005 & $\begin{array}{l}\text { Self study preparation of Thematic Essay II on SLO } \\
\text { process reveals concern by faculty that SLO's } \\
\text { corporate-ize higher education; Curriculum } \\
\text { Committee replaces "objectives" with SLO's in } \\
\text { course outlines }\end{array}$ & $\begin{array}{l}\text { September } 2005 \text { ASEC } \\
\text { minutes }\end{array}$ \\
\hline 2006 & $\begin{array}{l}\text { Academic Senate establishes SLO Task Force to } \\
\text { convene in Spring } 2007\end{array}$ & Resolution 2006.11.29.03 \\
\hline 2008 & $\begin{array}{l}\text { Academic Senate receives report that "WASC is } \\
\text { clamping down" and requires a cycle of SLO } \\
\text { analysis by the college } \\
\text { Academic Senate approves extension and } \\
\text { renaming of the SLO Ad Hoc committee }\end{array}$ & Resolution 2008.05.14.03 \\
\hline 2009 & $\begin{array}{l}\text { Report from WASC conference ( } 3 \text { CCSF attendees) } \\
\text { include rubric for colleges to use in this process }\end{array}$ & $\begin{array}{l}\text { November } 2009 \mathrm{DCC} \\
\text { meeting minutes }\end{array}$ \\
\hline $\begin{array}{l}2009- \\
2012\end{array}$ & $\begin{array}{l}\text { Dean of Instruction sets up an online course } \\
\text { outline system to incorporate "Major Learning } \\
\text { Outcomes" by course with varying participation }\end{array}$ & $\begin{array}{l}\text { DCC meeting minutes; AS } \\
\text { meeting minutes }\end{array}$ \\
\hline \multicolumn{3}{|c|}{ After the "show cause" sanction } \\
\hline $\begin{array}{l}\text { August } \\
2012\end{array}$ & $\begin{array}{l}\text { Chancellor assigns an SLO coordinator position } \\
\text { with team of faculty to lead effort in implementing } \\
\text { SLO's at course, program and institutional level }\end{array}$ & \\
\hline 2013 & $\begin{array}{l}\text { March "show cause" report demonstrates CCSF } \\
\text { has } 100 \% \text { of all course and program SLO's online }\end{array}$ & CCSF Report to ACCJC \\
\hline
\end{tabular}


This section described a chronological account of how expectations from the community (governing board), labor unions, and governance groups and the chancellors' response to meet expectations, resulted in an acceptance of deviations in fiscal and outcomes decision-making, which only perpetuated a culture of expectation to be "all things to all people". At SFCCD, the final and most significant factor that contributed to the normalization of deviance was the development of a self-affirming ideology.

\section{Self-affirming Ideology}

The term "self-affirming" was synthesized from existing theory and results of archival research in this study. Vaughan (1997) and others described the relevance of isolation in concealing the magnitude of problems within an organization. At CCSF, isolation concealed problems in the SLO process and contributed a sense of exceptional "uniqueness".

The term "self-affirming" was adopted from the language of accreditation. An accrediting agency "affirms" and "reaffirms" that an institution or program meets the standards of accreditation. Self-affirmation, then, is when the institution affirms itself, needing no outside organization to do so. Since state law mandates outside accreditation, the term "self-affirming" also implies a sense of arrogance within the institution about the capability of any outside agency. 
This culture developed out of a strong sense of local pride in the college; something that is an important part of any community college and also something encouraged by the standards of accreditation. But under certain conditions incrementally evolved into a sense of exceptional uniqueness that transcends the rules. These conditions are outlined in the following sections: exceptional uniqueness and isolation. What resulted was an acceptance of operational dysfunction and a collective belief that CCSF was so unique that "the rules don't apply to us."

\section{Exceptional uniqueness}

Evidence from the archives suggests that the SFCCD viewed itself as exceptionally unique among other California community colleges. In the ACCJC reports of 1972 and 1977, the institution was directed to clarify its mission related to the college and its centers. The district's response in 1982 reflected this exceptional uniqueness: "we regret that the evaluation team did not understand our philosophy"; "we pride ourselves on our unique organization" and "see no benefit to changing"; "recommendations such as this one are reflective of the lack of understanding about the SFCC". And again in 1988, the district responded to the ACCJC recommendation to consider reducing community service offerings by highlighting the "vital contributions to the cultural life in San Francisco."

In addition, participants described a persistent "we are unique arrogance" embedded in the culture of college. 
"City College lives in an incredible bubble. There was almost NO awareness of outside of the college itself. There is this amazing assumption that nobody understands City College. We're different" (INT 8 , line 528-531).

This is City College, you know, in a nutshell - very insulated, very arrogant, that we are different, we are special, we do things differently because we have San Francisco values. Now a lot of that has a really positive side to it, because we really care about our community, and we try to be all to everybody (INT 2, line 127-131).

One unique aspect mentioned by most participants was the large size of the SFCCD. Participants attributed the difficulties in maintaining stability to the absolute size of the institution. In addition to the size, complexity of the institution may also have been a contributing factor. The variety of operational studies, consultant evaluations, and financial audits over the decades compliment the district for providing expansive access to the community, and in reference to problems refer not to the size of the SFCCD, but the "fragmentation", which isolated areas of the college and made transparent communications difficult. An example of this fragmentation was described earlier in the vast array of governance committees, which may have given an 
appearance of providing faculty voice and input, but was often staffed by the same members and produced an overload of information without streamlined processes for communications to all areas of the college community. Also, fragmentation was demonstrated by a lack of coordination between departments that have common resources resulting in unnecessary duplication of equipment, materials, and resources, as FCMAT pointed out in its 2012 report. One participant supported this observation by commenting that his center has 9 computer labs but a separate department runs each one and none are open to the community unless enrolled in a class within that department.

The response to the critiques from outside consultants also demonstrates a culture of exceptional uniqueness. Only $41 \%$ of the recommendations of the $1993 \mathrm{KH}$ report were implemented, and others incomplete or refuted. As one participant noted: "We seem to have a history... we have outsiders come in, evaluate us, and then we go, "oh no, that doesn't work for us" (INT 2, line 549-551).

\section{Isolation}

Another common theme that arose during interviews was isolation. Participants who worked at the centers referenced a sense of isolation related to being at a site other than the main Ocean campus. Administrators felt that isolation intensify during Chancellor Griffin's tenure when the number of administrators was reduced, those with historical memory had retired, and travel to statewide meetings and conferences were 
cut. "It was the isolation, it was the lack of outside hires balancing inside hires, and it was just the insulated community" (INT 2).

The sense of isolation and "uniqueness" is also demonstrated through a suspicion of data produced by sources from both outside and inside of the institution. Throughout the history of the district, there is "a lot of questioning of data", which is a good for healthy academic debate but can cause paralysis in decision-making when taken to the extreme. Some participants related this to the "living in a bubble" isolation mentioned earlier. "People have no idea that there is alot of research going on. It's been done and it's been done really well and they don't seem willing to pick it up" (INT 5). Others pointed to a system of "governance dominated by the same people" (INT 1, 2, $6,7,8$ and 10 ). Although archival documents show evidence of college wide communication on SLO's (Table 3), several participants commented that either they had "never heard of an SLO", or "thought that what we were doing was SLO's". Overall, the isolation, sense of uniqueness, and the culture of expectation of faculty/governance input created paralysis on the SLO movement.

The evidence from meeting minutes (Table 3 ) also shows that at a critical juncture, faculty redefined the SLO process to one that did not meet the definition provided by the ACCJC in the rubric it provided to all colleges. Isolation and a sense of uniqueness allowed this to happen. Initially, the records from 2001-2008 reflect resistance from faculty for several reasons, including suspicion that SLO's were an 
instrument of privatization, difficulty applying SLO's considering the "unique" nature of the SFCCD particularly in noncredit offerings, and too much "additional workload". But in the years 2009-2012, when the opportunity arose to turn things around with the SLO movement, the type of resistance changed from objection to redefinition.

In 2009, meetings minutes of the DCC and ASEC reflect discussions of the SLO process and the WASC conference on accreditation, which was attended by several SFCCD faculty and administrators. The SLO process involved a cycle of evaluation and that WASC had developed a rubric to assist colleges in meeting the Fall 2012 deadline for one full cycle of SLO evaluation. Minutes reflect some skepticism related to the difficulty in applying the SLO process to the "unique issues" at CCSF. But there was also an acknowledgement that the process allows for colleges to determine what fits best for their own institution. In 2009 , minutes reflect a shift in the definition of the SLO process, which became equated with the course outline process: "we are currently performing our SLO obligations, so we just need help to present it in a manner acceptable to WASC". The evidence suggests that key faculty leaders believed that the faculty were "already doing SLO's" and simply needed to change the wording on their course outlines from "objectives" to "major learning outcomes". An online system was set up by the Office of Instruction for faculty to create course outlines using this new terminology; however, the system was voluntary and only included outline 
development, without linkage to the college's curriculum committee or program review process as required by WASC.

And participants also noted that as the fiscal crisis deepened during Griffin's tenure, the issue of SLO's was hardly mentioned. Even areas of the college that had been actively involve in the SLO process were allowed to atrophy:

So we kept up meeting for about a year, and then what happened is just all of the financial stuff started happening. And so our plates as started getting more and more full, and there was nobody pushing us from the top, nobody else was doing student learning outcomes, the instructional faculty weren't doing student learning outcomes, so we just stopped meeting. (INT 3, line 225-230)

As accreditation grew near, the self-study workgroup that met on SLO's raised questions about the rubric and the Fall 2012 deadline. It became apparent that they would not have completed a full cycle of SLO review in time for the visiting team's evaluation. In reports to the governing board on the accreditation self-study, the problems became apparent and the college believed that it only "partially met" the assessment of SLO's. The site visit team agreed and noted that "pockets of excellence" exist but full implementation was lacking. 


\section{Acceptance of operational dysfunction}

Isolation from outside influences prevented the college from developing best practices and a sense of uniqueness perpetuated the belief that the district cannot be compared to other colleges. Together this promoted the acceptance and normalization of operational dysfunctions as part of working at the district. One participant compared SFCCD to a "great, big overstuffed house" but "the roof is leaking and the basement is flooded". Another who works also at three other community colleges noted, "City College has always been the worst run college I have ever experienced". Several others referred to unique idiosyncrasies of college operation as "these weird little things that you run into when you first come to work here". For example, when the college transferred from paper to computer technology for class scheduling, in order to rectify operational aspects of the programming with that of faculty workload reporting, it was decided to publish the class schedule so that courses began on the hour, even though they actually started at ten minutes past the hour. This "workaround" was an approved board resolution and made it easier for reporting of faculty hours; however it created confusion for new students who came to class according to the time printed in the schedule only to find that the class begins ten minutes later. This irregularity in the course time schedule was approved at the highest levels of the district but resulted in students thinking their classes started on the hour, when the faculty knew it started at ten minutes past the hour. An entire system of faculty, administrators, board members 
and chancellors continued this practice knowing that it meant several weeks of confusion for students. It continued because it was collectively felt to be an insurmountable problem due to a mismatch in technology programming or it was simply accepted as another idiosyncrasy of organizational life at CCSF.

Participants noted at least three other operational workarounds that were not in the best interest of students: 1 . Illogical room numbering that didn't get changed during remodeling because "we (personnel) all know where the rooms are", but resulted in lost students wandering the halls looking for their classroom; 2 . The designation of lab time as "conference" so that faculty pay rates could match lecture rates but also increased units (and fees) for students; 3 . The creation of "X-labs", which were open labs that could earn FTES for the college but were not actually scheduled time and had no system of accountability for student attendance. The X-labs were created to recover FTES revenue for open lab sessions. When questions arose among administrators as to their legality, several commented that they were told it was approved by the State Chancellor's Office.

Reasons given for the persistence of these "workarounds" was that either "it was small enough so I just let it go", belief that this was approved practice at the district, or that it was done in the best interest of students. This illustrates that acceptance of dysfunctional practices and normalization of deviance is defended as "the way we do things here". 


\section{Summary of Findings}

Leader decision-making occurs within the context of history, politics, economic conditions, and organizational culture. At the SFCCD, an environment of competition for scarce resources and a persistent culture of expectation from the community, faculty, and labor leaders, developed over decades and create the conditions in which critical decisions about finances and outcomes were made. These conditions pressured SFCCD leaders to deviate from sound fiscal decision-making practices and stalled the SLO process. A self-affirming ideology developed under conditions of isolation and a sense of exceptional uniqueness and provided the justification for normalizing operational dysfunction within the institution. Deviations in fiscal and outcomes decision-making went without major institution wide consequence from regulators and accreditors, creating acceptance of deviations as "normal" and even "unique" to this district. This acceptance and normalization over time resulted in a "blindspot" to the magnitude of oncoming crisis. 
Chapter Five: Conclusions and Implications

City College of San Francisco is in a fight for survival after sanctions placed on the institution in 2012 and 2013 could terminate accreditation and public funding and close the institution. Reports from the Accrediting Commission for Community and Junior Colleges (ACCJC) and the Fiscal Crisis and Management Assistance Team (FCMAT) identified problem patterns that persisted for many years at the district. The district failed to respond to and address deficiencies despite repeated warnings from the state regulators, accreditors and outside agencies. A similar crisis in 1988 led to a major reorganization of the district but the crisis repeated 24 years later. Understanding early warning signs and the historical significance of repeated or continuous problems can have important implications for recovery of the district and more importantly for avoiding future crisis.

This study explored the evolution of the 2012 accreditation crisis at City College of San Francisco and explained how leaders at the college were unable to recognize the crisis before it happened. Specifically, this study examined leader decision-making over the history of the SFCCD on two problems identified most prominently in the accreditation "show cause" report: budget priorities and student learning outcomes. Archival data and interviews of key decision-makers at CCSF were used to examine the history and context of decisions made on these two issues. The study addressed the 
research question: Why did City College of San Francisco reach this stage of crisis that now threatens its existence? More specifically, the study asks: What factors may have contributed to the inability of leaders at CCSF to see the magnitude of the crisis as it approached?

The conceptual framework used in this study is based on the theory of normalization of deviance (Vaughan, 1997). Normalization of deviance occurs when organizational systems become faulty (Greve, Palmer \& Pozner, 2010; Vaughan, 1997, 2004, 2005). Small deviations from rules or norms that do not produce negative consequences become accepted as a new normal. As the pattern repeats, the culture becomes embedded, routinized, and eventually institutionalized as "the way we do things here", resulting in looser standards and increased vulnerability for failure (Greve, Palmer, \& Pozner, 2010). Analysis of the data from this research on the evolution of crisis at CCSF confirmed that deviations in decision-making on fiscal issues and SLO's were normalized over time and that this prevented crisis from being recognized and averted.

This chapter presents a review and discussion of the study's findings, recommendations for leaders at the institution, a summary of the challenges facing the district, and a review of study limitations and recommendations for future research. 


\section{The Findings}

\section{Normalization of deviance}

As stated in Chapter 1, normalization of deviance is more likely to occur under the following conditions: an environment focused on production and efficiency under pressure of limited resources, a culture that accepts risk by redefining norms, and processes that obscure the seriousness of problems within an organization (Vaughan 1997, 2004). The findings of this research parallel other studies of normalization of deviance (Banja, 2010; Cook, 2000; Prielipp, Magro, Morell \& Brull, 2010; Vaughan, 1997, 2004).

This study found that at CCSF, expectations from constituency groups (community, governing board, faculty, labor), pressured leaders to "be all things to all people" in an environment of increasingly scarce resources; an environment brought on by drastic reductions in state financing of higher education in California. This began in the 1970's after the formation of the district and expansion of credit and noncredit courses and programs to the diverse San Francisco community. Demand for classes came at the same time as two key pieces of legislation were passed that resulted in increases to labor compensation and benefits and reductions to community college funding in California. Leader decisions to expand programs and courses and support labor contracts for employees to live in the expensive region resulted in the 
commitment of resources to long term liabilities. Political decision-making prevented cuts to centers and programs even in times of fiscal instability. Together this promoted a sense of constant organizational life on the fiscal edge. As the institution survived each fiscal crisis over the decades of unpredictable state funding, risky fiscal decisionmaking became normalized.

During the 1990's and 2000's, changes in regulatory language and accreditation standards favored an environment of increasing productivity and accountability for student outcomes. These conditions made it more likely that leaders and decisionmakers would deviate from rules and create short cuts or workarounds to achieve organizational goals (Banja, 2010; Vaughan, 1997, 2004, 2005). Isolation and a culture of exceptional uniqueness allowed acceptance of deviations and redefined normal for the district. A self-affirming ideology pervaded the culture. Collectively, this kept the warning signs from getting the attention needed to correct the path and avoid crisis. Why problems persisted at CCSF

A wealth of literature from higher education supports the theory of the leader (chancellor, $\mathrm{CEO}$ ) as the key person in the development of and recovery from crisis (Berquist, 1992; Berquist \& Pawlak, 2008; Brigham-Sprague, 2001; Patel, 2012; Tierney, 2008). At CCSF, problems persisted over more than two decades and six chancellors, suggesting that other factors were important. This study found that problems persisted at the district for several reasons. First, decision-makers at the time 
were insulated from predicting the consequences of their actions because those actions were culturally consistent (Vaughan, 2004) and conformed to what became normal organizational life at CCSF. Since the decision makers maintained that CCSF was exceptionally unique among other colleges, even decisions that are obviously poor in hindsight were justified as necessary at the time and what was best for the "City College family".

Second, socialization of newly hired individuals and rationalization of short cuts, workarounds, and deviation from rules as legitimate, acceptable, and even necessary for the unique conditions of the institution allow deviations to carry on despite changes in leaders and structures. Newcomers may arrive at the institution unarmed with the knowledge of existing regulations or best practices; therefore, they may be taught deviations without realizing it (Banja, 2010; Vaughan, 1997). Even if the newcomer does become aware of a deviation, she may feel uncomfortable to speak up as several participants mentioned during the interviews.

Third, when there was confusion over how to implement certain standards or rules, isolation kept warning signals from reaching key people (Vaughan, 2004) and a sense of uniqueness preventing them from seeking outside assistance. During the SLO implementation CCSF faculty groups were faced with disagreements over the ACCJC definition of an SLO. Instead of reaching outside of the institution to directly ask the accrediting agency or obtain models from other successful community colleges, they 
chose to forge ahead with their own redefinition of the process that was only recognized as insufficient to meet standards after it was too late to meet the deadline.

Finally, at CCSF, the external regulations were sometimes felt to be superfluous and deviations justifiable because a pervasive sense of exceptional uniqueness made it so the "rules don't apply to us" (Banja, 2010; Predmore, 2006). The decisions to run low enrolled classes, continue expanding courses and programs despite the growth cap, refusing to cut categorical programs, not keep a 5\% reserve fund, not fund retiree benefits, and use one-time solutions to survive periods of fiscal crisis resulted from a collective belief that CCSF was so different and unique among the California community colleges, that it was too big to fail. This results in a collective expectation of institutional survival, despite financial instability. Complicating this are the mixed signals that on one hand depict an institution with problems and on the other hand recognize the institution for excellence. The district was on the state financial watch list twice in the 1990's and again in 2003, and it received warning that it was not compliant with accreditation standards on fiscal stability and student learning outcomes several times in the 2000 's. In contrast it also received national recognition in 2004 when it won the prestigious MetLife Foundation Community College Excellence Award for promising practices in recruitment, outreach, developmental education, and student support services and made the list as one of the top community colleges in the country by the New York Times. Those in the trenches (faculty, classified personnel, students) 
may interpret the positive recognition as verification that whatever they are doing is working despite the regulatory warnings. Administrators and leaders, aware of the seriousness of the problems with fiscal issues and SLO's, may have tried to warn the rest of the college community but were presented with this conflicting evidence as proof that everything was fine. And as the institution survived each crisis, existing behavior was reinforced.

The most critical aspect of normalization of deviance for leaders to recognize and understand is that it builds incrementally over time and therefore makes it difficult to detect until it is too late. Socialization of newcomers ensures that it becomes a part of the culture, deeply embedded into the routines of organizational life. Increasing complexity within an organization creates difficulty in predicting which of these complex elements has the potential for failure. The following sections outline the implications of this research and make recommendations for institutional change.

\section{Implications and Recommendations}

In the aftermath of a crisis, it is commonplace to criminalize (Dekker, 2012) the behavior of an individual or group viewed as the cause of the crisis. It only follows then that organizations tend to respond to crisis through sweeping changes in leadership (i.e. replace the chancellor, unseat the board member, fire administrators), or by disbanding powerful groups (i.e. restructure participatory governance). At CCSF, the response to crisis in 1990 and again in 2014 was to launch a major reorganization, redesign the 
organizational chart and lines of authority, hire a new chancellor, replace administrators and restructure participatory governance. At each point there were proposals to disband the DCC and the relationship with the Civil Service commission for its classified personnel or drastically reduce or eliminate noncredit programs. An analysis of this research suggests that none of these proposals represent viable long-term solutions to prevent future crisis at CCSF. The following sections use the results of this study to make recommendations for institutional leaders at all levels of the college. As stated in Chapter 1, this leadership begins with the governing board, which creates policies to carry forth the college mission, and the chancellor hired by the governing board to implement policy. Administrative and faculty leaders carry out the policies and support an environment of teaching and learning through shared leadership responsibility. Recommendations for Institutional Leaders

\section{Recognize the causes and historical roots of the crisis}

The most important immediate action for leaders at CCSF is to closely examine the historical roots and evolution of crisis at CCSF to better understand how deviations from standards could persist for so long. Leaders should recognize the bias and clarity that can come with an after-the-fact evaluation of crisis since hindsight and outcome knowledge can make the errors in past decisions seem obvious. Leaders must avoid simply blaming individuals or groups since that inevitably leads to simple non-viable solutions. Removal of key people, positions, or groups could actually be harmful in the 
long term since they remove critical members with historical memory and expertise in the industry.

Also, every crisis, no matter how large or small, is an opportunity to examine and investigate the processes that led to the problem. Leaders should resist the temptation to shift the problem to outside influences such as state fiscal issues or changes to regulatory standards, since these are sometimes the realities of the environment.

Problems should be examined in context of the conditions in which decisions are made and without fear of punishment. As Vaughan (1997) and Banja (2010) noted, front line workers (faculty, classified personnel), and middle managers (Department Chairs, Deans, Administrators), can be the beacons of warning assuming they are given the power and reporting environment to be heard and that the leadership culture learns from mistakes. Creating a just and equitable culture means balancing accountability with a learning environment (Dekker, 2012). At the CCSF, administrators noted that sometimes they felt they weren't backed up when they tried to warn of impending problems. Some faculty and administrators felt an environment of intimidation, reducing the likelihood of reporting problems. With each placement on "state watch", each accreditation letter, each warning about SLO's and accreditation "cracking down", the college had an opportunity to intervene and learn collectively from the problem from the perspective of an internal system failure. This should be the action every time 
a problem arises and can only happen if all employees feel safe to speak up and report potential problems as they arise (Vaughan, 1997; Prielipp, Magro, Morell \& Brull, 2010; Banja, 2010) and if the leadership fosters relationships based on honesty and responsibility (Dekker, 2012).

\section{Promote and practice evidence-based decision-making}

The use of evidence can help avoid political decision-making. Systems of accountability and assessment should be organizationally integrated with teaching and learning so that realistic expectations are set. Successful colleges demonstrate innovation and creativity in teaching practices, and a "culture of evidence" that permeates all levels of the institution (Lattimore, D'Amico, \& Hancock, 2012). In relation to accreditation, the college faculty should be directly involved in the accreditation process around the region, participating on teams, in workshops, and in reporting back to college. The college faculty, classified personnel, and administration should be a part of standards development and revisions with an emphasis on the underlying purpose of institutional accreditation: "to ensure overall educational quality and institutional effectiveness" (ACCJC, 2016). Realize that oversight and monitoring for rule compliance are never-ending (Banja, 2010).

\section{Develop best practices}

Isolation stifles innovation at CCSF. Innovate and bring concepts from outside the college that may improve processes and outcomes while maintaining the uniqueness 
that defines CCSF and its diverse community of students. Appreciation of other organizations and even of other departments and units within the same organization, and identification with common struggles can avoid exceptional uniqueness. CCSF supported Career and Technical Education (CTE) programs that received their own programmatic accreditation and had experience and expertise in learning outcomes assessment, competency evaluations, and using data to determine resource allocation. Yet these internal resources were untapped during the years of failed SLO implementation rather than utilized as a valuable internal leadership model. Best practices are developed from both internal and external resources.

\section{Challenges Facing the San Francisco Community College District (SFCCD)}

City College of San Francisco is currently accredited and on Restoration Status since 2015 , which provided the college with two years to demonstrate that it meets accreditation standards. In October of 2016, the ACCJC will perform a comprehensive site visit to re-evaluate CCSF for progress on achieving these standards. Over the past year, the college completed a comprehensive self-study document for re-evaluation of accreditation status with input from all levels of personnel. The college continues to struggle with reductions in enrollment and contentious labor negotiations that recently resulted in a one-day strike of faculty AFT2121 members. Although fiscal issues continue, CCSF has maintains a healthy reserve fund and is meeting the standards for funding retiree post employment benefits. Tremendous efforts in the institution wide 
implementation of the SLO process have resulted in near perfect compliance in time for the fall 2016 site visit. The governing board is reestablished and has begun meeting regularly, which renews the system of inclusive input by all stakeholders into the operations of the college. The major challenge for the institution is to create and sustain an organizational culture based on sound decision-making and leadership responsibility.

\section{Study Limitations}

This research has the limitations of being a case study (Yin, 2014) of a single community college; therefore it is limited in its ability to generalize to other institutions. Internal validity of the research was limited by a small number of participants $(n=20)$ for the researcher-conducted interviews, especially given the size of the institution. More importantly, interview data from these interviews suffer from the biases of hindsight and outcome knowledge (Cook, 2000). Attempts to improve the internal validity were accomplished through the 12 archival interviews, which took place before the crisis and are therefore free of hindsight bias, and through review of archival documents.

\section{Recommendations for Further Study}

This study examined problem persistence at CCSF that arose from organizational cultures and environmental influences. One worthwhile study would be to examine patterns of dysfunctional group and intergroup behavior that counters 
organizational goals as researched in other settings (Kahn, 2012), to understand their implications in institutional responsibility.

There are some who believe that the 2012 accreditation crisis is a tool of interest groups who seek to privatize higher education, a conspiracy against CCSF, or the product of rogue accreditors. This research did not examine the crisis from the standpoint of conspiracy or from the perspective of deviations in the accrediting agency. One possible research focus would be to look at this same crisis from the perspective of inside the accrediting agency, retracing decisions through time and in historical context as was done in this research from the perspective of the internal workings at CCSF.

\section{Conclusion}

This research examines the evolution of the 2012 accreditation crisis at City College of San Francisco. It uses a historical case study approach (Yin, 2014), and seeks to explain why the institution fell into a crisis of such large proportions and why leaders could not avoid it before it happened. Early data collection and research from the crisis literature shaped the conceptual framework, which is based on the organizational theory known as normalization of deviance. Results demonstrated that CCSF consistently normalized deviations in financial decision-making and student learning outcomes, and that this persisted due to the presence of three factors: an 
environment of competition for scarce resources, a culture of expectation to be "all things to all people", and a self-affirming ideology.

Normalization of deviance is rooted in the routines of organizational life and the complexity of organizational cultures (Vaughan, 1997; 2003). It is exacerbated under the pressures of increased regulation and reduced resources as leaders are tempted to take shortcuts or implement short-term solutions to ride out the storm of an immediate crisis. This research proposes that the evolution of crisis at the SFCCD was incremental and the outcome unintentional; not the result of any extraordinary action of an individual or group; no conspiracy; no major breaches of conduct. Rather, the result of a weak merger, an attempted integration of multiple organizational identities without synthesis into a new common identity, the acceptance of operational dysfunctions, a standoff between the mission of access and the call for accountability, and a resulting paralysis in decision making. Together these resulted in a threat to institutional survival. For a large public community college that has a responsibility to provide quality education to its very supportive San Francisco community, closure would abandon the primary stakeholders: the students. At CCSF, this represents the abandonment of tens of thousands of students, largely low-income students, immigrants, and first generation college students who rely on the local community college for access to higher education, workforce training, and social and economic empowerment. 
And therein lies the true crisis. History will likely depict this era of crisis as a time of fiscal or operational breakdown and regulatory autocracy; but the real tragedy is that an institution committed to being the "great equalizer", became entrapped in feeding itself for its own survival.

Hope for institutional recovery and renewal hinges on a collective recognition of the causes of the current crisis and the historical roots, the use of evidence-based decision-making at all levels of the college, integration of best practices from both outside and inside of the institution, and the importance of responsible leadership in avoiding normalization of deviance. Institutional renewal will only be realized when everything we do in our organizational life at CCSF reflects our recognition of responsibility to the community as a large public institution of higher education with a common mission and an unwavering commitment to students. 
References

Alexander, E. R. (2000). Rationality revisited: Planning paradigms in a postpostmodernist perspective. Journal of Planning Education and Research, 19(3), $242-256$.

Anderson, A. (2011). Engaging Resistance: How Ordinary People Successfully Champion Change. Stanford Business Books.

Ashforth, B. E., \& Anand, V. (2003). The normalization of corruption in organizations. Research in Organizational Behavior, 25, 1-52.

Astin, A. W. (1997). What Matters in College?: Four Critical Years Revisited (1st ed.). San Francisco: Jossey-Bass.

Auerbach, C., \& Silverstein, L. B. (2003). Qualitative Data: An Introduction to Coding and Analysis ( 1 edition). New York: NYU Press.

Bailey, T. R., Averianova, I. E., \& Columbia Univ., N. Y., NY.Community Coll.Research Center. (1998). Multiple Missions of Community Colleges: Conflicting or Complementary?

Bailey, T., \& Morest, V. S. (2006). Defending the community college equity agenda (1st ed.). Baltimore, MD: The Johns Hopkins University Press. 
Banja, J. (2010). The normalization of deviance in healthcare delivery. Business Horizons, 53(2), 139.

Bergman, J., Mathes, V. S., \& White, A. (2010). City College Of San Francisco. Arcadia Publishing.

Bergquist, W. H. (1992). The Four Cultures of the Academy. Jossey-Bass Inc., Publishers, 350 Sansome Street, San Francisco, CA.

Bergquist, W. H., \& Pawlak, K. (2007). Engaging the six cultures of the academy: Revised and expanded edition of the four cultures of the academy. Jossey-Bass.

Bethel, S. M. (2009). A New Breed of Leader: 8 Leadership Qualities that Matter Most in the Real World: what Works, what Doesn't, and why. Penguin.

Bolman, L. G., \& Deal, T. E. (2008). Reframing organizations: Artistry, choice and leadership (4th ed.). San Francisco, CA: Jossey-Bass.

Brigham-Sprague, M. (2001). A case study of crisis, leadership, and change in the community college. Retrieved from http://arizona.openrepository.com/arizona/handle/10150/289779

Burke, J. C. (2005). Achieving accountability in higher education: Balancing public, academic, and market demands. Jossey-Bass.

Bush, T. (2010). Theories of educational leadership and management (4th ed.). London, UK: Sage. 
Cameron, K. S., \& Quinn, R. E. (2005). Diagnosing and changing organizational culture: Based on the competing values framework. San Francisco, CA.: JosseyBass.

Clark, K. L. (2012). Navigating California's stormy seas: A multi-case study of presidential leadership in the midst of fiscal crisis. Dissertations Available from ProQuest, 1-189.

Desai, S. A. (2012). Is Comprehensiveness Taking Its Toll on Community Colleges?: An In-Depth Analysis of Community Colleges' Missions and Their Effectiveness. Community College Journal of Research and Practice, 36(2), $111-121$.

Emerson, R. M., Fretz, R. I., \& Shaw, L. L. (1995). Writing ethnographic fieldnotes: Chicago guides to writing, editing, and publishing. Chicago: University of Chicago Press.

Greve, H. R., Palmer, D., \& Pozner, J.-E. (2010). Organizations Gone Wild: The Causes, Processes, and Consequences of Organizational Misconduct. The Academy of Management Annals, 4(1), 53-107.

Gummer, B. (1998). Decision Making Under Conditions of Risk, Ambiguity, and Uncertainty. Administration in Social Work, 22(2), 75-93.

Hutchings, P. (2010). Opening doors to faculty involvement in assessment. NILOA Occasional Paper, 4. 
Kahn, W. A. (2012). The functions of dysfunction: Implications for organizational diagnosis and change. Consulting Psychology Journal: Practice and Research, 64(3), 225-241.

Kazis, R., \& Newton, A. (2004). Rewarding Results: The MetLife Foundation Community College Excellence Award. Community College Journal, 74(6), 3235 .

Kezar, A. J., \& Eckel, P. D. (2002). The effect of institutional culture on change strategies in higher education: Universal principles or culturally responsive concepts? The Journal of Higher Education, 73(4), 435-460.

Kotter, J. P. (1996). Leading Change. Harvard Business Press.

Kotter, J. P., \& Cohen, D. S. (2002). The Heart of Change: Real-Life Stories of How People Change Their Organizations. Harvard Business Press.

Kuh, G. D., Kinzie, J., Schuh, J. H., \& Whitt, E. J. (2010). Student Success in College, (Includes New Preface and Epilogue): Creating Conditions That Matter. San Francisco, CA.: Jossey-Bass.

Lattimore, J. B., D’Amico, M. M., \& Hancock, D. R. (2012). Strategic Responses to Accountability Demands: A Case Study of Three Community Colleges. Community College Journal of Research and Practice, 36(12), 928-940.

Locke, M. G., \& Guglielmino, L. (2006). The Influence of Subcultures on Planned Change in a Community College. Community College Review, 34(2), 108-127. 
Meyer, J. W., \& Rowan, B. (1977). Institutionalized organizations: Formal structure as myth and ceremony. American Journal of Sociology, 340-363.

Mileti, D. S., \& Gailus, J. L. (2005). Sustainable development and hazards mitigation in the United States: Disasters by design revisited. Mitigation and Adaptation Strategies for Global Change, 10(3), 491-504.

Nevarez, C., \& Wood, J. L. (2010). Community college leadership and administration: Theory, practice and change (Vol 3). Peter Lang Publishing.

Palter Gill, D. (2012). Noncredit and Credit Divisions in Community Colleges: The Dilemma of Multiple Organizational Identities. ProQuest $L L C$.

Pascarella, E. T., \& Terenzini, P. T. (2005). How College Affects Students: A Third Decade of Research. San Francisco: Jossey-Bass.

Patel, D. D. (2012). Impact of accreditation actions: A case study of two colleges within Western Association of Schools and Colleges' Accrediting Commission for Community and Junior Colleges (Ed.D.). University of Southern California, United States -- California.

Pratt, M. G., \& Foreman, P. O. (2000). Classifying managerial responses to multiple organizational identities. Academy of Management Review, 25(1), 18-42.

Predmore, S. (2006). The normalization of deviance. Keynote address at the annual meeting of the American Association of Airport Executives, August 22, 2006. 
Prielipp, R. C., Magro, M., Morell, R. C., \& Brull, S. J. (2010). The normalization of deviance: do we (un) knowingly accept doing the wrong thing? Anesthesia \& Analgesia, 110(5), 1499-1502.

Quinn, R. E. (2011). Building the Bridge As You Walk On It: A Guide for Leading Change. John Wiley \& Sons.

Roberto, M. A. (2009). Know What You Don't Know: How Great Leaders Prevent Problems Before They Happen. Pearson Prentice Hall.

Saldaña, J. (2015). The coding manual for qualitative researchers. Sage.

Schein, E. H. (1985). Defining organizational culture. Classics of organization theory, 3, 490-502.

Schein, E. H. (1985). Organisational culture and leadership: A dynamic view. San Francisco.

Seidman, I. (2006). Interviewing as qualitative research: A guide for researchers in education and the social sciences. New York, NY: Teachers College Press.

Shaw, K. M., \& London, H. B. (2001). Culture and ideology in keeping transfer commitment: Three community colleges. The Review of Higher Education, $25(1), 91-114$.

Smart, J. C., Kuh, G. D., \& Tierney, W. G. (1997). The Roles of Institutional Cultures and Decision Approaches in Promoting Organizational Effectiveness in TwoYear Colleges. The Journal of Higher Education, 68(3), 256-281. 
Tierney, W. G. (1988). Organizational culture in higher education: Defining the essentials. The Journal of Higher Education, 2-21.

Tierney, W. G. (2008). The impact of culture on organizational decision-making: Theory and practice in higher education. Stylus Publishing, LLC.

Vaughan, D. (1997). The Challenger launch decision: Risky technology, culture, and deviance at NASA. University of Chicago Press.

Vaughan, D. (2004). Theorizing disaster analogy, historical ethnography, and the Challenger accident. Ethnography, 5(3), 315-347.

Vaughan, D. (2005). Slopes, repeating negative patterns, and learning from mistake? Organization at the Limit: Lessons from the Columbia Disaster, 41-59.

Willson, R. (2006). The Dynamics of Organizational Culture and Academic Planning. Planning for Higher Education, 34(3), 5-17.

Yin, R. K. (2011). Applications of case study research. Sage publications.

Yin, R. K. (2013). Case study research: Design and methods. Sage publications. 
Appendix 1

\section{DATA SOURCES}

\section{INTERVIEWS}

Researcher conducted interviews ( $n=20)$ :

Formal: 2 former chancellors, 6 administrators, 5 faculty leaders

Informal: 4 faculty, 1 administrator

Targeted: 2 administrators

Archival interviews 2006-2008 $(n=12)$ :

3 former chancellors, 2 former presidents, 2 trustees, 2 administrators, 2 faculty leaders, 1 classified staff leader

\section{OBSERVATIONS (videotapes)}

\section{Board meeting videos}

July 18, 2012; July 10, 2012; June 28, 2012; June 21, 2012; May 31, 2012; May 24, 2012; A pril 26, 2012; March 22, 2012; February 23, 2012; January 26, 2012

December 15, 2011 ; November 17, 2011; November 3, 2011 (Planning \& Budgeting committee); October 27, 2011; September 22, 2011; August 25, 2011; August 17, 2011 (Planning \& Budgeting committee); July 28, 2011 ; July 23, 2011 ; June 20, 2011 (Planning \& Budgeting committee); June 2, 2011 (Planning \& Budgeting committee); May 26, 2011; April 28, 2011; March 24, 2011; February 24, 2011; January 27, 2011

\section{ARCHIVAL DOCUMENTS}

\section{ACCJC related documents}

ACCJC Visiting Team Recommendations 1977, 1982, and 1988 and the SFCC District Responses 1982, 1988, 1990; 150 pages.

March 1988 Institutional Self Study: A separate report from City College faculty on Standards III, VII, VIII, and IX. 100 pages.

April 1988 Report of the Institutional Self Study for Reaffirmation of Accreditation. 282 pages.

March 1989 A Self-Study Report Criteria Approach prepared for WASC and CA State Dept of Education. 122 pages.

March 1994 Institutional Self Study for Reaffirmation of Accreditation. 250 pages October 1996 Midterm Report to WASC

Spring 2000 Institutional Self Study in support of Reaffirmation of Accreditation. 218 pages. 
October 2002 Midterm Report to WASC 25 pages.

Spring 2004 WASC Self Study Handbook: Striving for excellence. 46 pages. January 2005 Accreditation Self-Study Co-Chair Reports: Standards I-IV. 75 pages. April 2005 Accreditation Self-Study Theme Essays I-VI. 75 pages. 2006 Institutional Self Study for Reaffirmation of Accreditation. 348 pages. 2012 Institutional Self-Study report in support of Reaffirmation of Accreditation. 450 pages.

July $2012 \mathrm{WASC} / \mathrm{ACCJC}$ decision letter to CCSF and comprehensive report on accreditation decision (show cause)

March 2013 CCSF Show Cause report to WASC/ACCJC

July 2013 WASC/ACCJC decision letter to CCSF and report on accreditation decision (terminate July 2014)

\section{SFCCD reorganization documents}

The Challenge of Change: Part I, Strategic Planning Associates, January 1990

KH Consulting Organizational Evaluation of the SFCCD: Executive Summary, KH Consulting 1993

Politics of the Reorganization of the San Francisco Community College District (master's thesis), December 1991

\section{Chancellor's speeches}

Evan Dobelle inaugural address November 1990

Del Anderson inaugural address August 1995

Phil Day inaugural address 1998

Phil Day Flex Day addresses: January 2001 through January 2008 (15 speech transcripts)

Don Griffin Flex Day addresses: August 2008-January 2012 (4 speeches)

\section{Budget documents}

SFCCD budget reports to governing board $(1988,1989,1993,1996,2000-2012)$

FCMAT report 2012

FCMAT report 2013

SFCCD Budget 2012-2013

SFCCD Total cost of operation/ownership of the "Centers" 2012-2013

Academic Senate documents (2005-2012)

March 12, 2012 Memo from AS President to the Chair of the ACCJC Visiting Team AS Meeting Minutes

Department Chairperson Council documents (1994-2000)

DCC Meeting Minutes 


\section{Appendix 2}

\section{Chancellor Interview Protocol}

1. Why did you decide to compete for the Chancellor position at CCSF?

2. Take me back to when you first became Chancellor and describe your vision for the college?

3. Tell me about the challenges you encountered during your tenure.

4. Tell me about your work with various constituent groups. [Note: no need to name each group but listen for major constituent groups]

5. Describe the fiscal climate in the period of time you served as Chancellor.

6. Tell me about how you created a new program(s).

7. Tell me what it was like to try to make a major change at CCSF.

8. Tell me about the accreditations during your tenure.

9. The college was (and still is) made of the college campus and many "centers". What was the purpose of the many centers?

10. What metaphor would you use to describe the environment at City College of San Francisco during the time you were chancellor?

11. Is there anything that I have not asked about that you think is relevant to CCSF history?

\section{Faculty/VC/Dean Interview Protocol}

1. Tell me about your personal history at CCSF?

2. Tell me about each of the Chancellors that you worked for: (prompt as needed)

3. What work have you done that you are most proud of?

4. What work do you see as incomplete or unaccomplished?

5. Tell me about the various constituent groups at CCSF.

6. Describe the process for evaluating programs.

7. Tell me what it was like to try to make a major change at CCSF.

8. Tell me about the accreditations during your tenure.

9. The college has many "centers". What was the purpose of the many centers?

10. What metaphor would you use to describe the environment at City College of San Francisco?

11. Is there anything that I have not asked about that you think is relevant to CCSF history? 
Appendix 3

\section{San Francisco State University Informed Consent to Participate in a Research Examining the evolution of crisis at City College of San Francisco}

\section{PURPOSE AND BACKGROUND}

The purpose of this research is to explore and increase understanding of how the crisis at City College of San Francisco (CCSF) evolved over time and reached the current state that threatens the existence of the institution. The researcher, Megan Corry, is a graduate student at San Francisco State University (SFSU) conducting research for a doctorate degree in Educational Leadership through the Department of Education. You are being asked to participate in this study because you have been employed at CCSF and participated on decision-making committees between the period of 1988 and 2012.

\section{PROCEDURES}

If you agree to participate in this research, the following will occur: you will be interviewed for approximately 60-90 minutes about your experiences at City College of San Francisco the interview will be audiotaped to ensure accuracy in reporting your statements. The interview will take place at a time and location convenient to you. The researcher may contact you later to clarify your interview answers for approximately 20 minutes. Total time commitment will be $80-110$ minutes.

\section{RISKS}

The researcher will ask if you wish to remain anonymous. There is a risk of loss of privacy. However, no names or identities of participants who wish to remain anonymous will be used in any published reports of the research. Only the researcher will have access to the research data.

\section{CONFIDENTIALITY}

The research data will be kept in a secure location and only the researcher will have access to the data. All research data will be stored in an encrypted document on a password-protected computer. At the conclusion of the study, all identifying information will be removed and the data will be kept in a locked cabinet or office. Audio or video recordings will be destroyed at the end of the study. Written notes, transcripts, and files will be maintained for three years in a locked cabinet in the researcher's locked office, which is only accessible to the researcher. After a period of three years, the documents will be destroyed. 


\section{DIRECT BENEFITS}

There will be no direct benefits to the participant.

\section{COSTS}

There will be no cost to you for participating in this research.

\section{COMPENSATION}

There will be no compensation for participating in this research.

\section{ALTERNATIVES}

The alternative is not to participate in the research.

\section{QUESTIONS}

You have spoken with Megan Corry about this study and have had your questions answered. If you have any further questions about the study, you may contact the researcher by email at mcorry@mail.sfsu.edu or you may contact the researcher's advisor, Professor Gabriner at gabriner@sfsu.edu.

Questions about your rights as a study participant, or comments or complaints about the study, may also be addressed to the Office for the Protection of Human Subjects at 415: 338-1093 or protocol@sfsu.edu.

\section{CONSENT}

You have been given a copy of this consent form to keep.

\section{PARTICIPATION IN THIS RESEARCH IS VOLUNTARY. You are free to} decline to participate in this research, or to withdraw your participation at any point, without penalty. Your decision whether or not to participate in this research will have no influence on your present or future status at San Francisco State University.

Signature

$$
\text { Research Participant }
$$

Signature

$$
\text { Researcher }
$$

Date:

Date: 